\title{
Fewer and better-educated children: Expanded choices in schooling and fertility in rural Pakistan
}

\author{
Zeba Sathar \\ Population Council \\ Cynthia B. Lloyd \\ Population Council \\ Minhaj ul Haque \\ Mumraiz Khan \\ Population Council \\ Monica J. Grant
}

Follow this and additional works at: https://knowledgecommons.popcouncil.org/departments_sbsr-pgy

Part of the Demography, Population, and Ecology Commons, Education Commons, Family, Life Course, and Society Commons, Gender and Sexuality Commons, and the International Public Health Commons How does access to this work benefit you? Let us know!

\section{Recommended Citation}

Sathar, Zeba, Cynthia B. Lloyd, Minhaj ul Haque, Mumraiz Khan, and Monica J. Grant. 2006. "Fewer and better-educated children: Expanded choices in schooling and fertility in rural Pakistan." Islamabad: Population Council. 


\section{Fewer and Better-Educated Children:}

Expanded Choices in Schooling and Fertility in Rural Pakistan

Islamabad

Zeba A. Sathar Minhaj ul Haque Mumraiz Khan

\section{New York}

Cynthia B. Lloyd Monica J. Grant

\section{(1) Population Council}




\section{Population Council}

The Population Council, an international, non-profit, non-governmental organization established in 1952, seeks to improve the well-being and reproductive health of current and future generations around the world and to help achieve a humane, equitable, and sustainable balance between people and resources.

The Council analyzes population issues and trends; conducts research in the reproductive sciences; develops new contraceptives; works with public and private agencies to improve the quality and outreach of family planning and reproductive health services; helps governments design and implement effective population policies; communicates the results of research in the population field to diverse audiences; and helps strengthen professional resources in developing countries through collaborative research and programs, technical exchanges, awards, and fellowships.

\section{For inquiries, please contact:}

\section{Population Council}

\#7, Street 62, F-6/3, Islamabad, Pakistan

Tel: 92512277439

Fax: 92512821401

Email: info@pcpak.org web: http://www.popcouncil.org

Cover Photo: Ehtesham ul Haq Layout \& Design: Mehmood Asghar \& Ali Ammad Printed by: The Army Press, Islamabad 


\section{Table of Contents}

Acronyms $\quad$ vi

Acknowledgements vii

Executive Summary ix

Chapter 1 Introduction 1

Chapter 2 Sampling Design, Questionnaires, Fieldwork and Samples 7

Chapter 3 The Changing Education and Service Environment 19

Chapter $4 \quad$ Changes in School Characteristics 47

$\begin{array}{lll}\text { Chapter } 5 & \text { Educational Participation and Attainment }\end{array}$

Chapter 6 Trends in Family Building: Fertility Preferences, Contraceptive Use, and Fertility Behavior $\quad 75$

$\begin{array}{lll}\text { Chapter } 7 & \text { Conclusions } & 99\end{array}$

References $\quad 103$

Annex $\quad$ List of Staff Involved in the Survey 105 


\section{List of Tables}

$\begin{array}{lll}\text { Table 2.1 Follow-up rates for households } & 15\end{array}$

Table 2.2 Follow-up rates for women 16

Table 2.3 Reasons why women could not be interviewed in $2004 \quad 16$

Table 2.4 Breakdown of primary schools surveyed in $1997 \quad 17$

$\begin{array}{lll}\text { Table 2.5 Breakdown of primary schools surveyed in } 2004 & 18\end{array}$

Table 3.1 Breakdown of primary schools in 2004, by school type, year of visit, and year of establishment 21

Table $3.2 \quad$ Distribution of schools by de jure status, province, and survey year

Table 3.3 Breakdown of schools by location inside or outside the community boundaries, province, and survey year 23

Table 3.4 Service availability by community and survey year 25

Table 3.5 Distribution of health facilities by community and survey year 26

Table 4.1 Access to primary schooling 50

Table 4.2 Indicators of school quality 53

Table 5.1 Trends in percentage of children who ever attended school (pre-primary or primary) 65

Table 5.2 Trends in the percentage of 15-19 year olds who completed primary, of those who ever attended school 68

Table 5.3 School status of 10-14 year olds in 2004 70

Table 5.4 Type of primary school last attended of those who ever $\begin{array}{ll}\text { attended class one or higher } & 71\end{array}$

Table 5.5 De jure type of primary school last attended, of those who have ever attended class one or higher $\quad 72$

Table 6.1 Mean children ever born (standardized by age) by districts, 1997-2004

Table 6.2 Proportion of currently married women 20-45 wanting no more children, and contraceptive use status by fertility intentions 
Table 6.3 Presence of family planning services* by location, 19972004

Table 6.4 Distribution of decision-makers among female contraceptive users by district, 1997-2004

Table 6.5 Parity at first use by district and by age, currently married women aged 20-45

Table 6.6 Contraceptive use rates 1997-2004, currently married women aged 20-44

Table 6.7 Most recent contraceptive method used, currently married women, ages 20-44, using contraception by district

Table 6.8 Changes in fertility intentions of panel women 86

Table 6.9 Changes in fertility preferences and in contraceptive use by preference, age, and district

Table 6.10 Number of births in the period by age and district, 19972004

Table 6.11 Births in the last six years by fertility intentions of mothers and current contraceptive use levels 


\section{List of Figures}

Figure 2.1 Geographic location of sample districts 9

Figure 2.2 Percentage of children aged 5-9 attending school in rural areas, sample districts

Figure 2.3 Number of primary schools per 1000 population aged 5-9 years, sample districts

Figure 4.1 Mean physical amenities by district, survey year and school type

Figure 4.2 Mean number of students per classroom, by district, school type, and survey year

Figure 4.3 Mean number of primary teachers per school facility (for grades 1-5), by district, survey year, and school type

Figure 4.4 Mean primary teacher absenteeism by district, school type, and survey year

Figure 5.1 Trends in the percentage of 10-14 year olds who have ever attended school by district and survey year

Figure 5.2 Trends in the percentage of 5-9 year olds who ever attended school by school level attended

Figure 5.3 Trends in the percent of 10-14 year olds currently attending school by district

Figure 6.1 Proportion of women (20-45) who do not want more children by district, 1997-2004

Figure 6.2 Proportion of women (20-45) using contraception among those who do not want more children by district, 1997-2004 $\quad 78$

Figure 6.3 Proportion of currently married women aged 20-44 currently using contraception by district, 1997-2004

Figure 6.4 Currently married women aged 20-44 who have ever used a contraceptive method by district, 1997-2004

Figure 6.5 Distribution of women in the panel by status of fertility intentions by district, 1997-2004

Figure 6.6 Scatter plot of standardized CPR and standardized school enrollment for boys 5-9 years 
Figure 6.7 Scatter plot of standardized CPR and standardized school enrollment for boys 10-14 years

Figure 6.8 Scatter plot of standardized CPR and standardized school enrollment for boys 15-19 years

Figure 6.9 Scatter plot of standardized CPR and standardized school enrollment for girls 5-9 years

Figure 6.10 Scatter plot of standardized CPR and standardized school enrollment for girls 10-14 years

92

Figure 6.11 Scatter plot of standardized CPR and standardized school enrollment for girls 15-19 years

Figure 6.12 Scatter plot of mean number of births in last 5 years and school enrollment for boys 5-9 years

Figure 6.13 Scatter plot of mean number of births in last 5 years and school enrollment for boys 10-14 years

Figure 6.14 Scatter plot of mean number of births in last 5 years and school enrollment for boys 15-19 years

Figure 6.15 Scatter plot of mean number of births in last 5 years and school enrollment for girls 5-9 years

Figure 6.16 Scatter plot of mean number of births in last 5 years and school enrollment for girls 10-14 years

Figure 6.17 Scatter plot of mean number of births in last 5 years and school enrollment for girls 15-19 years 


\section{Acronyms}

BHU Basic Health Unit

CPR Contraceptive Prevalence Rate

DEI District Education Index

D.G. Khan Dera Ghazi Khan

ESR Education Sector Reform

FBS Federal Bureau of Statistics

FWC Family Welfare Centre

IUD Intrauterine (contraceptive) Device

LHW Lady Health Worker

Madaris Religious Schools

MBBS Bachelor of Medicine and Bachelor of Surgery

MGDs Millennium Development Goals

NGO Non Governmental Organization

NIPS National Institute of Population Studies

N.W.F.P. North West Frontier Province

PESRP Punjab Education Sector Reform Programme

PIHS Pakistan Integrated Household Survey

PRSP Poverty Reduction Strategy Paper

PSU Primary Sampling Unit

R. Y. Khan Rahim Yar Khan

SAP Social Action Program

SMC School Management Committee

SPDC Social Policy and Development Centre

UQPE Universal Quality Primary Education Program 


\section{Acknowledgements}

This study was conducted jointly by colleagues from the Policy Research Division of the Population Council, New York, and the country office in Pakistan. Dr. Cynthia B. Lloyd and Dr. Cem Mete (formerly a Population post-doctoral fellow at Yale and currently a senior economist at the World Bank) conceptualized the study and sought funding for it. They were assisted in New York by Monica Grant in the design and analysis leading up to the report. Barbara Miller patiently and carefully made editorial changes and finally assembled the draft of the report.

In Pakistan, the team was led by Minhaj ul Haque and closely supported by Mumraiz Khan. The core team, comprising of Tahira Perveen, Shaheen Islam, Naseem Raza, Aneela Sardar, Ehtesham ul Haq, Nasir Aziz and Rehan Niazi, worked tirelessly and with dedication on the study from beginning to end. Dr. Zeba Sathar provided oversight for the study and later contributed to the writing of the Report.

Dr. Shahrukh Khan, who has conducted extensive research in education in Pakistan, and is now teaching Economics at Mount Holyoke, graciously accepted to review the Report at very short notice. Farwa Zafar produced a report on educational policy and reforms during the recent past. Zainab Fazil was extremely valuable as a research assistant to Zeba Sathar and made significant contributions by providing the educational context in Pakistan.

The final report was edited by Sabiah Askari. Mehmood Asghar and Ali Ammad finalized the layout of the report. We thank Imran Ahmad, Abrar Ahmad and Imran Ahmed for their continued support throughout the survey.

Funds for the study were provided by the Spencer Foundation and supplemented by funds from DFID, United Kingdom. We are extremely grateful to both these agencies for providing support for social research in Pakistan.

The survey was conducted under difficult conditions and we thank all the trainers, interviewers, supervisors, data processing and checking teams (listed by name in Annex) for carrying out their work so diligently and conscientiously. It was difficult to follow the panel of households and women and particularly to track down information about their children six years after the first interview. This was done cautiously, ensuring that the confidentiality of the information given by respondents in the earlier survey was not compromised.

We must also acknowledge the permission granted by the Ministry of Education and District Education authorities that allowed us to conduct interviews in government 
schools. We would also like to thank all the respondents in both government and private schools who gave of their time to answer questions that allowed us to assess the quality of the schools.

Finally, we thank the respondents who were gracious enough to answer a detailed questionnaire, especially so since most of them had been interviewed six years earlier as well. In the end, we do hope that all their time and our efforts at doing this piece of research will result in improvements in the social options for families in rural Pakistan. 


\section{Executive Summary}

This report presents the results of a longitudinal study of changing educational opportunities in rural Punjab and N.W.F.P. from late 1997 to early 2004. The purpose of the study was to answer two major research questions: firstly, what are effects of changes in schooling opportunities in the community over the past six years on enrollment and attainment; and, secondly, what are the effects of changes in the schooling opportunities in the community over the past six years on family planning and fertility behavior? This study builds on an earlier study in these same communities undertaken in 1997 (Sathar, Lloyd and Haque 2000).

Underlying the study are several broader questions: (1) How widely has the demand for fewer but higher quality children spread among parents in rural Pakistan? (2) To what extent have these changes in demand been influenced by changing educational opportunities and family planning services? Both these sectors have been impacted by a general emphasis on social sector development in Pakistan and specifically by national policies such as the PRSP, NEP, ESR, and the Population Policy 2002 and international agreements such as the United Nations Millennium Development Goals (MDGs).

The study is innovative in several ways: (1) it is longitudinal; (2) it combines consideration of three dimensions of schooling opportunity structures in the community-access, choice, and quality; (3) it considers the availability of school choicein particular, private versus government and religious versus secular-as a factor in educational attainment and performance; and (4) it defines schooling opportunity structures separately for boys and girls on all three dimensions.

The survey: Within each community, approximately 60 households were selected for the study in 1997. Efforts were made to interview in each household all women married at the time and aged between 20 to 45 years, as well as their husbands. These same households were re-contacted in 2004 and efforts were made to locate households that had split during the inter-survey period. Furthermore, the sample in 2004 was expanded to include all women aged 20 to 55 who had ever been married; this procedure allowed the survey team to identify and re-interview most of the women who had been interviewed previously-regardless of changes in marital status, household residency, or discrepancies in age reporting-and still preserve confidentiality. In all, 832 women were successfully interviewed in 2004: 597 women had previously been interviewed in December 1997, and 235 women were interviewed for the first time in January 2004.

The structure of the questionnaires, as well as the wording of specific questions, was retained, to ensure comparability across the two surveys; however, some additional 
questions were added in 2004 concerning economic shocks experienced by the households.

Data were also collected in both years on key features of each of the 12 communities and from all primary schools attended by children in the sample. When the communities were revisited in 2004, all of the schools contacted in 1997 were visited again. In addition, all primary schools that had been established within each community during the previous six years were visited for the first time, as were those schools outside the community which had not been previously visited, if it was determined that some community children were attending those schools.

The results: Over the course of six years, the sample communities had experienced significant improvements in schooling opportunities, in community infrastructure, and in the availability of basic health services and facilities. Only three communities showed no change in their infrastructure while a decline was witnessed in two. In addition to the public health investment in sewerage, many communities had also established additional health facilities.

Of the 104 primary schools visited in 2004, 54 had not been previously visited. Of the new schools visited, 22 had been in existence in 1997 but were not attended by children in the study; and 32 had been established during the intervening 6 years. Of these newly established schools, all but two were private schools. The expansion of schools has created new opportunities for girls, though the expansion is unevenly distributed across communities.

Although more private primary schools than government primary schools have opened in these communities since 1997, the gap in school quality between government and private schools is closing. Since 1997, government primary schools have increased access to material resources, in particular physical amenities such as electricity and toilet facilities, and classroom furnishings. Furthermore, there has been a substantial decline in teacher absenteeism in government schools, particularly girls' schools. Private primary schools still maintain fewer students per classroom and employ more teachers per school than government primary schools, but a higher proportion of teachers in government primary schools had teaching certificates and greater teaching experience than was the case in 1997. There has been a shift towards instruction in Urdu in government schools, most likely in response to policy change.

While the quality of teachers in girls' government primary schools has improved and is now comparable to the quality of teachers in boys' government schools, the number of teachers in girls' government schools is not keeping pace with demand. On average, girls' government schools have four teachers-one teacher less than in boys' government schools and two fewer teachers than mixed sex schools. While the student-teacher ratio 
in girls' government schools is comparable to that in boys' government schools, the classrooms are more crowded.

Against this backdrop of a changing school environment, there is evidence that more girls are enrolling in school, that more boys and girls are remaining in school for more years

(including completion of primary schooling), and that more parents are choosing to send their children to private primary schools than in the past. However, the growth in enrollment and retention is less than might have been expected, given the rapid expansion in school choice.

Indeed, these overall trends disguise the continuing importance of household and local contexts in shaping children's schooling outcomes. Communities with fewer new schools and less community development show evidence of some improvement in enrollment, but have largely preserved the gender disparities in enrollment and schooling attainment observed in 1997. In contrast, districts with higher levels of development and numerous recently created schools show little difference in the enrollment rates of girls and boys. Likewise, there is evidence that children whose parents did not attend school are less likely to attend and remain in school than the children of parents who received primary or higher schooling.

Taken together, these changes imply that when educational choice and opportunity are available, households committed to educating their children respond in ways that suggest that they are seeking to find the best educational options for their children within the local area. Unfortunately, nearly one-third of girls in these villages remain outside the school system, having never attended school. The recent changes described here have been insufficient to bring these girls into the school system.

Our data also document the changes that are occurring in family building patterns in these twelve villages. Younger women are in the lead with their adoption of modern reversible methods at lower parities. The cross-sectional data over the two time periods shows categorically that condoms and injectables have emerged as more popular contraceptive methods and that women are starting to use contraceptives with fewer average children. Further, men appear to be more dominant in the decision to start using a family planning method than they were six years earlier. The availability of family planning services has increased substantially across the communities represented in our sample, with all but one having access to services within the community. The increased placement of Lady Health Workers (LHWs) has had a visible impact in increasing health facilities. All these changes augur well for fertility decline in rural communities across Pakistan.

Examining the panel data, it is clear that the cohort of women followed across this six year period have largely maintained their earlier fertility intentions: for the majority, 
fertility preferences have remained the same. A substantially larger proportion of women are acting upon their intentions of postponing or terminating childbearing by using contraception in 2004 than were doing so in 1997. Nonetheless, despite this encouraging progress, over 50 percent of the births which occurred to women in our study in the past six years were unwanted, confirming that much more work will have to be done to build on past progress to help couples fully achieve their desires.

Some of the trends and associations further elaborated upon in this report illuminate the synergy that exists between the social sectors, with positive strides in family planning contributing to enrollment gains, particularly for girls, and enrollment gains contributing to growing preferences for smaller families. It appears that, as long as the prevalence of unwanted fertility remains high, the ability of families to support completion of primary school for girls will be compromised. Furthermore, without progress toward gender equality and without a rise in the enrollment rates of girls, rural communities (and therefore the majority of Pakistan) will continue to lag behind in the pace of fertility decline. 

access. The longitudinal nature of the study has two dimensions: a school component and a household-based component. All schools visited in the first survey (1997) were revisited in the second survey (2004) as were women previously interviewed in 1997.

\subsection{Problem statement}

The premise of the earlier study was to test the hypothesis proposed by John Caldwell that the enforcement of compulsory schooling laws by the state would change the economics of the family, leading to fertility decline, even among uneducated parents, with a rise in the cost of raising children (Caldwell 1980). In particular, it is hypothesized that increased accessibility of girls to schools will have a positive effect on the motivation to stop child bearing. Furthermore, improvements in access to girls' schools and an increase in their quality will increase parents' desires for higher-quality girls, thus narrowing the gap between the desires for girls and boys of high quality. A rising desire for higher-quality girls will increase the costs associated with such gender-specific goals and should lead to a reduction in overall fertility desires. The result should be an increasing desire in parents to stop childbearing, with a diminution in gender preference for children. In sum, we would expect increased motivation to adopt family-planning methods in communities where there is greater gender equity in access to and quality of primary schooling. Analysis of the earlier survey revealed a close association between the presence of a girl's primary school in a community and the uptake of contraception (Sathar, Lloyd and Mete 2003).

Additionally, women who have attended school at any point are significantly more likely to use contraception than those who have never been to school, suggesting that a mother's schooling influences contraceptive use, primarily by helping women to operationalize their desires rather than by inducing changes in their fertility desires. This is entirely supportive of Caldwell's argument that mass schooling is an important determinant of fertility change, particularly when educational opportunities are extended to both sexes. It appears that a change in fertility patterns will come about much more slowly when girls are left behind in terms of access to education. This is because family planning also involves generating awareness among individuals, a sort of education, and in order to be on the receiving end of this information, it is crucial that gender equity be practised widely.

In the years since the last survey in 1997, there is evidence of rapid uptake in family planning and continuing improvements in primary enrollment for girls in Pakistan, suggesting rapid changes in the service and schooling environment at the community level. Given the earlier survey in 1997, six years seemed like an appropriate time interval to revisit the communities to assess the changes that have taken place. 
The prior study, conducted in 1997, had already found evidence of very rapid recent growth in enrollments in private schools at the primary level in rural areas. Given the fairly strong supportive policy environment for both education and population and health in Pakistan in the past few years, we were interested in revisiting the communities. The objective was to observe for ourselves changes in the types of schools available as well as other changes in the actual quality of the education as assessed through direct observation and interview. We were also interested in discovering whether NGO schools (which had not been particularly noticeable in our rural communities in 1997) were becoming more prevalent in later years.

\subsection{Policy background}

Since the early 1990s, a number of strategies, policies, and reforms have been introduced to address the continuing problems of poor education and literacy indicators in Pakistan. The Social Action Program starting in the early 1990s was perhaps the starting point of efforts to direct funds towards the social sectors and to education in particular. In the recent past, the government has made even stronger commitments to achieve education for all though various means, including greater financial commitment to education, improving school quality, increasing access for girls, encouraging publicprivate partnerships, and decentralization of education sector responsibilities to provinces and districts. Collectively, these policies represent important milestones in the development of education. These new priorities have been recently reflected in the Education Sector Reform (ESR) action plan (2001-2005) and the Poverty Reduction Strategy Paper's (PRSP) education strategy (2003).

The Education Sector Reform 2001-2005 was developed under the umbrella of a number of other macro-level initiatives, including the Devolution and Local Government Plan 2000, the Interim Poverty Reduction Strategy Paper 2001-2004, SAP II Restructuring, and the Task Force on Human Development. It is based on a long-term framework linked to Education for All goals up to 2015, with a four-year action plan for 2002-2006. It is a comprehensive sector-wide program for increased access, enhanced equity and efficiency, and improved quality at all levels of education.

The government's Poverty Reduction Strategy Paper, issued in December 2003, included a more focused human development strategy. It linked social and poverty related expenditures with the attainment of key social and human development targets. This strategy marked a paradigm shift in the government's efforts and provided a holistic approach to meeting development challenges. The strategies of the ten-year perspective development plan 2001-2011 were also structured into the PRSP. The human development program has gained in budgetary allocation under the PRSP and education has the highest share. This is based on the clear expectation that higher 
expenditure on education will help to reduce poverty levels in the country as illiteracy is directly linked to poverty.

The implementation of ESRs is a complicated and long-term process; it is however gaining momentum as is evident in the progressive ownership by the provincial and district governments. Under these reforms, the provincial and district governments have entered a performance contract to fulfill district-based targets for enhancing enrollments, reducing dropouts, increasing completion rates, and operationalizing non-functional schools. Other important features of the strategy are the reduction of the gender imbalance and promotion of gender equality across programs. Important private-public partnerships have also been introduced to increase enrollments through incentive programs. Prominent NGOs have embarked on independent ventures in order to deal with the problems of illiteracy, high drop-out rates, and low enrollment rates: in fact, several NGOs are operating in the Punjab and the N.W.F.P. and contributing to the changing educational environment.

The Government of Punjab declared education to be its number one priority with the launching of the Punjab Education Sector Reform Program (PESRP) in 2003, reflecting an increase of 541 percent in the development budget, with the World Bank providing US $\$ 300$ million over the next three years. In the Punjab, the compulsory education act has been promulgated and is being enforced, with the aim of improving access, equity, quality, and governance. A total of 100,000 teachers have been trained and 13,000 new teachers recruited in the previous year; Rs. 15 billion has been disbursed to districts for enhancing missing school facilities. About 600 school councils have been empowered, and restructuring of the Punjab Education Foundation is underway. To address quality issues, the Universal Quality Primary Education program (UQPE) was started in six districts, including Rahim Yar Khan, with the aim of building the capacity of the district government officials to support the processes in achieving UQPE and 90 percent primary level enrolment in these areas.

The N.W.F.P. government has also outlined a similar program, focusing on quantity and quality as well as on mainstreaming of madaris. It is collaborating with the Frontier Education Foundation and its Elementary Education Foundation to supplement this activity. The underlying theme of the reforms is educational improvement for achieving long-term economic development and poverty reduction. As the indicators for education in this province are relatively low, the key objectives in the sector are (1) to improve primary education-both enrolment and quality; (2) to reduce gender and ruralurban disparities; and (3) to expand capacity at the secondary school level.

In sum, a review of past and recent trends in educational development in Pakistan shows that the country has moved into an era of change characterized by political and financial commitment, spurred by the realization of the urgency of dealing with this 
national crisis of human development. An examination of the educational policies and strategies since 1997 indicates that these efforts do strongly reflect a shift from earlier attempts for educational reforms in the country. A number of innovative measures have been introduced for solving fundamental issues that have thwarted earlier efforts. The impact of these actions on improving access, equity, and quality of education in Pakistan is beginning to manifest itself.

These reforms, which go beyond just an increase in budgetary allocations, have been spurred on by the realization that in order for Pakistan to achieve its international and national commitments, the education sector has to make some bold changes. These changes have been facilitated by changes taking place in both the national and international environments at the end of the 1990s. The thrust for re-thinking education in Pakistan was further stimulated through commitments made at the international fora. The role of the donor community through financial and technical support has also been crucial in achieving these reforms.

Finally, the population and health sectors also took strong initiatives to improve service delivery during this period. Health sector reforms supporting stronger governance structures and encouraging private and public partnerships were all moves meant to enhance the options of service delivery in these sectors. The Population Policy of 2002 strongly promoted partnerships with the health and other sectors. Most notable perhaps for the rural areas of Pakistan, is the expansion of the Lady Health Worker scheme, which is designed to ensure that each village with a population of about 1000-1500 should have one educated primary health care worker to deal mainly with preventive health care, including advice on family planning. 



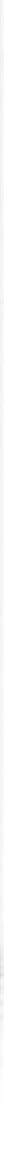

\section{Chapter 2 \\ Sampling Design, Questionnaires, Fieldwork and Samples}

This chapter describes the sampling design of the initial survey started in December 1997 (Sathar, Lloyd and Haque 2000) as well as the sampling strategy for the follow-up survey in the same 12 communities from December 2003 through March 2004 (roughly six years later). At the time of the first survey, there were no plans for a follow-up. However, subsequent plans were made to revisit the same communities and households because of the very interesting trends that were observed from the first survey, both in terms of the changing schooling environment and changes in family-building behavior and family size preferences, the basic design of the survey instruments and any changes introduced are also described in this chapter as are the fieldwork procedures and experience. At the end of the chapter, the size and distribution of each of the resulting samples is presented: the household sample, the woman sample, and the school sample for each of the two surveys. For the sake of simplicity, in the discussion that follows, we refer to the first survey fielded in December 1997 through spring 1998 as "1997", and the 
follow-up survey fielded in late 2003 through spring 2004 as "2004." In each case, the single year identified is when most of the data were collected (late 1997 and early 2004).

\subsection{Sample design}

In preparation for the fielding of the first survey, district schooling and income data from the 1995-6 Pakistan Integrated Household Survey (PIHS) were used to strategically select districts to cover the complete range of schooling conditions in rural Punjab and N.W.F.P. Within each province, a simple linear regression was run

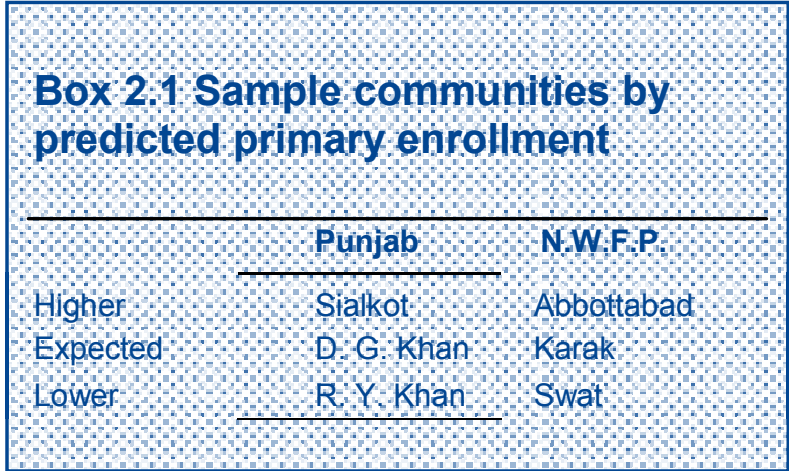
across districts in order to estimate the statistical relationship between per capita income and the proportion of children ages 714 currently enrolled in school. In each province, three districts were then selected for our study: one with higher- than-predicted schooling levels, based on the regression; one with predicted schooling levels; and one with lower-than-predicted schooling levels (Box 2.1). Two communities within each of the selected districts which had enrollment rates that appeared to be average for the district (as calculated from the PIHS) were then selected. The result was a sample drawn from 12 communities, reflecting a range of schooling conditions within each of the 2 provinces.

It is important to point out the diverse situation in the six districts located across the Punjab and the N.W.F.P. selected for the study (Figure 2.1). The six districts, even those within the same province, vary with regard to education and other developmental factors. Unfortunately, not enough data was available to analyze these differences until data from the 1998 Census became available. A district level analysis undertaken to measure educational disparities confirms the relationship between inequality in education and developmental levels, nationally (SPDC 2003). 


\section{Figure 2.1 Geographic location of sample districts}

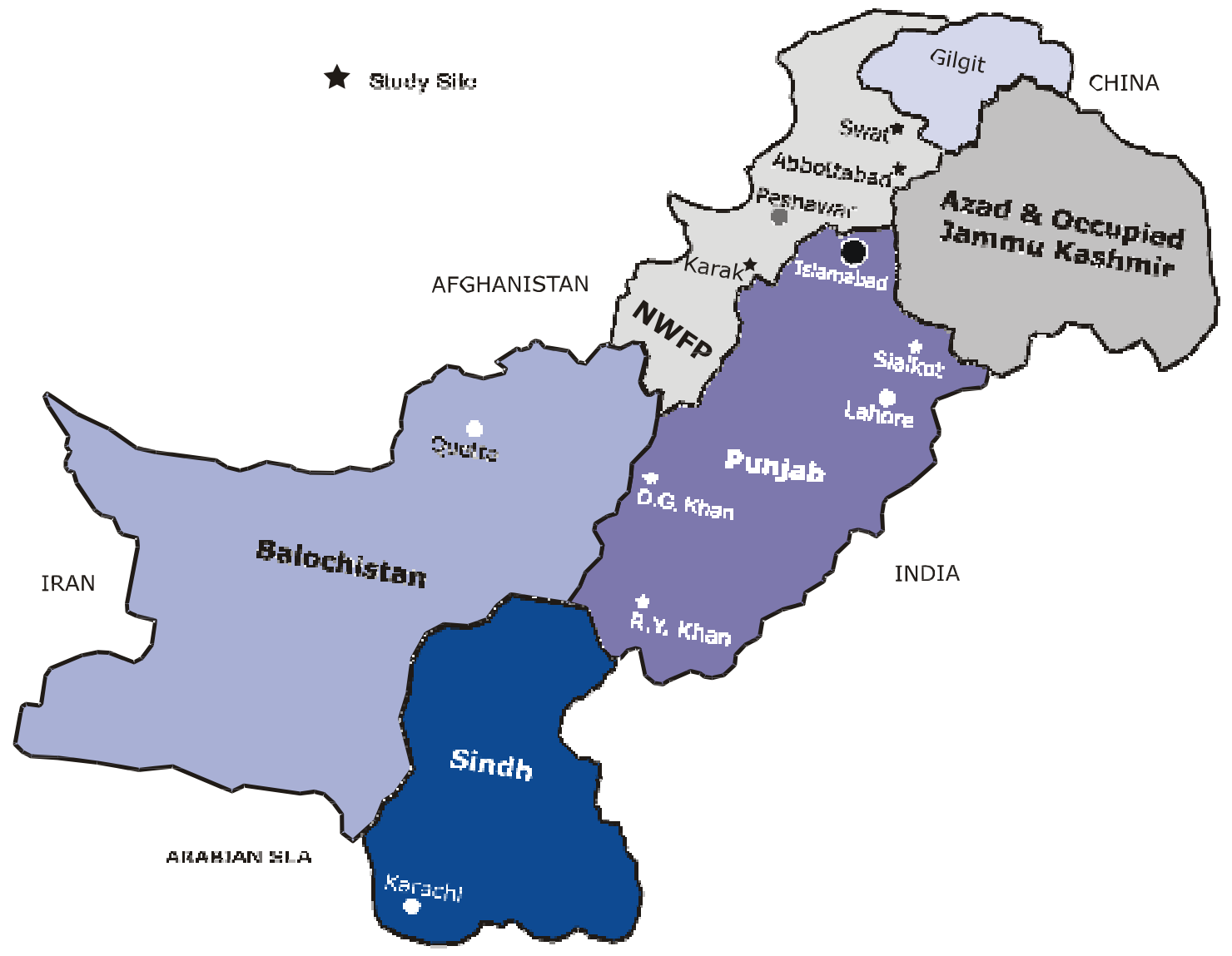

The District Education Index (DEI) measures educational status extracted from five different aspects of enrollment rates and literacy levels in different age cohorts. ${ }^{1}$

According to the SPDC study, the DEI is lowest in Balochistan (score of 23) followed by the

N.W.F.P. (31), Sindh (34), with Punjab (40) at the top. Females in rural N.W.F.P. were particularly at a disadvantage, as their DEI average is 20 compared to 42 for boys. There is greater gender equity in the Punjab, with the average for girls at 35 compared to boys at 47 . Using the measure of the DEI, the six districts in our study ranked the sample districts in the following order in terms of educational attainments: Highest quintile: Sialkot and Abbottabad; fourth quintile: Karak; third quintile: Rahim Yar Khan; and second quintile D. G. Khan and Swat.

\footnotetext{
1 The DEI is based on data from the 1998 Census and is the outcome of a principal component analysis of five measures of educational attainment, including enrollments of 5-9, 10-14, 15-19 year olds in general disciplines; and student enrollment of 15-24 year olds in professional disciplines and the adult literacy rate.
} 
In 1998, just after the first round of our survey, the districts in the Punjab (with the exception of Abbottabad) had higher enrollment rates than the N.W.F.P. (Figure 2.2). It is especially important to look at gender differentials and gender equity: certainly Sialkot was already placed much ahead of the other districts, followed by Abbottabad and then Rahim Yar Khan and Karak, with D. G. Khan and Swat demonstrating the lowest enrollment rates for girls. In Sialkot, female enrollment almost equals to that of males, whereas in D. G. Khan it is less than half that of boys.

\section{Figure 2.2 Percentage of children aged 5-9 attending school in rural areas, sample districts}

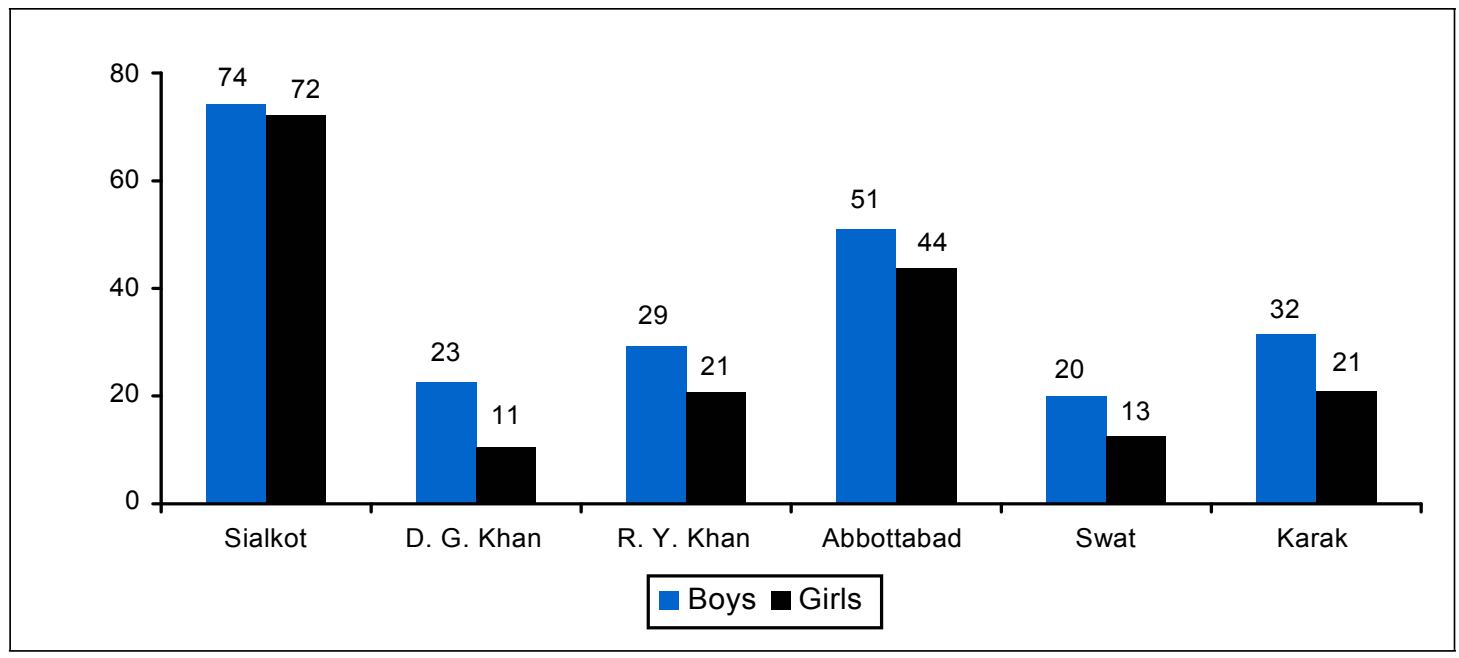

Source: 1998 Population Census

Another indicator of the diverse educational environment in Pakistan is seen in the variation in the number of government primary schools in each of these districts. Interestingly, the N.W.F.P. appears to be better endowed in the average number of government schools per primary school-age population (Figure 2.3). Whereas the average is about 4.5 schools per 1000 population in all three Punjabi districts, the averages were more than double and as high as 9.3 and 9.6 in Abbottabad and Karak.

Unfortunately, information disaggregated by gender is not readily available, making it difficult to judge whether the gender differentials seen in the earlier figure are reflected in availability of schools. Most likely the situation of girls' schools is far worse in the N.W.F.P. than in the Punjab. 
Figure 2.3 Number of primary schools per 1000 population aged 5-9 years, sample districts

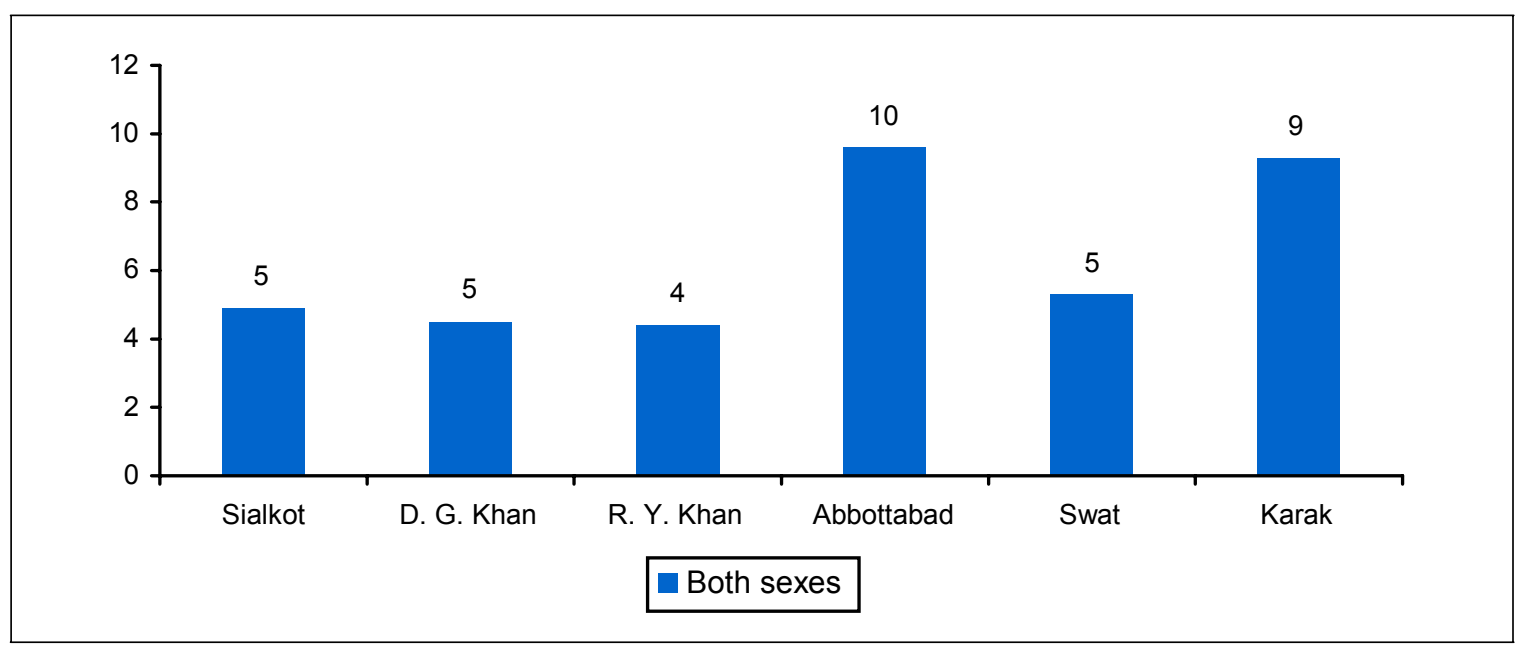

Source: 1998 Population Census

Within each of the communities, selected from the six sample districts, approximately 60 households were selected systematically with a random start. Efforts were made to interview all currently married women aged 20 to 45 and their husbands in each household. These same households were re-contacted in 2004, and efforts were made to locate households that had split during the inter-survey period. Furthermore, the sample in 2004 was expanded to include all women aged 20 to 55 who had ever married; this procedure allowed the survey team to identify and re-interview the same panel of womenregardless of changes in marital status, household residency, or discrepancies in age reporting-and still preserve confidentiality (see further discussion below in Section 2.3).

Data in both surveys were also collected on key features of each of the 12 communities and from all primary schools attended by children in the sample. In 1997, the survey team contacted every primary school attended by at least two or three sample children, regardless of whether or not the school was located within the community boundary.

When the communities were revisited in 2004, all of the schools contacted in 1997 were visited again. In addition, all primary schools that had been established within each community during the past six years were visited for the first time, as were schools outside the community which had not been previously visited, if it was determined that some community children were attending those schools. Furthermore, in 2004, data were also collected on religious and non-formal NGO schools. 


\subsection{The questionnaires}

\section{Questionnaire for females (1997 and 2004)}

For both surveys, eligible currently married women in the specified age range who gave their consent to be interviewed were questioned about a range of topics, including:

- basic background information about themselves and their husbands;

- their birth history;

- the education history for each child aged 5 to 21 ;

- their knowledge and use of contraceptive methods;

- household economic activity; and

- their attitudes and aspirations regarding their children's schooling.

Moreover, in 2004, women were asked whether or not their household had experienced any negative economic shocks in the six years since the previous survey and what, if any, strategies the household used to respond to the shock.

\section{Questionnaire for husbands (1997 only)}

In 1997, husbands of eligible women were also interviewed. The male survey covered the same topics as the female survey, but also included a modified module on income and consumption for the household, developed in collaboration with PIHS. When the husband could not be interviewed, women were asked to complete the schedule on household consumption.

\section{Household questionnaire (2004 only)}

In 2004, husbands were not interviewed, and the household consumption module was moved to a newly-created household questionnaire. A complete household roster and a module on household asset ownership were also included in the household questionnaire.

\section{In-depth interviews of parents (1997 only)}

In 1997, two men and two women (no couples) with children of school-going age were selected from each community to participate in follow-up in-depth taped interviews to probe parental attitudes about schooling. Twenty-three men and 22 women were interviewed at that time. No in-depth interviews with parents were conducted in 2004. 


\section{Primary school survey (1997 and 2004)}

For both surveys, the field researchers filled out a basic inventory for each school with the assistance of a teacher, head teacher or principal. The inventory included data on the following topics:

- the type of school (government, private, NGO, religious; girls, boys, or mixed);

- the condition of the buildings and classrooms;

- the availability of amenities such as running water, toilets, and electricity;

- the medium of education and the medium of instruction;

- the availability of textbooks;

- the total fees;

- the duration of daily sessions and the number of days in session per year;

- the total enrollment, as well as the attendance on the day of the visit;

- the background of all of the teachers assigned to the school; and

- information on school management committees (SMCs) and other forms of social support.

In 2004, an additional formal discussion was conducted with teachers at each primary school. These discussions resulted in the collection of qualitative information on teachers' opinions related to the schools and educational system, allowing the field team to gain a deeper understanding of the rapidly changing schooling environment in Pakistan.

\section{Community survey (1997 and 2004)}

In each community, the field team leaders collected information on community characteristics from key informants, covering such topics as:

- the availability of facilities and services (e.g. health care providers, post office, factory);

- a community development history focused on the availability of public amenities, transportation, and communications;

- migration;

- NGOs operating in the community;

- the availability of post-primary schools;

- local economic activities and work opportunities; and 
- changes in cropping patterns.

Furthermore, in 2004, community informants helped the survey team develop a rough map of each community (see maps in Chapter 3). Each map indicates the official community boundary, the location of schools visited by the survey team, the location of major community health facilities, and the location of any other significant features of the community. The maps assisted the survey team in locating the schools in sample communities. Interviewers also used these maps during the female survey to confirm with mothers which schools their children attended.

\subsection{Fieldwork}

The same fieldwork procedures were followed in each survey. Each of three survey teams covered four of the twelve communities. Interviews in the six sites in the Punjab and two communities in the N.W.F.P. district of Abbottabad were conducted in Punjabi and Siraiki, while a Pushto-speaking team covered the sample communities in Swat and Karak in N.W.F.P.

Most of the interviewers in the two Punjabi-speaking teams (one of which also covered the Hindko-speaking district of Abbottabad in N.W.F.P.) were selected from the Population Council's own pool of trained interviewers. In 1997, each team was composed of three males and three females, while in 2004, each team included three males and four females. The training was carried out in Islamabad at the Population Council office over 10 days with one major field pre-test to ensure that the interviewers had ironed out all practical issues in the questionnaire.

Data were first collected in December 1997. At that time, households were contacted and the female and husband surveys completed. Primary schools were also visited. The second phase of the first survey, in May 1998, involved data collection from the schools that had been missed in the initial data collection phase. Finally, in May of 1999, primary schools were re-contacted in order to add a module on the history of the formation of the school.

Some initial aspects of the second survey began with data collection in August and September 2003, when survey teams re-contacted the sample communities and began preliminary work to identify and locate the households and schools surveyed in 1997. Data collection began in December 2003 and continued through March 2004, with most data collected in January 2004, in order to replicate the same seasonal variations in school patterns collected in the first survey. In May 2004, schools missed in the initial data collection phase and schools identified by women in the female surveys were visited and data collected. 
In the second survey, the interviewer only knew which households had been visited in the first survey and not which women had been previously interviewed. The expanded definition of eligible women (see discussion above under Section 2.1) raised the likelihood that previously interviewed women would be re-interviewed. The team leader in the office matched women interviewed in both 1997 and 2004 after the data were collected, in order to preserve confidentiality.

In each survey, schools were visited without prior notification in order to avoid the usual courtesy bias that is involved in situation analyses of schools or family planning clinics. This allowed for the possibility that some schools might be closed on a regular school day during the school term due to teacher absence, weather, or other factors.

\subsection{The samples}

\section{Household sample}

In 1997, the number of households visited was 649. The plan for 2004 involved the location and re-contact ideally with all 649 households sampled in 1997. Not only were the original households targeted for re-interview, but any new households that may have been created due to a split off from the earlier survey household were also targeted for re-interview. Thus, in 2004, a total of 763 households were identified for potential interview: this comprised the 649 original households and 114 additional households, created due to splits from the original households. Of the 763 households identified, 666 (87 percent) were interviewed (Table 2.1). The remaining households were not interviewed because their members refused to participate in the survey, the household was locked, or household members had shifted to a new location outside the community.

\section{Table 2.1 Follow-up rates for households}

\begin{tabular}{lrrr}
\hline & Identified in 2004 & Interviewed in 2004 & Percentage interviewed \\
\hline Household split $^{2}$ & 223 & 133 & 57.1 \\
Household did not split & 540 & 533 & 98.7 \\
& & & \\
Total & 763 & 666 & 87.3 \\
\hline
\end{tabular}

\section{Sample of married women}

In 1997, all currently married women aged 20-45 in each sample household were interviewed, resulting in a sample of 731 women. In 2004, the sample was expanded to 
include all women aged 20 to 55 who had ever married and were living in households identified for interviewing as described above. This procedure made it easier for the survey team to identify and re-interview as many of the same panel of women as possibleregardless of changes in marital status, household residency, or discrepancies in age reporting-and still preserve confidentiality. In total, 832 women were successfully interviewed in 2004: (1) 597 women previously interviewed in 1997; and (2) 235 women interviewed for the first time in 2004 (Table 2.2). Of the 731 women who had participated in 1997, 81 percent were re-interviewed in 2004, which is a good follow-up rate after six years.

Table 2.2 Follow-up rates for women

\begin{tabular}{lrrr}
\hline & Interviewed in 1997 & Identified in 2004 & Interviewed in 2004 \\
\hline Panel Women & 731 & 731 & 597 \\
Women Identified in 2004 & n/a & 267 & 235 \\
Total & 731 & 998 & 832 \\
\hline
\end{tabular}

Table 2.3 illustrates the reasons why some of the women from the original 1997 sample could not be interviewed in 2004. A household shifting to a new location outside the PSU was the most common explanation for not following up, followed by the household's refusal to participate in the survey and the woman's absence from the home at the time the survey team was in the area.

Table 2.3 Reasons why women could not be interviewed in 2004

\begin{tabular}{|c|c|c|}
\hline Reason not interviewed (\%) & $\begin{array}{r}\text { Women interviewed in } 1997 \\
\text { only }\end{array}$ & $\begin{array}{r}\text { Women identified in } 2004 \\
\text { only }\end{array}$ \\
\hline Absent & 17.4 & 46.7 \\
\hline Refused & 21.0 & 40.0 \\
\hline Overage & 5.8 & 10.0 \\
\hline Household not located & 2.2 & 0.0 \\
\hline Household shifted & 46.4 & 0.0 \\
\hline Died & 4.3 & 0.0 \\
\hline Other & 2.9 & 3.3 \\
\hline Total non-respondents $(\mathrm{N})$ & 138 & 32 \\
\hline
\end{tabular}

As explained above, in 2004 the survey team also identified 267 women who had not previously been interviewed. This number includes women who were not eligible or chose not to participate in 1997, as well as many younger women who had joined the

\footnotetext{
${ }^{2}$ Households could have split into two or more additional households.
} 
household in the previous six years through marriage to a household member. Thirty of the newly identified women (11 percent) were not interviewed; refusal to participate and the woman's absence were the most common reasons (Table 2.3).

In total, 998 women were identified for interview in 2004, out of which 832 women (83 percent) were interviewed.

\section{Primary school sample}

In 1997, all primary schools located inside each community were visited. In addition, the survey team visited all those schools that were located outside the community boundaries and were attended by at least two sample children. In total, 50 schools were visited in 1997, including 13 government schools for girls, 23 government schools for boys, 12 private-for-profit schools, and 2 private schools operated by NGOs (Table 2.4). No information on schools providing informal or religious education was collected in 1997.

Table 2.4 Breakdown of primary schools surveyed in 1997

\begin{tabular}{lrrr|rrrrr}
\hline & \multicolumn{3}{c|}{ Government } & \multicolumn{5}{c}{ Private } \\
\cline { 2 - 9 } & Girls & Boys & Mixed & For profit & $\begin{array}{c}\text { NGO } \\
\text { (Formal) }\end{array}$ & $\begin{array}{c}\text { NGO } \\
\text { (Informal) }\end{array}$ & Religious & Total \\
\hline All classes 1-5 & 13 & 22 & 0 & 12 & 1 & NA & NA & 48 \\
Some classes 1-5 & 0 & 1 & 0 & 0 & 1 & NA & NA & 2 \\
Locked/Refused & 0 & 0 & 0 & 0 & 0 & NA & NA & 0 \\
Other & 0 & 0 & 0 & 0 & 0 & 0 & 0 & 0 \\
& 13 & 23 & 0 & 12 & 2 & 0 & 0 & 50 \\
Total & & & & & & & & \\
\end{tabular}

The same 50 schools were revisited in 2004. Additionally, the survey team visited all primary schools that had opened during the previous six years and any schools located outside the community boundaries that community children were now attending. Data were also collected on informal and religious schools. Altogether, school inventories were collected from 114 primary schools in 2004, more than double the number of schools for which data were collected in 1997. However, three schools were closed at the time of school visits or refused to participate in the survey, meaning that complete information was collected from 111 schools.

Table 2.5 shows the distribution of schools visited in 2004. Ninety-eight schools offer a full complement of primary classes one through five. An additional six schools offer less than a full five classes; the two government schools that fall under this category are 
mosque maktab, while the four private schools opened recently and are in the process of adding additional classes as each cohort ages through the school.

Table 2.5 Breakdown of primary schools surveyed in 2004

\begin{tabular}{|c|c|c|c|c|c|c|c|c|}
\hline & \multicolumn{3}{|c|}{ Government } & \multicolumn{4}{|c|}{ Private } & \multirow[b]{2}{*}{ Total } \\
\hline & Girls & Boys & Mixed & $\begin{array}{r}\text { For } \\
\text { profit }\end{array}$ & $\begin{array}{r}\text { NGO } \\
\text { (Formal) }\end{array}$ & $\begin{array}{r}\text { NGO } \\
\text { (Informal) }\end{array}$ & Religious & \\
\hline All classes 1-5 & 19 & 27 & 2 & 45 & 5 & 0 & 0 & 98 \\
\hline Some classes 1-5 & 0 & 1 & 1 & 2 & 2 & 0 & 0 & 6 \\
\hline Locked/Refused & 1 & 0 & 0 & 1 & 0 & 0 & 1 & 3 \\
\hline Other & 0 & 0 & 0 & 0 & 0 & 3 & 4 & 7 \\
\hline Total & 20 & 28 & 3 & 48 & 7 & 3 & 5 & 114 \\
\hline
\end{tabular}

Note that three schools are designated as providing informal education, most often in the form of literacy and numeracy skills meant to supplement the education of those who left school prematurely or never attended (Table 2.5). The survey also identified five religious schools that focus on teaching the Quran. Although data were collected from these eight schools, for the purposes of this report, we will only report on the characteristics of those schools that offer primary classes and prepare children to attend middle or high school. Therefore, the analysis in subsequent chapters is restricted to the 104 primary schools in 2004 that offer some or all primary classes one through five.

The most striking difference between Tables 2.4 and 2.5 is the increased number of private schools identified in 2004, the majority of which were established during the previous six years. Although two government schools for girls were established during the inter-survey period, the increased number of government schools attended by community children in 2004 is mostly attributable to the increased utilization of existing government schools located outside community boundaries. Chapter 3 will use the community maps to explore the distribution of primary schools across the twelve sample communities in each survey. 


\subsection{Background on the changing educational environment in Pakistan}

While the majority of students enrolled in primary schools attend government schools, private schools-particularly private-for-profit schools-represent an increasingly significant share of total enrollment. Indeed, nearly one-third of students enrolled at the primary level now attend private schools (Andrabi, et. al. 2002). The most rapid recent growth in private schools has taken place in rural areas. These for-profit institutions offer mainly co-educational schooling, in sharp contrast to the typical single-sex government school. Private schools call themselves English-medium schools (though in fact little English is used in the classrooms), follow a curriculum different from the one prescribed by the provincial government, and many have sufficiently low fees to make them relatively affordable for low and middle income families, even in rural areas. This growth in private schools appears to reflect a rising demand for better quality schools. While much less significant in terms of numbers, there has also been a growth in the supply of private NGO schools as well.

Madaris (religious schools) are of potential importance but not much could be learned about the full extent of enrollment in these schools from sample surveys, because they tend to be geographically concentrated in one part of Pakistan-the 'Pashtun Belt' - on the western border of Afghanistan. However, the data we do have would suggest that on a national basis these schools represent no more than a tiny minority of Pakistani students. Recent estimates would suggest that, nation-wide, no more than one percent of Pakistani students are enrolled in madaris (Andrabi, et. al. 2005).

\subsection{The changing educational environment in the Punjab and the N.W.F.P.}

As noted in Chapter 2, the 2004 school survey identified 114 primary schools, including the

50 schools that were surveyed in 1997 (see Tables 2.3 and 2.4). Although data were collected from all 114 schools, this report restricts analysis to the 104 schools that offer primary classes leading towards continued schooling at the middle and secondary levels. Of the ten schools omitted from the analysis, three were NGO schools that offered informal education, four were religious schools that focused on teaching the Quran and three schools were locked or refused to participate in the survey.

Of the 104 schools, 54 were not surveyed in 1997. Although many of these schools had been established after the first survey, a large number were extant prior to 1997, though not visited by the survey team. These schools were excluded from the survey in 1997 either because community children did not attend them or because the criteria for 
visiting schools were different at that time. Table 3.1 explores this issue and shows the distribution of schools surveyed in 2004 by their date of establishment.

Table 3.1 Breakdown of primary schools in 2004, by school type, year of visit, and year of establishment

\begin{tabular}{lrr|rr}
\hline & \multicolumn{2}{c|}{$\begin{array}{c}\text { Schools established before 1997 } \\
\text { and visited in survey }\end{array}$} & $\begin{array}{c}\text { Schools established after 1997 } \\
\text { and visited in survey }\end{array}$ & Total \\
\cline { 2 - 6 } School type & $\mathbf{1 9 9 7}$ and 2004 & $\mathbf{2 0 0 4}$ & $\mathbf{2 0 0 4}$ & \\
\hline Government & 36 & 12 & 2 & 50 \\
Private & 12 & 9 & 26 & 47 \\
NGO & 2 & 1 & 4 & 704 \\
& & & 32 & \\
Total & 50 & 22 & & \\
\hline
\end{tabular}

Although 14 government schools were added to the sample of schools in 2004, Table 3.1 shows that only two of these schools were established between the two surveys, both of them for girls. The remaining twelve government schools existed outside community boundaries and did not meet the criteria for inclusion during the first survey in 1997. In contrast, 26 of the 35 new private schools and four of the five new NGO schools had been established after 1997. However, the most striking trend is the recent growth in private schools. Of the 30 newly established private and NGO schools, 22 were established between 2001 to 2003-the three years immediately prior to the 2004 survey.

It is clear from Table 3.1 that the observed increase in private primary schools in the sample is due to the recent establishment of new schools, while the increase in government primary schools is due to the increased utilization of government schools that existed in 1997 but were not attended by community children at that time. Whereas in 1997 government primary schools outnumbered private and NGO primary schools almost three to one, by the time of the 2004 survey they were present in almost equal numbers across the sampled communities.

These two forces-the establishment of new schools and the increasing utilization of existing schools outside the community boundaries-have transformed the schooling environment across the 12 sample communities. Most private schools are mixed, or open to both boys and girls, while almost all government schools are officially single sex. Although children of the opposite sex are occasionally allowed to attend a single sex school, the official, or de jure, status defines a realistic picture of the access children have to educational opportunities. Table 3.2 explores how the distribution of schools defined de jure, as open to boys, girls, or both, has changed between the two surveys. 
Table 3.2 Distribution of schools by de jure status, province, and survey year

\begin{tabular}{lcccr}
\hline & \multicolumn{5}{c}{ De jure } \\
\cline { 2 - 5 } Province and Survey Year & Boys & Girls & Mixed & Total \\
\hline & & & & \\
Punjab \& N.W.F.P. & 22 & 13 & 15 & 50 \\
$\quad 1997$ & 33 & 21 & 50 & 104 \\
2004 & & & & \\
& & & & \\
Punjab & 12 & 7 & 30 & 60 \\
1997 & 17 & 13 & & \\
2004 & & & 7 & 23 \\
N.W.F.P. & 10 & 6 & & \\
1997 & 16 & 8 & 20 & \\
2004 & & & & \\
\end{tabular}

As expected, the greatest change is the increased number of mixed schools in both provinces, from eight to 30 mixed schools in the Punjab and from seven to 20 mixed schools in the N.W.F.P. Almost all of these schools are private or NGO schools, although three mixed government were located schools in 2004. The increased number of boys' schools is similar across the two provinces; however, there are only two additional girls' schools in N.W.F.P. in 2004, as compared to six additional girls' schools in Punjab. Table 3.2 shows that boys still have more opportunities to attend primary school than girls do, although the gap is narrowing, and that there are fewer opportunities for girls in the N.W.F.P. than there are in the Punjab.

An additional dimension of primary schools in 2004 is the increased number of schools that are located outside the community boundaries. Whereas in 1997, only nine of 50 schools (18 percent) were considered to be outside, 38 of 104 schools (37 percent) were outside in 2004; the percentage of schools that were outside in 2004 is roughly the same in the Punjab and the N.W.F.P. (Table 3.3). However, the greater increase in the number of schools outside the communities relative to the increase in schools inside the communities disguises the findings from Table 3.1; almost all of the new inside schools were established during the six years between the two survey, whereas the majority of new outside schools existed at the time of the 1997 survey but were not attended by community children at that time. 
Table 3.3 Breakdown of schools by location inside or outside the community boundaries, province, and survey year

\begin{tabular}{lrrr}
\hline Province and Survey Year & Inside & Outside & Total \\
\hline & & & \\
Punjab \& N.W.F.P. & & & \\
1997 & 41 & 9 & 50 \\
2004 & 66 & 38 & 104 \\
& & & \\
Punjab & & & \\
1997 & 24 & 3 & 27 \\
2004 & 38 & 22 & 60 \\
& & & \\
N.W.F.P. & & & \\
1997 & 17 & 6 & 23 \\
2004 & 28 & 16 & 44 \\
\end{tabular}

The additional primary schools identified in 2004 have changed educational opportunities in the sample communities. In particular, the recent growth in the number of private schools has created new opportunities for girls. However, these changes have not been evenly distributed across the twelve communities. Section 3.3 will use the maps developed during the community surveys to explore this variation in educational opportunities.

\subsection{The changing service environment}

In addition to changes in educational opportunities, the availability of services and health facilities has also changed. The first part of this section will examine the level of infrastructure in each community, and the second will examine the distribution of health facilities.

The level of infrastructure was assessed by the existence or absence of each of seven amenities and structures: a metal road, public transportation within the community, sewerage, electricity, telephones, natural gas, and paved streets. Most communities improved their infrastructure over the six years from late 1997 to early 2004, although there was no change in three communities and a decline in infrastructure in two (Table 3.4). By the time of the 2004 survey, only one community had all seven amenities (Kakul), while two communities (Feroza and Kotla Drigh) only had one. In general, the communities in the N.W.F.P. had higher levels of infrastructure than the communities in the Punjab. 
Electricity and public transportation are the two most common forms of infrastructure, present in almost every community. Kotla Drigh is the only community that lacks widespread access to electricity: although community leaders report that electricity is available, only 34 percent of sampled households have electricity. Most communities have at least two forms of transportation available, except for Feroza, which lacks public transport; Noopur, which is serviced only by wagon; Kotla Drigh, which is serviced only by tonga; and Kakul, which is serviced only by Suzuki/pickup. Natural gas was the least common form of infrastructure, present only in Kakul.

At the time of the 1997 survey, no community possessed all seven forms of infrastructure. In addition to natural gas, sewers were the least common form of infrastructure at that time. In contrast, sewers were the feature that communities were most likely to have added, and were present in four additional communities by the time of the 2004 survey.

In addition to the public health investment of sewerage, many communities had also established additional health facilities during the six years between the two surveys. Access to health facilities was measured by the presence of each of four health providers inside community boundaries: a lady health worker (LHW), a basic health unit (BHU), a private doctor (MBBS), and a chemist/medical store. 
Fewer and Better Children: Expanded Choices in Schooling and Fertility in Rural Pakistan

Table 3.4 Service availability by community and survey year

\begin{tabular}{|c|c|c|c|c|c|c|c|c|}
\hline $\begin{array}{l}\text { Community \& } \\
\text { Survey Year }\end{array}$ & $\begin{array}{r}\text { Metalled } \\
\text { road }\end{array}$ & $\begin{array}{r}\text { Public } \\
\text { transport }\end{array}$ & Sewerage & Electricity & $\begin{array}{l}\text { Phone } \\
\text { service }\end{array}$ & $\begin{array}{r}\text { Natural } \\
\text { gas }\end{array}$ & $\begin{array}{l}\text { Paved } \\
\text { streets }\end{array}$ & $\begin{array}{l}\text { Count of } \\
\text { services }\end{array}$ \\
\hline \multicolumn{9}{|l|}{ Dhado Basra } \\
\hline 1997 & $\checkmark$ & $\checkmark$ & & $\checkmark$ & & & $\checkmark$ & 4 \\
\hline 2004 & $\checkmark$ & $\checkmark$ & $\checkmark$ & $\checkmark$ & & & $\checkmark$ & 5 \\
\hline \multicolumn{9}{|l|}{ Ram Garha } \\
\hline 1997 & $\checkmark$ & $\checkmark$ & & $\checkmark$ & $\checkmark$ & & $\checkmark$ & 5 \\
\hline 2004 & $\checkmark$ & $\checkmark$ & $\checkmark$ & $\checkmark$ & $\checkmark$ & & $\checkmark$ & 6 \\
\hline \multicolumn{9}{|l|}{ Gadai } \\
\hline 1997 & $\checkmark$ & $\sqrt{ }$ & $\checkmark$ & $\checkmark$ & $\checkmark$ & & $\sqrt{ }$ & 6 \\
\hline 2004 & $\checkmark$ & $\checkmark$ & $\checkmark$ & $\checkmark$ & $\checkmark$ & & $\checkmark$ & 6 \\
\hline \multicolumn{9}{|l|}{ Noorpur } \\
\hline 1997 & & & & $\checkmark$ & & & & 1 \\
\hline 2004 & & $\checkmark$ & & $\checkmark$ & & & & 2 \\
\hline \multicolumn{9}{|l|}{ Feroza } \\
\hline 1997 & & & & $\checkmark$ & & & $\checkmark$ & 2 \\
\hline 2004 & & & & $\checkmark$ & & & & 1 \\
\hline \multicolumn{9}{|l|}{ Kotla Drigh } \\
\hline \multicolumn{9}{|l|}{1997} \\
\hline 2004 & & $\checkmark$ & & & & & & 1 \\
\hline \multicolumn{9}{|l|}{ Islampur } \\
\hline 1997 & $\checkmark$ & $\checkmark$ & & $\checkmark$ & $\checkmark$ & & $\checkmark$ & 5 \\
\hline 2004 & $\checkmark$ & $\checkmark$ & $\checkmark$ & $\checkmark$ & $\checkmark$ & & $\checkmark$ & 6 \\
\hline \multicolumn{9}{|l|}{ Alaabad } \\
\hline 1997 & $\checkmark$ & $\checkmark$ & & $\checkmark$ & $\checkmark$ & & & 4 \\
\hline 2004 & $\checkmark$ & $\sqrt{ }$ & & $\sqrt{ }$ & $\checkmark$ & & $\checkmark$ & 5 \\
\hline \multicolumn{9}{|l|}{ Duresh Khel } \\
\hline 1997 & $\checkmark$ & $\sqrt{ }$ & & $\checkmark$ & & & & 3 \\
\hline 2004 & $\checkmark$ & $\checkmark$ & & $\checkmark$ & $\checkmark$ & & $\checkmark$ & 5 \\
\hline \multicolumn{9}{|l|}{ Mandawa } \\
\hline 1997 & $\checkmark$ & $\checkmark$ & $\checkmark$ & $\checkmark$ & $\checkmark$ & & $\checkmark$ & 6 \\
\hline 2004 & & $\sqrt{ }$ & & $\checkmark$ & $\checkmark$ & & $\sqrt{ }$ & 4 \\
\hline \multicolumn{9}{|l|}{ Tarmuchian } \\
\hline 1997 & & $\checkmark$ & & $\sqrt{ }$ & & & & 2 \\
\hline 2004 & & $\checkmark$ & & $\checkmark$ & & & & 2 \\
\hline \multicolumn{9}{|l|}{ Kakul } \\
\hline 1997 & $\checkmark$ & $\checkmark$ & & $\checkmark$ & $\sqrt{ }$ & $\checkmark$ & $\checkmark$ & 6 \\
\hline 2004 & $\checkmark$ & $\checkmark$ & $\checkmark$ & $\checkmark$ & $\checkmark$ & $\checkmark$ & $\checkmark$ & 7 \\
\hline
\end{tabular}


Table 3.5 Distribution of health facilities by community and survey year

\begin{tabular}{|c|c|c|c|c|}
\hline $\begin{array}{l}\text { Community \& } \\
\text { Survey Year }\end{array}$ & LHW/FWC $^{*}$ & $\begin{array}{r}\text { Basic Health } \\
\text { Unit (BHU) }\end{array}$ & 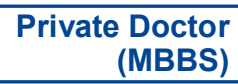 & $\begin{array}{r}\text { Chemist } \\
\text { Medical Store }\end{array}$ \\
\hline \multicolumn{5}{|l|}{ Dhado Basra } \\
\hline \multicolumn{5}{|l|}{1997} \\
\hline 2004 & $\checkmark$ & & & \\
\hline \multicolumn{5}{|l|}{ Ram Garha } \\
\hline \multicolumn{5}{|l|}{1997} \\
\hline 2004 & $\checkmark$ & & & \\
\hline \multicolumn{5}{|l|}{ Gadai } \\
\hline 1997 & $\checkmark$ & & $\checkmark$ & $\checkmark$ \\
\hline 2004 & $\checkmark$ & $\checkmark$ & $\checkmark$ & $\checkmark$ \\
\hline \multicolumn{5}{|l|}{ Noorpur } \\
\hline \multicolumn{5}{|l|}{1997} \\
\hline 2004 & $\checkmark$ & & & \\
\hline \multicolumn{5}{|l|}{ Feroza } \\
\hline 1997 & $\checkmark$ & & & \\
\hline \multicolumn{5}{|l|}{2004} \\
\hline \multicolumn{5}{|l|}{ Kotla Drigh } \\
\hline \multicolumn{5}{|l|}{1997} \\
\hline 2004 & $\checkmark$ & & & \\
\hline \multicolumn{5}{|l|}{ Islampur } \\
\hline \multicolumn{5}{|l|}{1997} \\
\hline 2004 & $\checkmark$ & & $\checkmark$ & $\checkmark$ \\
\hline \multicolumn{5}{|l|}{ Alaabad } \\
\hline 1997 & $\checkmark$ & & & $\checkmark$ \\
\hline 2004 & $\checkmark$ & & & $\checkmark$ \\
\hline \multicolumn{5}{|l|}{ Duresh Khel } \\
\hline 1997 & & $\checkmark$ & & $\checkmark$ \\
\hline 2004 & $\checkmark$ & $\checkmark$ & & $\checkmark$ \\
\hline \multicolumn{5}{|l|}{ Mandawa } \\
\hline 1997 & & & $\checkmark$ & $\checkmark$ \\
\hline 2004 & & & & $\checkmark$ \\
\hline \multicolumn{5}{|l|}{ Tarmuchian } \\
\hline \multicolumn{5}{|l|}{1997} \\
\hline 2004 & $\checkmark$ & & & \\
\hline \multicolumn{5}{|l|}{ Kakul } \\
\hline 1997 & $\checkmark$ & $\checkmark$ & $\checkmark$ & $\checkmark$ \\
\hline 2004 & $\checkmark$ & $\checkmark$ & $\checkmark$ & $\checkmark$ \\
\hline
\end{tabular}

${ }^{*}$ Family Welfare Center 


\subsection{Community maps}

In order to visually examine the changes in the educational and service environment over the six years from 1997 to 2004, a rough map of each community was drawn with the help of knowledgeable community informants. Two maps were prepared in each community, one for each wave of the survey, to show all schools and health facilities, regardless of their location inside or outside community boundaries. By comparing the two maps, a picture of recent development emerges.

Each map shows the location of each primary school included in the surveys in 1997 and 2004. The color of the school indicates whether it is run by the government, an NGO, or private sector, and a symbol indicates whether the school is a boys' primary school, a girls' primary school, or mixed and open to both boys and girls. Furthermore, the maps include the location of informal NGO and religious schools, even though they are not included in the analysis of school characteristics earlier in this chapter and in subsequent chapters. A star indicates which schools were established after 1997.

Each map also shows the location of each of the four types of health facilities: an LHW, a $\mathrm{BHU}$, an MBBS doctor, and a chemist/medical store. In addition to these facilities of specific interest, each map also depicts prominent community landmarks and natural features, such as major roads and footpaths, post-primary schools, mosques, rivers, and canals.

\section{Sialkot}

\section{Dhado Basra}

In 1997, there were four primary schools in Dhado Basra: two boys' government schools, one girls' government school, and one mixed private school. However, Dhado Basra experienced significant changes in its schooling environment in the six years from late 1997 to early 2004. First, two schools-a girls' government school and a mixed private school-that existed in 1997 but were not included in the survey at that time, were now attended by children from the community. Second, one mixed private school opened inside the community in 1997 but was not included in the 1997 survey. Third, three NGO schools for girls opened in 2003 to provide informal education to supplement the education of girls.

Furthermore, the 2004 survey found two religious schools in Dhado Basra. The school for boys was open at the time of the 1997 survey, but was not included at that time. The second religious school was open to both boys and girls and opened in 1998.

There were no health facilities inside the community in 1997. An LHW was appointed in the village in 1997 and was still present at the time of the 2004 survey. 


\section{Ram Garha}

In 1997, five primary schools were located inside the community-three mixed private schools, one boys' government school, and one girls' government school-and one girls' government school was located outside the community boundary. By the time of the 2004 survey four private schools-three mixed and one for boys-and one mixed NGO school had opened inside the community. Besides these, two mixed private schools, one girls' government school, and one boys' government school had been opened outside the community and were attended by community children.

There were no health facilities inside the community in 1997, but an LHW had been posted to Ram Garha by the time of the 2004 survey. 

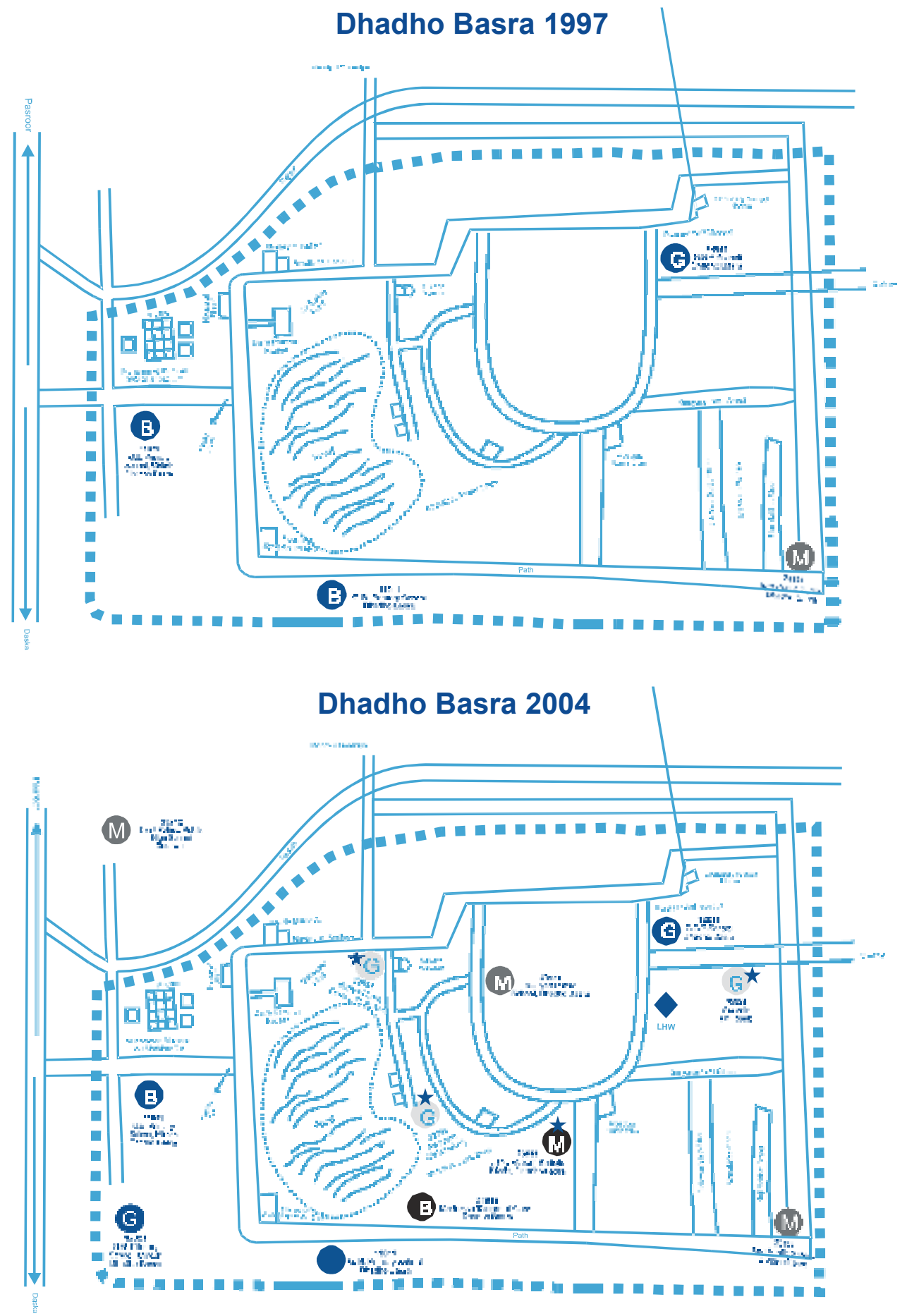

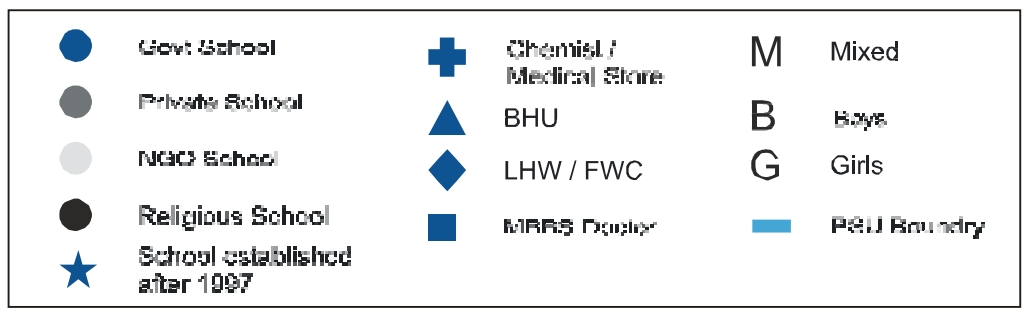




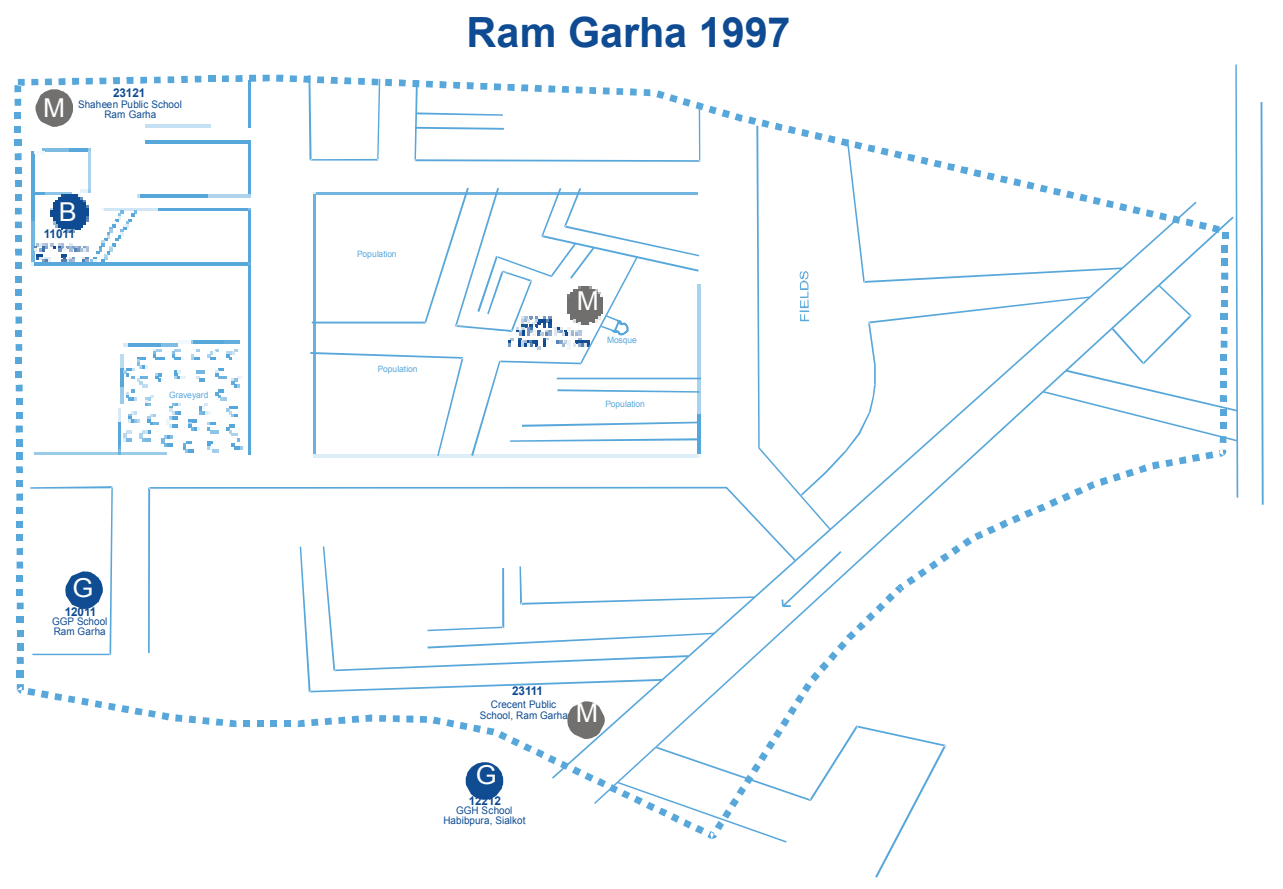

\section{Ram Garha 2004}

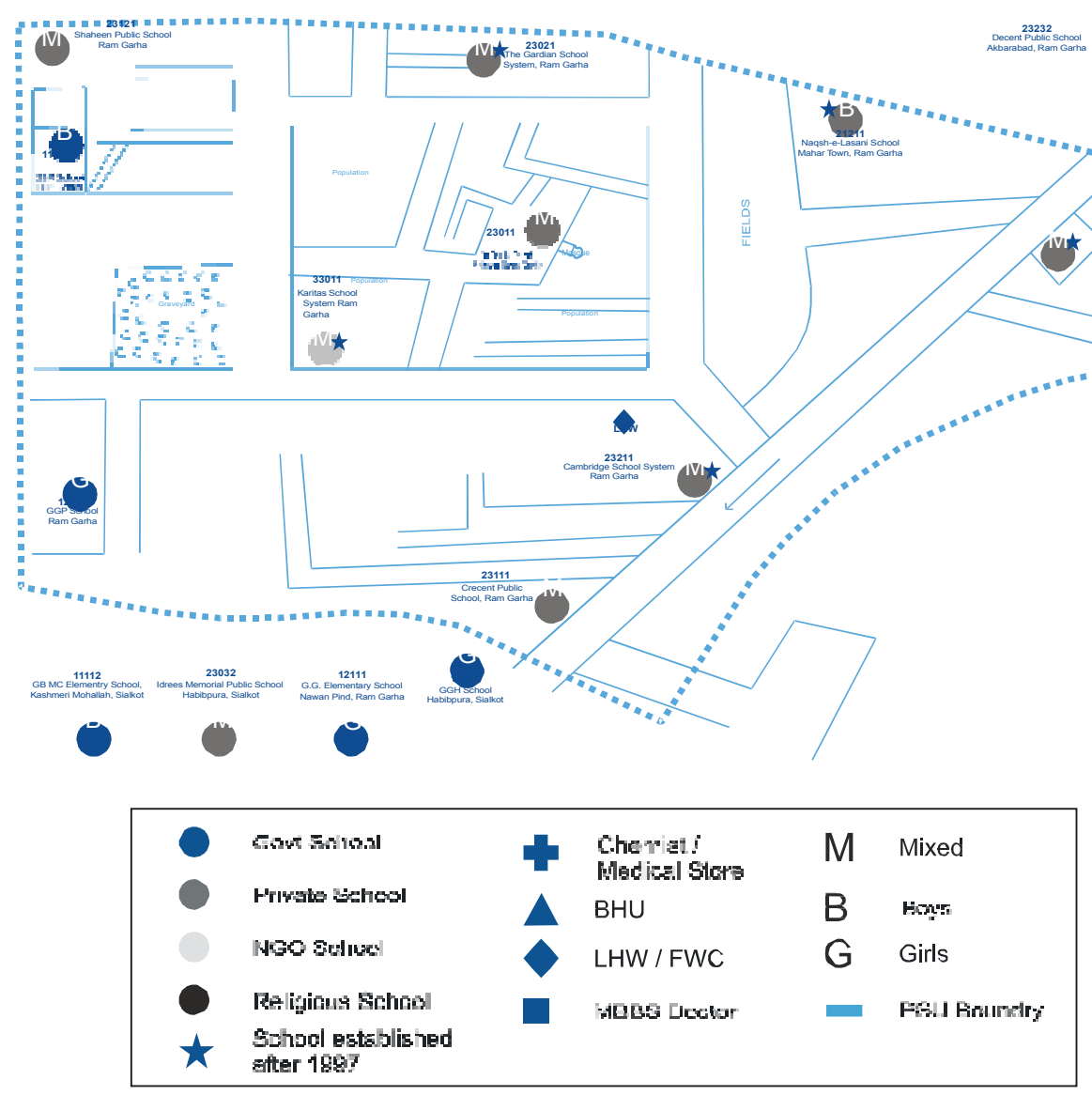


Dera Ghazi Khan (D. G. Khan)

\section{Gadai}

As of 1997, there were seven primary schools located inside the community-three mixed private schools, two boys' government schools, and two girls' government schools-and one mixed government school located outside the community. However, by 2004 , seven private schools had opened inside the community, including one private school for girls. One boys' private school was opened outside the community boundary after 1997. An additional three mixed private schools located outside the community boundaries were also attended by children from the community. By 2004, there was also one religious school outside the community boundary.

In terms of health facilities, an FWC, a private doctor, and a chemist/medical store facilities were available in 1997; an additional LHW and BHU facility had been established by 2004.

\section{Noorpur}

There were no private schools in Noorpur in 1997, although there was one girls' government school and two boys' government schools. In the six years between the surveys, no new schools opened inside the community, but two mixed private schools opened outside. Furthermore, children attended a girls' government school located outside the community boundary.

In 1997, no health facilities were located inside the community. By 2004, an LHW was available in the village. 

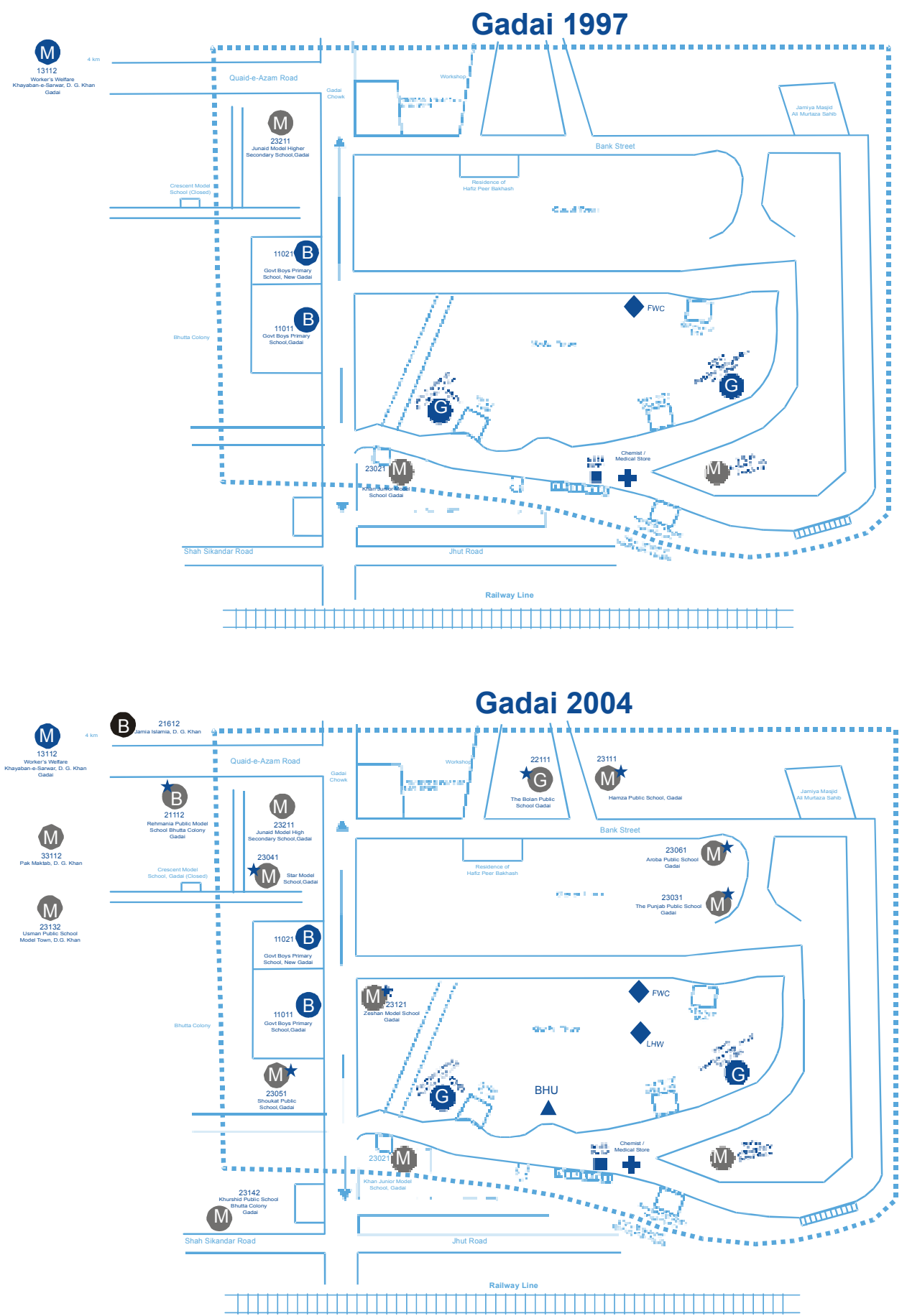

\begin{tabular}{|c|c|c|c|c|}
\hline 0 & Gewt Decheo & $\begin{array}{l}\text { Cheriat if } \\
\text { Medical Stero }\end{array}$ & $\mathrm{M}$ & Mixed \\
\hline 0 & 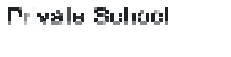 & $\mathrm{BHU}$ & $B$ & Hingh \\
\hline 0 & NGo tarmanl & LHW / FWC & $\mathrm{G}$ & Girls \\
\hline $\begin{array}{l}0 \\
\star\end{array}$ & 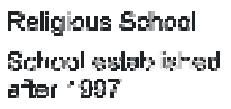 & MDES Doulor & ש & Fist Esundy \\
\hline
\end{tabular}




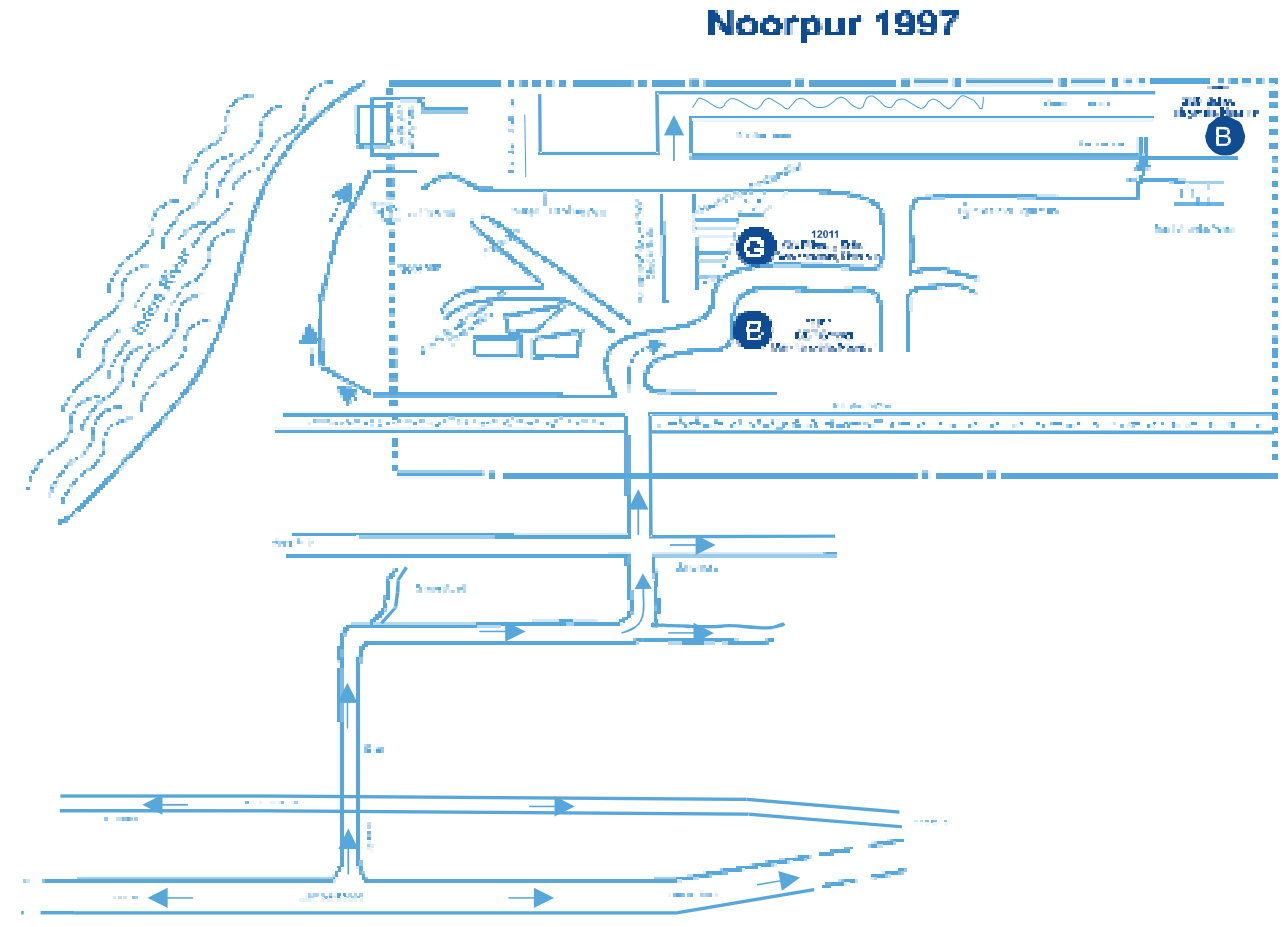

Noorpur 2004

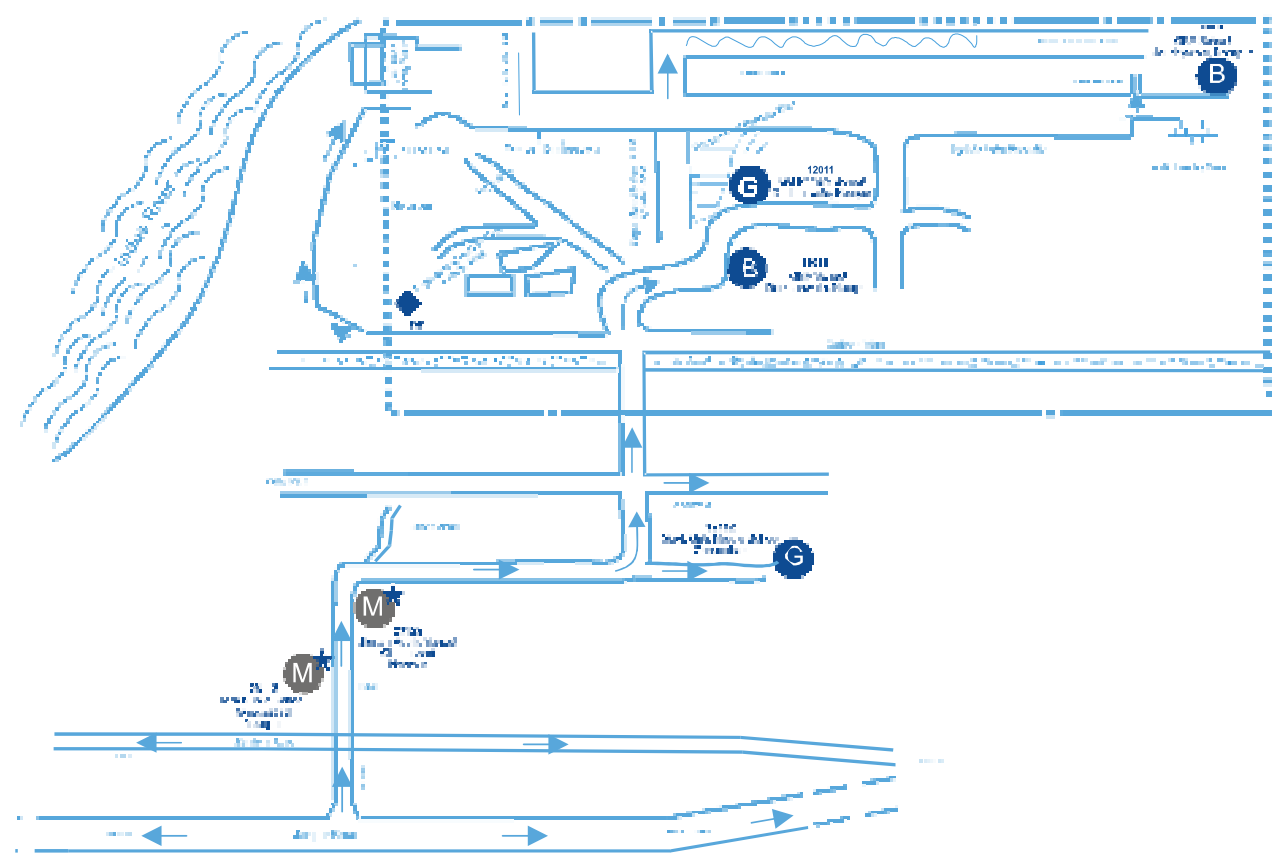

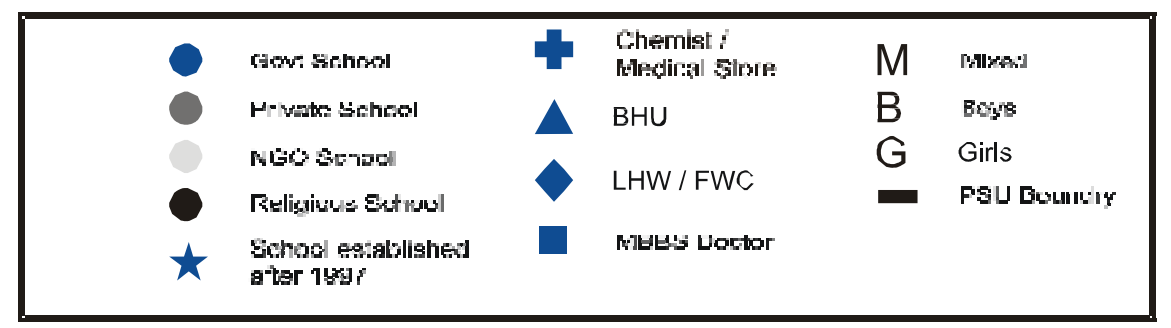




\section{Rahim Yar Khan (R. Y. Khan)}

\section{Feroza}

There were no private schools in Feroza in 1997, although there were two boys' government schools and one girls' government school inside the community and an additional boys' government school outside the community at that time. However, one of the boys' schools located inside the community is a masjid boys school and does not offer full primary school education. An additional three outside schools existed in 1997, but were not attended by community children at that time: one mixed private school, one girls' government school and one NGO school. Furthermore, one mixed private school and one girls' government school opened outside the community boundaries.

An LHW was posted to Feroza in 1997, but by 2004 there was no health and family planning facility as the LHW had left.

\section{Kotla Drigh}

In 1997, there were only two boys' government schools inside Kotla Drigh. By 2004, no new schools had opened, although community children were also attending a boys' government school located outside the community boundaries. Two girls' government school existed inside the community in 2004, but were locked at the time of the survey and no data were collected.

There were no health facilities in Kotla Drigh at all in 1997. However, an LHW was posted to the community in 2004. 

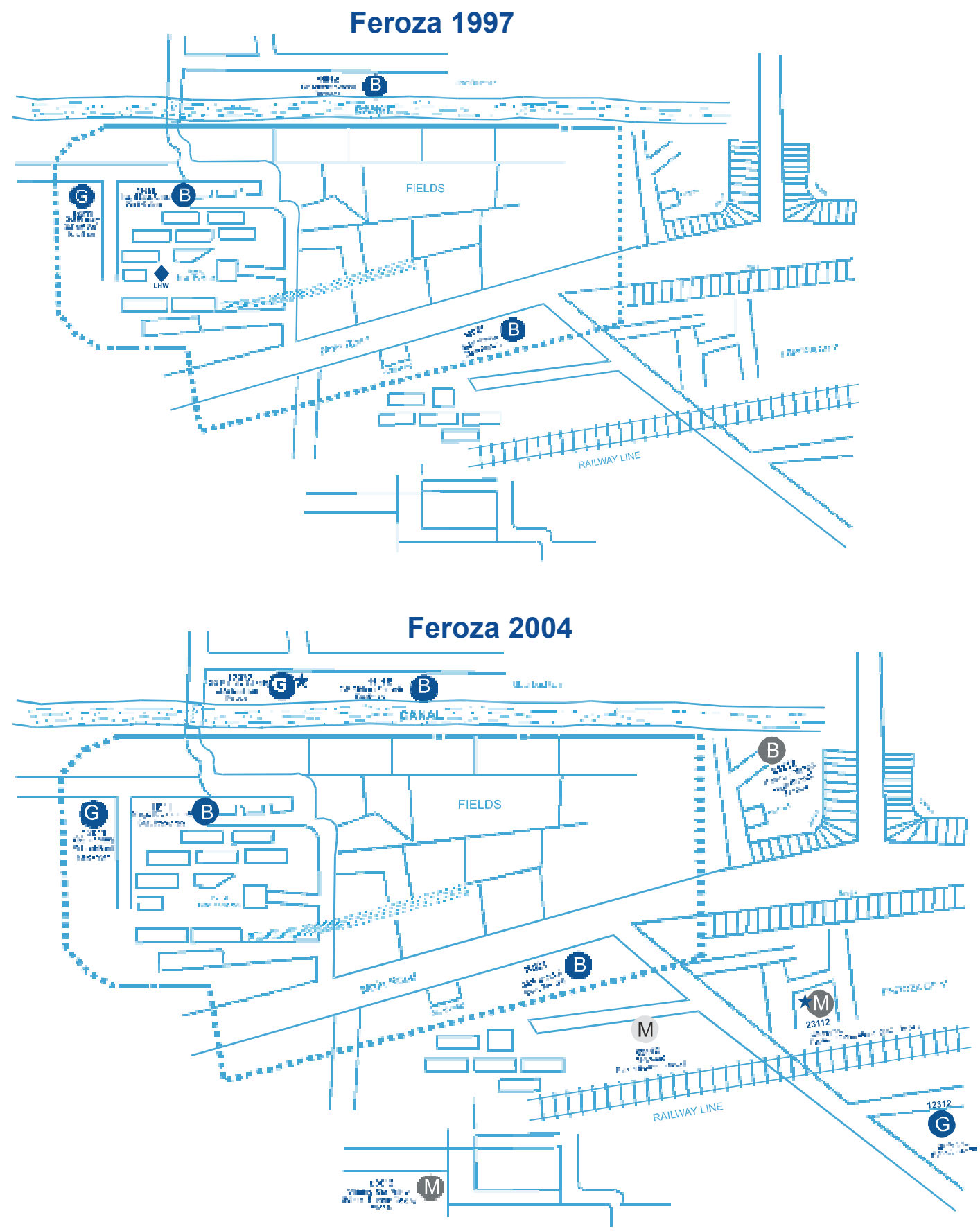

\begin{tabular}{|c|c|c|c|c|}
\hline 0 & Gom sromal & $\begin{array}{l}\text { Chem a1: } \\
\text { hed losel Store }\end{array}$ & $M$ & Mixed \\
\hline 0 & Privitus Echoral & BHU & B & $\Delta c y s$ \\
\hline 0 & NGO Achool & LHW / FWC & $\mathrm{G}$ & Girls \\
\hline $\begin{array}{l}0 \\
\star\end{array}$ & 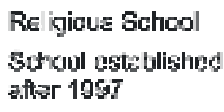 & MAR $=8$ DNon & - & PSU Eouridy \\
\hline
\end{tabular}




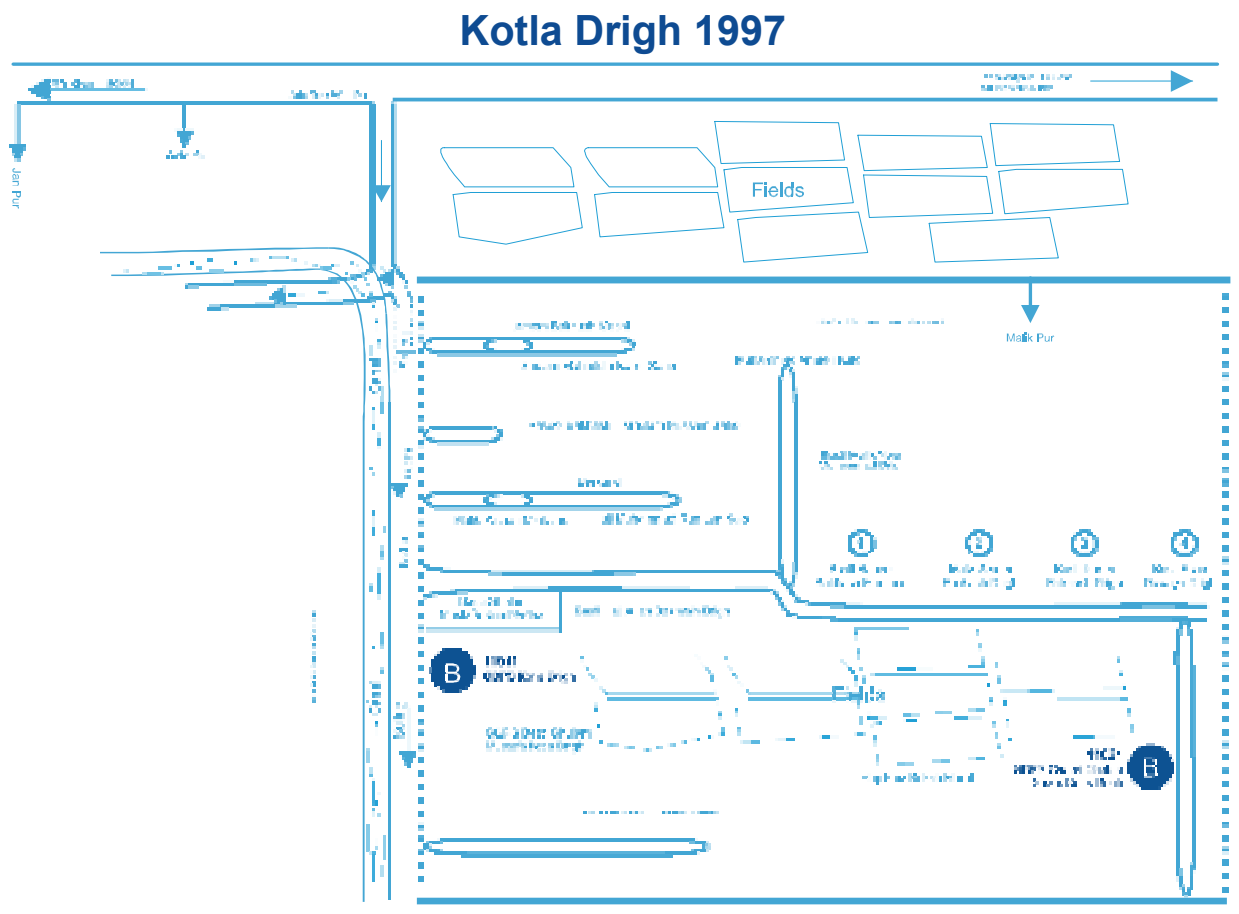

Kotla Drigh 2004

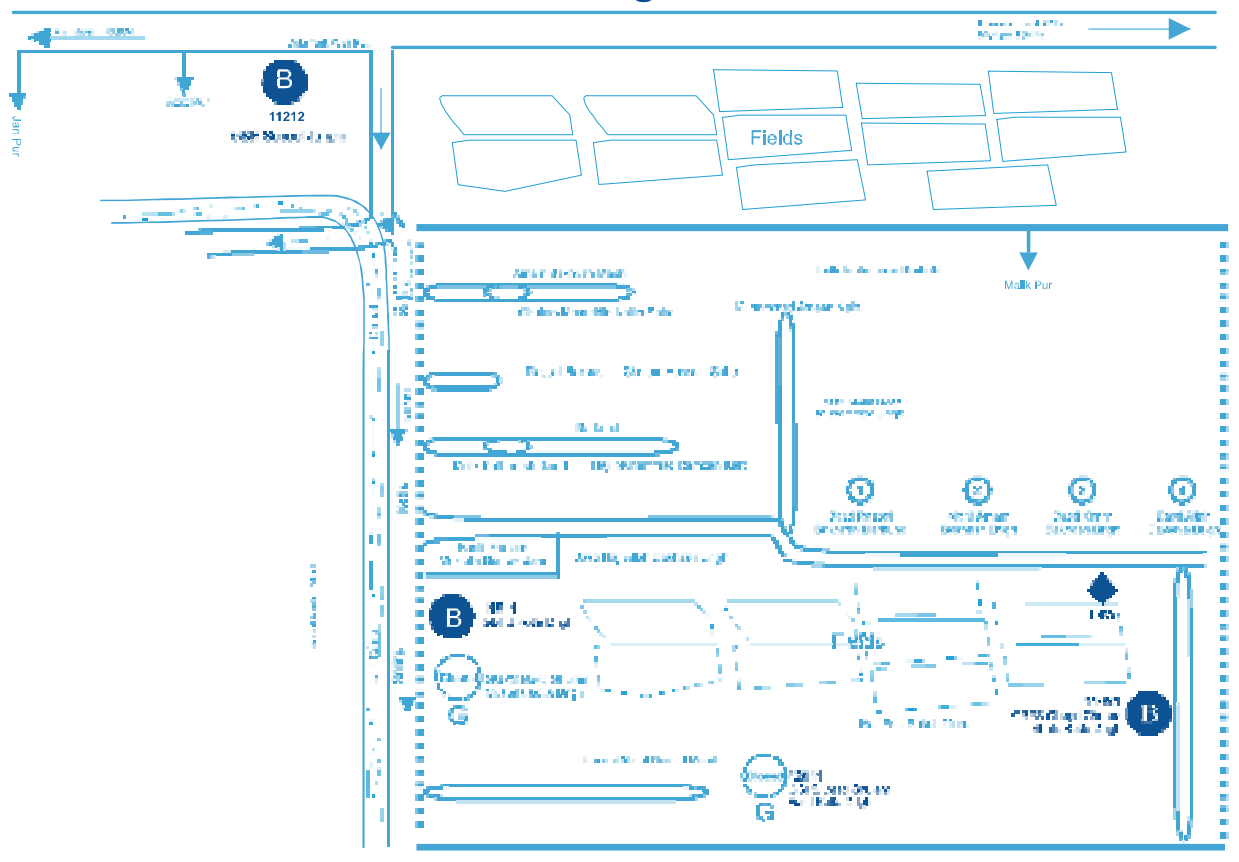

\begin{tabular}{|c|c|c|c|}
\hline Grmel Athrml & $\begin{array}{l}\text { Lhemist: } \\
\text { Hedical Brone }\end{array}$ & $\mathrm{M}$ & Mixed \\
\hline 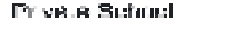 & $\mathrm{BHU}$ & $\mathrm{B}$ & Hoys \\
\hline Paso isengal & LHW / FWC & $\mathrm{G}$ & Girls \\
\hline $\begin{array}{l}\text { Religious Schacl } \\
\text { School onbbl thod } \\
\text { atter } 1997\end{array}$ & WARE DnTis' & 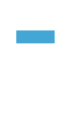 & P언 Bourtity \\
\hline
\end{tabular}




\section{Swat}

\section{Islampur}

In 1997, there was one boys' government school, one girls' government school, and one mixed NGO school located inside Islampur, and one mixed private school located outside the community, attended by community children. By 2004, three new schools had opened inside the community-one mixed private school, one boys' private school, and one mixed NGO school. Community children also attended an additional two boys' government schools outside the community at that time.

In 1997, only a chemist/medical store facility was available in the community but during 2004, an LHW, an FWC, and a private doctor were available in the community.

\section{Alaabad}

In 1997, there was one government school for girls and one for boys, located inside the community; and one mixed NGO school located outside the community. No new schools had opened by the time of the 2004 survey, but children from the community were attending an additional two boys' government schools and one mixed private school outside the community boundary at that time.

There was an LHW and a chemist/medical store available in Alaabad in 1997. In 2004, no additional health facilities were found in the community. 

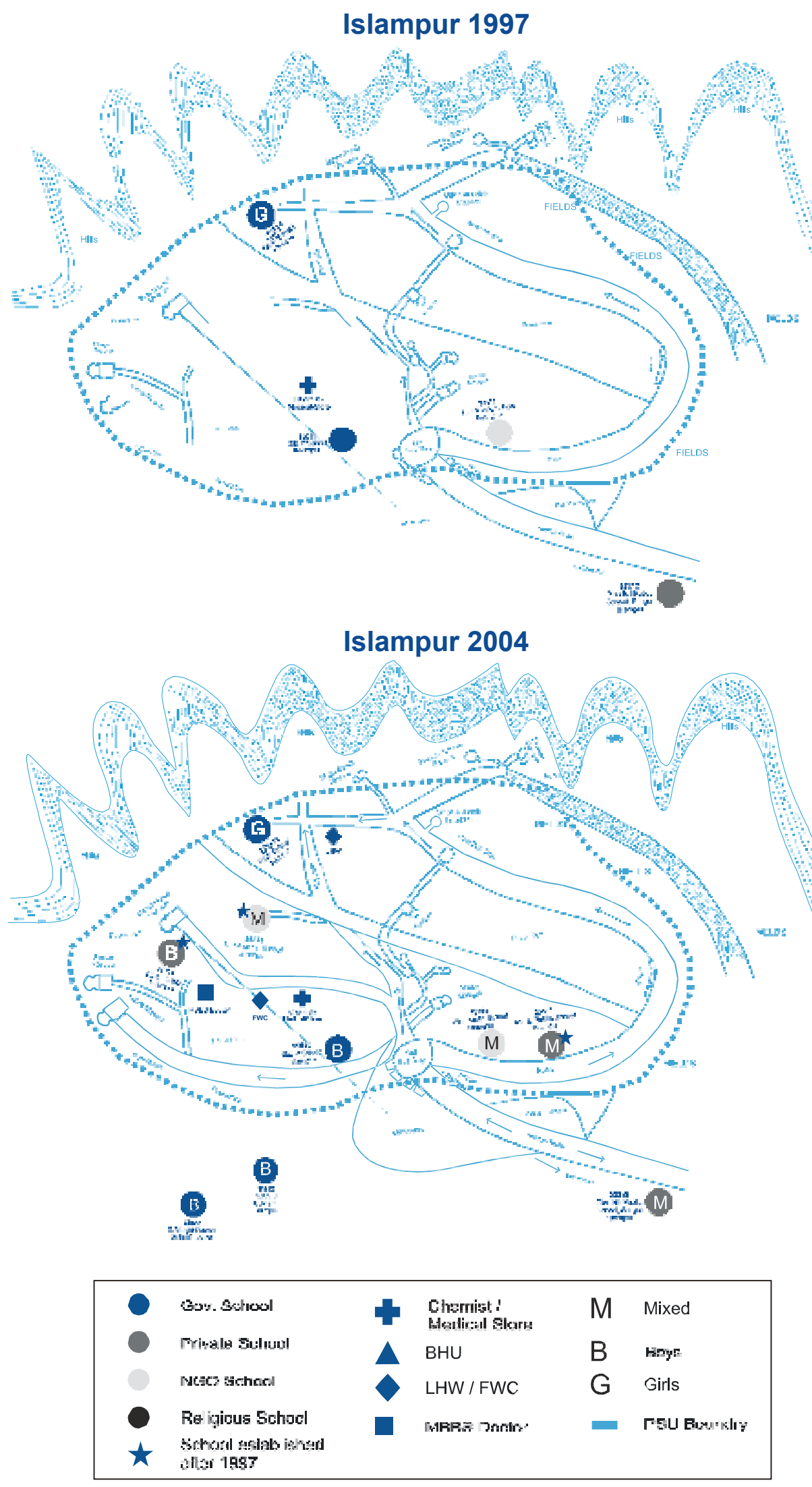

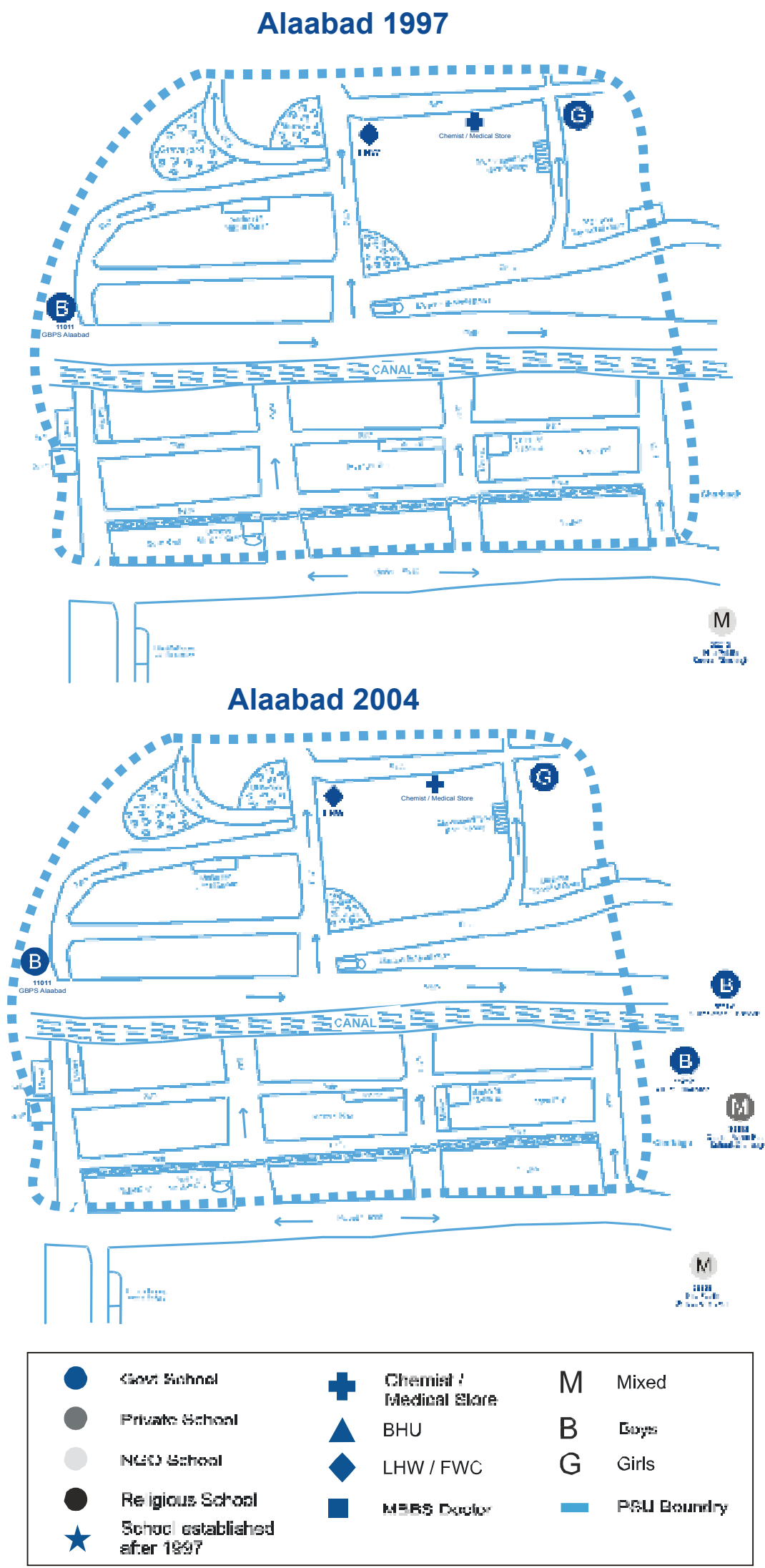


\section{Karak}

\section{Duresh Khel}

In 1997, there were two boys' government school and one girls' government primary school inside the community. By the time of the 2004 survey, one mixed private school had been established. Furthermore, children from the community were also attending a boys' government school located outside the community boundary.

A BHU and a chemist/medical store were located in the community in 1997. By 2004, a LHW was also available within the community.

\section{Mandawa}

In 1997, no schools were officially open to girls; the only schools present at that time were two boys' government schools. However, by 2004 two mixed schools had opened, one privately operated and one run by an NGO.

A private doctor and a chemist/medical store were available during the first survey but, in 2004, the private doctor had closed down and left the community. 


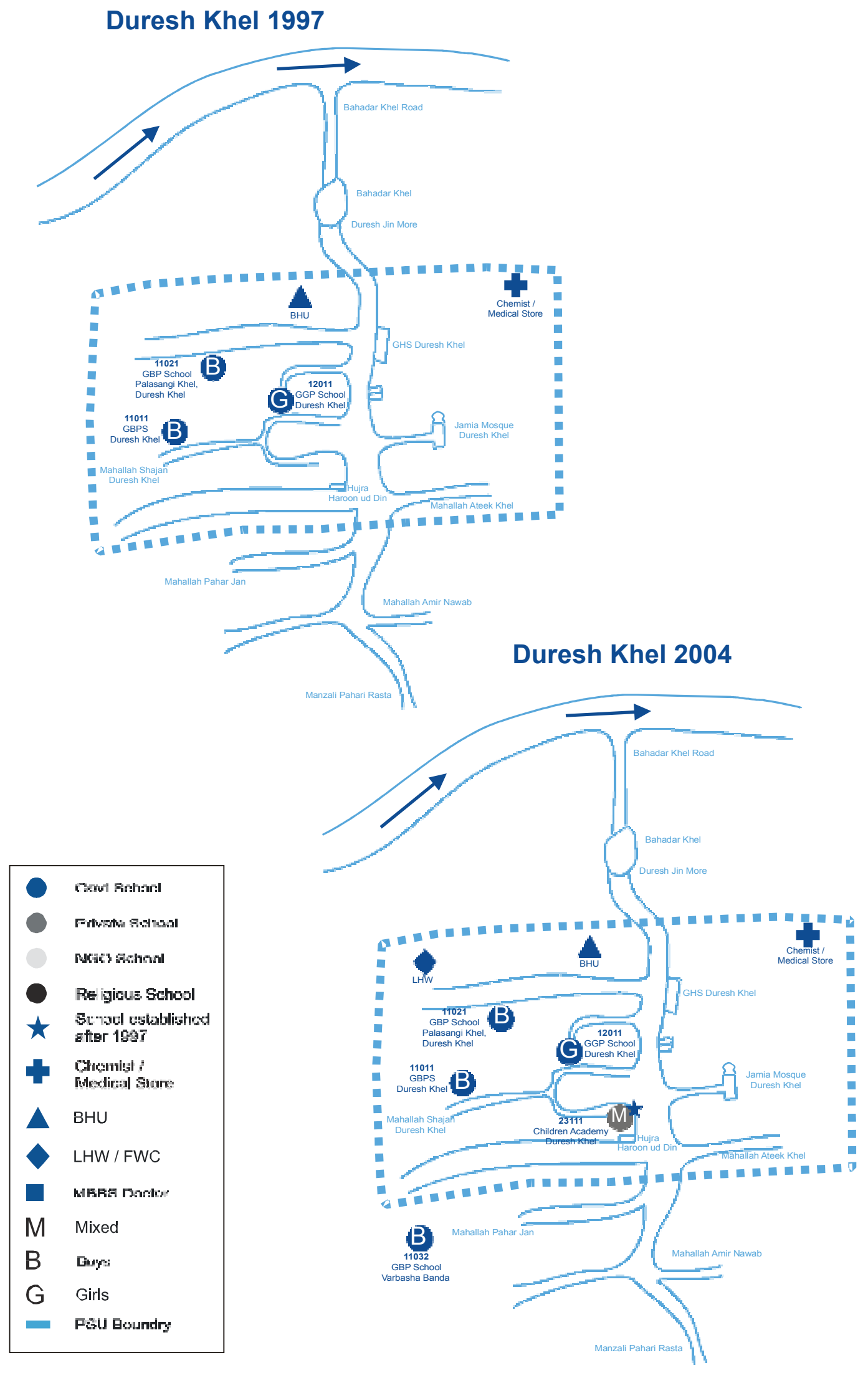



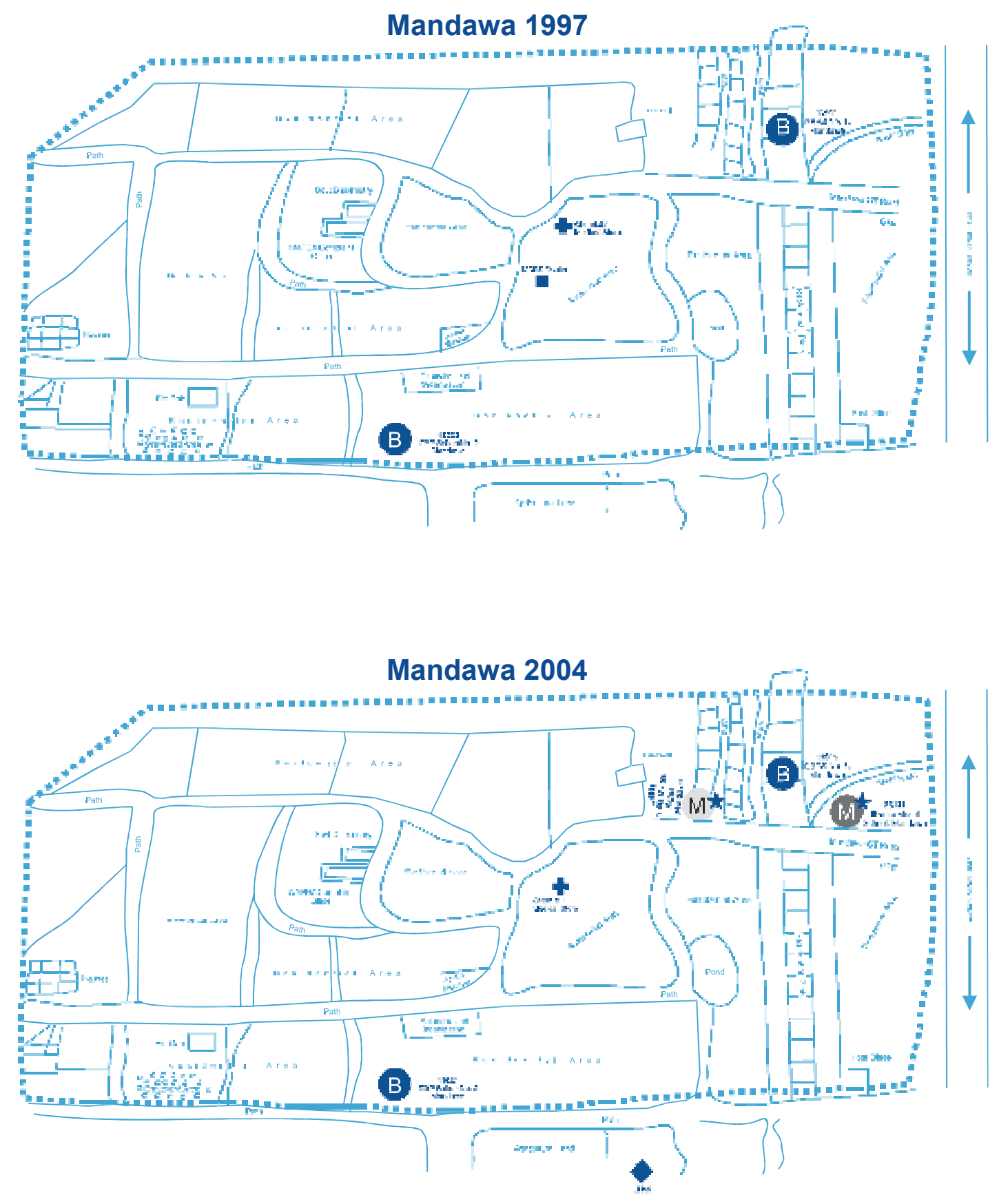

\begin{tabular}{|c|c|c|c|c|}
\hline 0 & 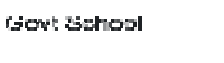 & $\begin{array}{l}\text { Chemrist / } \\
\text { Modiral Brers }\end{array}$ & $\mathrm{M}$ & Mixed \\
\hline O & rivals Sulwal & $\mathrm{BHU}$ & $B$ & Aniza \\
\hline 0 & NaO sathod & LHW / FWC & $G$ & Girls \\
\hline 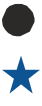 & 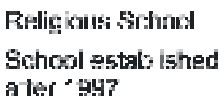 & FilBDes Jeckisr & - & PSU Bsurori \\
\hline
\end{tabular}




\section{Abbottabad}

\section{Tarmuchian}

Although five primary schools were attended by community children in 1997, only two were located inside the community-one girls' and one boys' government school. Two boys' and one girls' government school were located outside the community boundary. No private schools were established inside the community, but four private schools had opened outside and were attended by community children. These included three mixed schools and one for girls. Furthermore, a girls' government school opened inside the community.

There were no health facilities available in the village in 1997, but in 2004 an LHW had been appointed in the community.

\section{Kakul}

In 1997, five of Kakul's six primary schools were located inside the community, including one boys' government school, one girls' government school, and three mixed private schools. One mixed private school was located outside. In 2004, two additional mixed schools were included in the survey-one government and one private-which had existed in 1997 but were not included in the survey at that time; both of these schools were affiliated with the army and were not open to all community children at that time. Furthermore, two mixed private schools opened during the six years between the two waves of the survey.

In addition to these schools, two religious schools had opened in the past six years, one for boys and one open to both boys and girls.

In 1997 and 2004 an LHW, a BHU, a private doctor and chemist/medical store were present in Kakul. 


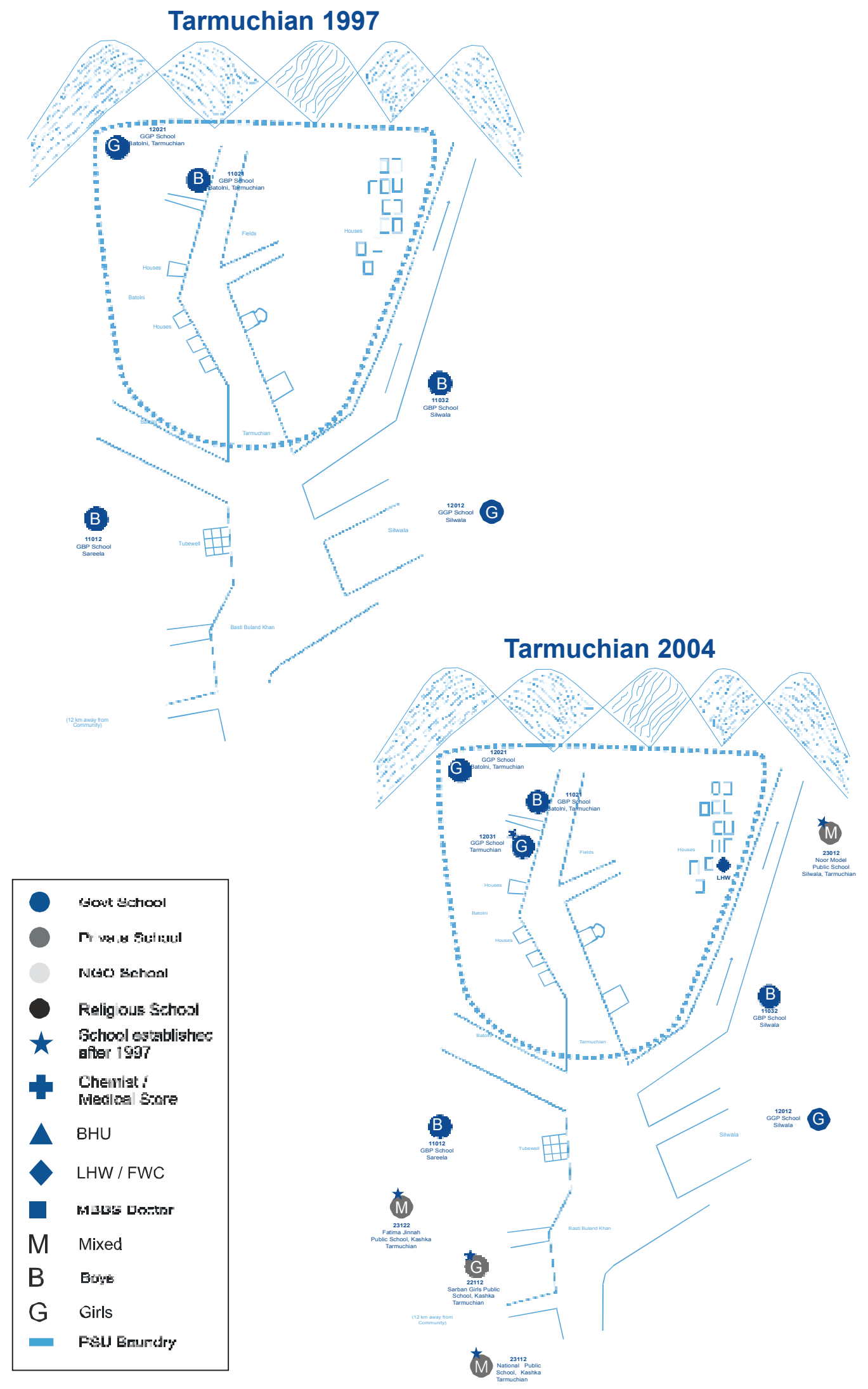



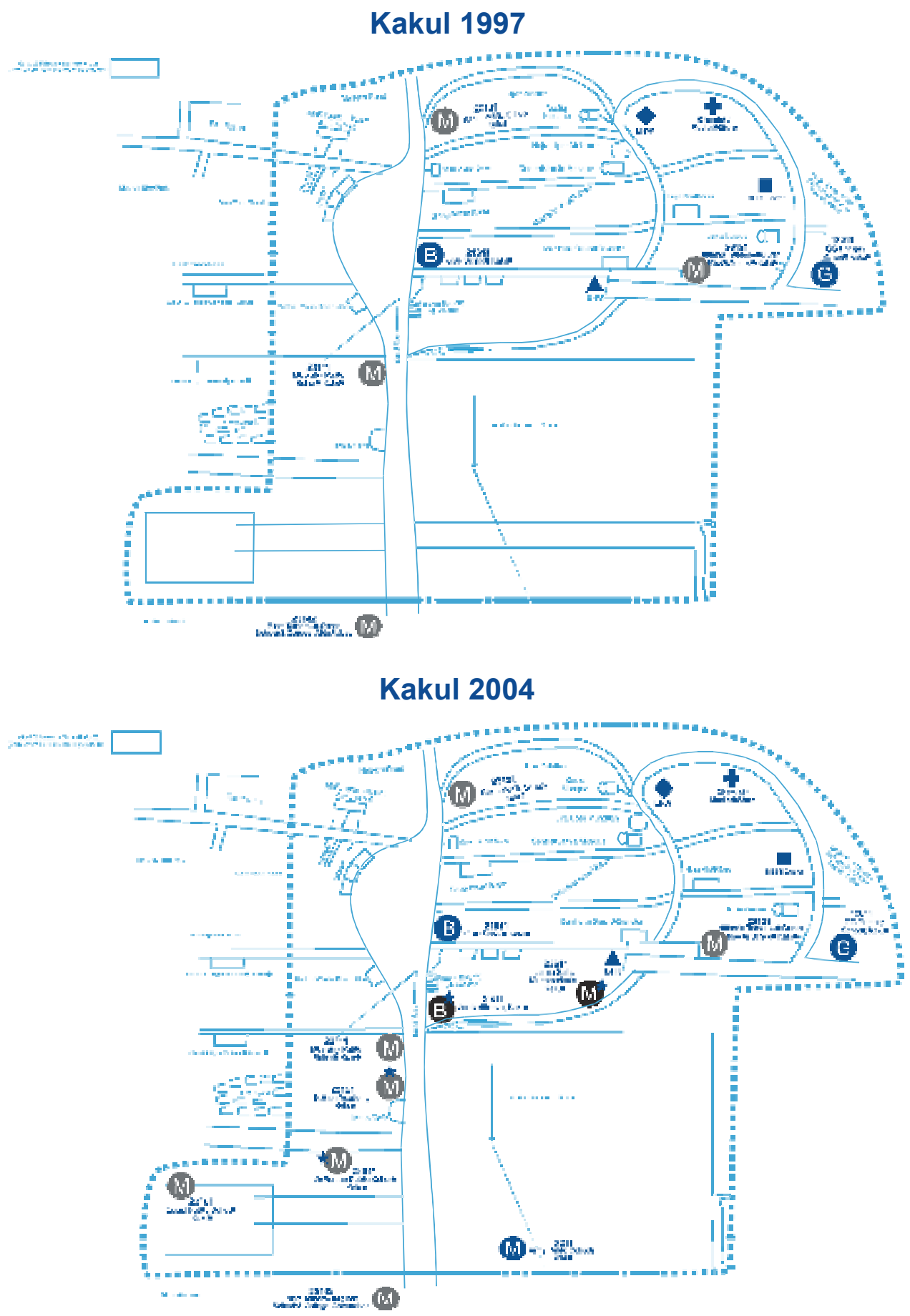

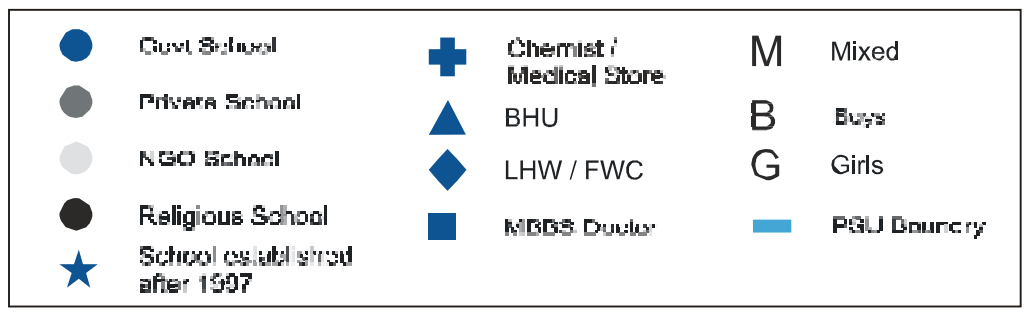





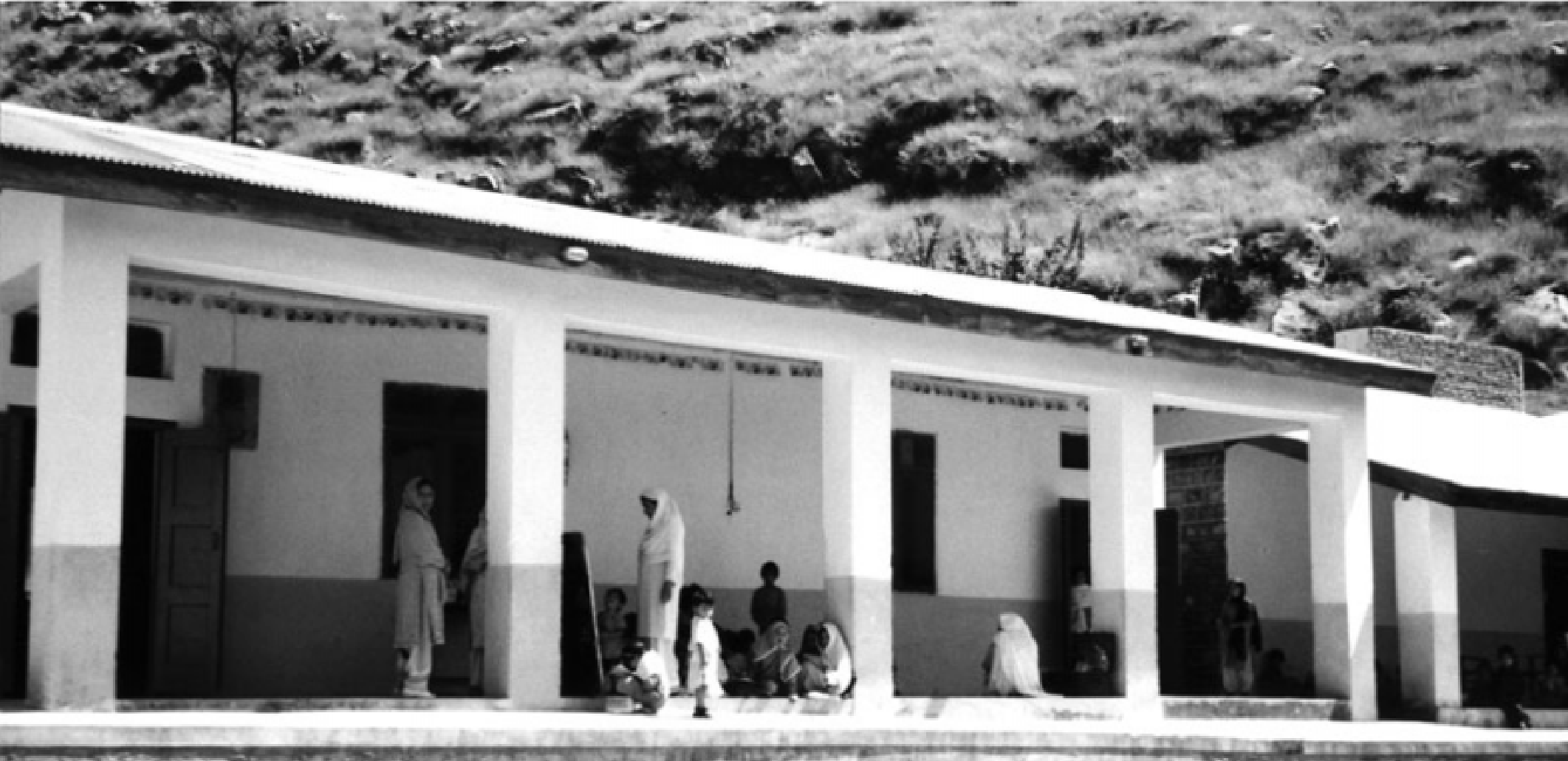

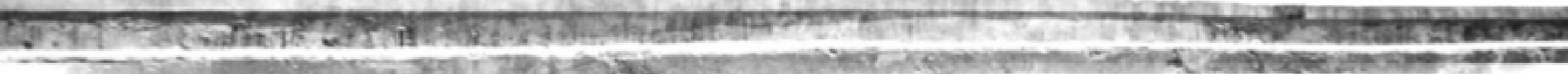
(a)

\section{Chapter 4}

\section{Changes in School Characteristics}

\subsection{Introduction}

In Chapter 3, we focused on the service environment at the community level, in particular on changes from 1997 to 2004 in the number of primary schools available to community residents. This chapter describes changes in other aspects of the schooling environment, including additional dimensions of school access and various dimensions of school quality.

As noted in Chapter 2, the number of schools attended by children from these communities more than doubled from 1997 to 2004, increasing from 50 to 114. The sample of schools for 2004 includes all types of schools attended by school-aged children, ranging from formal primary schools that offer classes one through five, to schools run by nongovernmental organizations (NGOs) that provide non-formal literacy and numeracy training to older children who did not have the opportunity to complete their education, to religious schools that focus on reading the Quran. 
Information on non-formal NGO schools and religious schools was not collected in 1997, making it impossible to compare changes in these forms of education.

For the purposes of this report, we focus on the characteristics of those schools that offer primary classes and prepare children to attend middle or high school. Therefore, the analysis in this chapter is restricted to the 104 primary schools in 2004 that offered some or all primary classes one through five.

The 104 formal primary schools sampled in 2004 include 50 schools that are run by the government, 47 private-for-profit schools, and 7 private NGO schools. When data were collected in 1997, no distinction was made between private-for-profit schools and NGO schools; therefore, for the sake of comparability these two categories of primary school will be combined into the single category, "private." It is also important to note that while most private schools are mixed, the sample includes five single sex private schools for boys and two for girls. There are also three de jure mixed government schools, a relatively new development. In the past, all government schools were de jure single sex.

Using the sample of 104 primary schools, this chapter will examine those characteristics of schools that may influence school accessibility and quality. The first section focuses on various dimensions of school access for boys and girls within the sample communities and examines factors that influence the ability of children to attend school, such as distance and cost. The second section focuses on school quality and addresses a range of factors, including the time available for learning, material resources, teaching resources, and aspects of the curriculum. Select dimensions of school quality are presented by district, in order to capture patterns and variations obscured by aggregate calculations.

\subsection{Accessibility of schools}

The maps presented in Chapter 3 show that, at the time of the survey in 2004, all communities contained at least two primary schools within the community boundaries (although two communities did not have schools that were open to girls) in addition to schools located outside the community that were attended by local children. However, the physical presence of a school in the community does not necessarily mean that all children are able to or choose to attend school. Table 4.1 examines the features of primary schools that influence the ability of children to attend, such as the commuting distance and time, school fees, and whether or not the school was in fact open to boys or girls, regardless of de jure status.

As noted in Chapter 2, the majority of new schools are mixed private schools. Therefore, as the number of schools has increased, so has the proportion of primary schools that are 
accessible to girls (Table 4.1). A school was considered to be accessible to girls if it was a de jure single sex school for girls, if it was a mixed school, or if it was a de jure single sex school for boys but girls constituted at least 10 percent of the students actually enrolled in grades one through five. In 1997, 34 of 50 schools (68 percent), were accessible to girls, as compared to 82 of 104 schools (79 percent) in 2004. In contrast, there has been less change in the accessibility of schools to boys. In 1997, 41 of 50 schools ( 82 percent) were accessible to boys, as compared to 90 of 104 (88 percent) in 2004.

As mentioned earlier, the increased number of schools attended by sample children is the product both of schools that have opened since 1997 and of the greater utilization of existing schools located outside of the community boundaries. These two influences have played out differently in the provinces of N.W.F.P. and the Punjab. In the N.W.F.P., the mean distance from a school to the center of the community, in kilometers, has declined from $0.6 \mathrm{~km}$ to $0.4 \mathrm{~km}$ for government schools and from $1.8 \mathrm{~km}$ to $1.5 \mathrm{~km}$ for private schools, suggesting that the opening of new schools has increased school availability within the communities. In contrast, the mean distance has increased in the Punjab, from $0.5 \mathrm{~km}$ to $1.3 \mathrm{~km}$ for government schools and from $0.1 \mathrm{~km}$ to $1.0 \mathrm{~km}$ for private schools, resulting in a growth in the attendance of schools outside the communities. However, traveling time-the mean number of minutes it takes a student to commute to their school-has increased in both provinces. This may indicate that access to transportation and the quality of local roads have not improved.

Most government schools were more or less free, with annual tuition fees less than 10 rupees per year on average (Table 4.1). The cost of enrolling in a private school varied greatly; some private schools were run by NGOs and charged no fees, while others charged fees as high as 7200 rupees per year. On average, private schools in the Punjab were less expensive than those in the N.W.F.P. However, mean school fees in private schools in Punjab doubled from 1997 to 2004 . While there was a modest increase in cost at the seven private schools visited in 1997 and revisited in 2004, the larger portion of the difference in school fees was based on the greater cost of schools established since 1997. 
Table 4.1 Access to primary schooling

\begin{tabular}{|c|c|c|c|c|c|c|c|c|c|c|}
\hline \multirow[b]{3}{*}{ Variable } & \multicolumn{5}{|c|}{1997} & \multicolumn{5}{|c|}{2004} \\
\hline & \multicolumn{2}{|c|}{ N.W.F.P. } & \multicolumn{2}{|c|}{ Punjab } & \multirow[b]{2}{*}{ Total } & \multicolumn{2}{|c|}{ N.W.F.P. } & \multicolumn{2}{|c|}{ Punjab } & \multirow[b]{2}{*}{ Total } \\
\hline & Govt. & Private & Govt. & Private & & Govt. & Private & Govt. & Private & \\
\hline \multicolumn{11}{|l|}{ Number of levels taught } \\
\hline Pre+Incomplete primary & 0 & 0 & 0 & 0 & 0 & 1 & 2 & 1 & 2 & 6 \\
\hline Pre+Primary & 16 & 2 & 17 & 6 & 41 & 18 & 1 & 18 & 8 & 45 \\
\hline Pre+Primary+Middle & 0 & 5 & 3 & 1 & 9 & 2 & 15 & 5 & 16 & 38 \\
\hline Pre+Primary+Middle+High & NA & NA & NA & NA & NA & 2 & 3 & 3 & 7 & 15 \\
\hline \multicolumn{11}{|l|}{ Accessible to Girls (N) } \\
\hline Yes & 10 & 5 & 12 & 7 & 34 & 15 & 20 & 15 & 32 & 82 \\
\hline No & 6 & 2 & 8 & 0 & 16 & 8 & 1 & 12 & 1 & 22 \\
\hline \multicolumn{11}{|l|}{ Accessible to Boys (N) } \\
\hline Yes & 12 & 7 & 15 & 7 & 41 & 18 & 21 & 18 & 33 & 90 \\
\hline No & 4 & 0 & 5 & 0 & 9 & 5 & 0 & 9 & 0 & 14 \\
\hline Mean distance $(\mathrm{km})$ & 0.6 & 1.8 & 0.5 & 0.1 & 1 & 0.4 & 1.5 & 1.3 & 1.0 & 1.0 \\
\hline Mean commuting time ( $\mathrm{min}$ ) & 13 & 8 & 12 & 7 & 11 & 14 & 17 & 17 & 14 & 16 \\
\hline Mean fees (rupees/year) & 22 & 1841 & 20 & 732 & 375 & 7 & 1953 & 9 & 1554 & 877 \\
\hline Total number of schools & 16 & 7 & 20 & 7 & 50 & 23 & 21 & 27 & 33 & 104 \\
\hline
\end{tabular}


The physical and financial aspects of school access are not the only elements that have changed; the 2004 sample of schools shows a significant increase not only in the number of primary schools in the communities, but also an increase in the number of primary schools that share premises with an upper division school (Table 4.1). In 1997, the field researcher recorded whether or not each school also included a middle school in the same compound; in 2004, data were also collected on the presence of a high school.

There was a considerable growth in the number of schools-from 9 to 38-that also included a middle school as well. Of the new schools identified in 2004 that included both primary and middle levels, 26 were private schools, as compared to only six that were government schools. An additional 15 schools visited in 2004 also included a high school within the same compound. Those schools were more evenly divided between government and private schools. Although this count does not include information on middle and high schools that do not include a primary division, the increase in the number of primary schools that share premises with an upper division school is an encouraging trend which should be supportive of the continued enrollment of current students. Studies in other countries have shown evidence that the presence of educational opportunities beyond primary school can be an incentive for parents to enroll their children in school (Lavy 1996).

In contrast, there was very little change between the two surveys in the number of schools that only offered classes at the primary level, from 41 in 1997 to 45 in 2004 (Table 4.1). An additional six schools offered incomplete primary, or less than all five primary classes, in 2004. Of these, the two government schools were mosque maktabs, i.e., they are run by the government but located inside a mosque, most often for lack of adequate facilities elsewhere in the community. The four private schools offering less than a complete complement of primary classes have been recently established and are in the process of adding classes as each cohort of students progresses through primary school.

Finally, all 104 schools visited in 2004 offer at least one pre-primary section on the premises, in addition to classes one through five. However, because the focus of the remaining section of this chapter is the quality of primary classes one to five offered in schools utilized by these communities, analysis from this point forward will focus exclusively on the facilities, resources, and characteristics of classes one through five.

\subsection{School quality}

In addition to access to primary schools, the decision about whether to send a child to school and which school that child should attend is influenced by factors of school quality (Lloyd, Mete and Sathar 2005). School quality has many dimensions, including time to learn, material resources, teachers, curriculum, and management. It is particularly interesting to compare school quality across types of schools, in particular 
Chapter 4 Changes in School Characteristics

single sex and mixed schools, and government and private schools, and how these measurements of quality have changed from 1997 to 2004 (Table 4.2). 
Table 4.2 Indicators of school quality

\begin{tabular}{|c|c|c|c|c|c|c|c|c|c|c|c|c|}
\hline \multirow[b]{3}{*}{ Indicator } & \multicolumn{6}{|c|}{1997} & \multicolumn{6}{|c|}{2004} \\
\hline & \multicolumn{3}{|c|}{ De jure } & \multicolumn{2}{|c|}{ Type } & \multirow[b]{2}{*}{ Total } & \multicolumn{3}{|c|}{ De jure } & \multicolumn{2}{|c|}{ Type } & \multirow[b]{2}{*}{ Total } \\
\hline & Boys & Girls & Mixed & Govt. & Private & & Boys & Girls & Mixed & Govt. & Private & \\
\hline \multicolumn{13}{|l|}{ Time for instruction } \\
\hline Hours per day (mean) & 5.2 & 5.4 & 5.3 & 5.2 & 5.3 & 5.3 & 5.1 & 5.2 & 5.2 & 5.2 & 5.2 & 5.2 \\
\hline Days per year (mean) & 220 & 225 & 230 & 218 & 238 & 224 & 233 & 232 & 243 & 229 & 245 & 237 \\
\hline \multicolumn{13}{|l|}{ Material resources } \\
\hline $\begin{array}{l}\text { Amenities Score (0-3) } \\
\text { Water (\%) }\end{array}$ & $\begin{array}{r}1.3 \\
72\end{array}$ & $\begin{array}{r}1.0 \\
69\end{array}$ & $\begin{array}{r}2.8 \\
92\end{array}$ & $\begin{array}{r}1.1 \\
69\end{array}$ & $\begin{array}{r}2.9 \\
93\end{array}$ & $\begin{array}{r}1.6 \\
76\end{array}$ & $\begin{array}{r}1.9 \\
81\end{array}$ & $\begin{array}{r}1.9 \\
70\end{array}$ & $\begin{array}{r}2.9 \\
100\end{array}$ & $\begin{array}{l}1.8 \\
77\end{array}$ & $\begin{array}{r}2.9 \\
98\end{array}$ & $\begin{array}{l}2.4 \\
88\end{array}$ \\
\hline Toilet (\%) & 25 & 8 & 92 & 15 & 93 & 38 & 45 & 70 & 94 & 49 & 96 & 74 \\
\hline Electricity (\%) & 38 & 15 & 100 & 26 & 100 & 47 & 61 & 50 & 96 & 53 & 96 & 76 \\
\hline Classrooms with furniture (\%) & 31 & 17 & 89 & 22 & 91 & 45 & 56 & 57 & 94 & 55 & 92 & 75 \\
\hline Students per classroom (mean) & 36 & 48 & 29 & 41 & 27 & 37 & 33 & 47 & 20 & 39 & 21 & 29 \\
\hline Total number enrolled students & 132 & 115 & 99 & 123 & 111 & 120 & 148 & 114 & 119 & 141 & 114 & 127 \\
\hline \multicolumn{13}{|l|}{ Teaching resources } \\
\hline Primary teachers per school (mean) & 4.4 & 4.2 & 5.3 & 4.3 & 5.2 & 4.5 & 5.2 & 4.1 & 6.1 & 4.9 & 5.8 & 5.4 \\
\hline Teachers with teaching certificates (\%) & 90.0 & 95.9 & 7.5 & 95.5 & 10.6 & 71.7 & 82.6 & 91.2 & 32.9 & 90.1 & 32.9 & 60.7 \\
\hline Years teaching experience (mean) & 11.8 & 9.1 & 2.9 & 11.4 & 2.7 & 9.0 & 12.7 & 12.6 & 4.1 & 13.1 & 4.0 & 8.4 \\
\hline Teachers' years of education (mean) & 11.6 & 11.5 & 11.3 & 11.5 & 11.3 & 11.5 & 12.3 & 12.0 & 12.6 & 12.2 & 12.6 & 12.4 \\
\hline Teacher absent on day of visit (\%) & 19 & 31 & 9 & 25 & 8 & 20 & 11 & 14 & 11 & 14 & 9 & 12 \\
\hline Teacher residing in community (\%) & 31 & 35 & 81 & 31 & 77 & 44 & 41 & 43 & 54 & 37 & 58 & 48 \\
\hline $\begin{array}{l}\text { Teachers teaching more than } 1 \text { subject } \\
\text { to more than one grade }(\%)\end{array}$ & 48 & 44 & 27 & 47 & 29 & 42 & 44 & 49 & 39 & 51 & 36 & 43 \\
\hline Student/teacher ratio & 28 & 27 & 23 & 27 & 25 & 27 & 28 & 27 & 19 & 28 & 19 & 24 \\
\hline
\end{tabular}


Chapter 4 Changes in School Characteristics

\begin{tabular}{|c|c|c|c|c|c|c|c|c|c|c|c|c|}
\hline \multirow[b]{3}{*}{ Indicator } & \multicolumn{6}{|c|}{1997} & \multicolumn{6}{|c|}{2004} \\
\hline & & De jure & & Тур & & & & De jure & & Typ & & \\
\hline & Boys & Girls & Mixed & Govt. & Private & Total & Boys & Girls & Mixed & Govt. & Private & Total \\
\hline
\end{tabular}

\section{Curriculum}

Teaching in local language (\%)

Textbook in Urdu (\%)

$\begin{array}{rrr}88 & 69 & 8.3 \\ 84 & 85 & 58\end{array}$

Other

Functional school management

committee or other community support

(\%)

$32 \quad 23 \quad 0$

28

7

22

88

80

20

92

19

53

Total number of schools

$\begin{array}{llll}25 & 13 & 12\end{array}$

14

50

$33 \quad 21 \quad 50$

50

54

104 


\section{Time for instruction}

While there has been little change in the length of the school day from 1997 to 2004, the school year has lengthened by an average of 13 days of instruction (Table 4.2). Both government and private schools have added time to the school year, although in 2004 private schools remained in session for an average of 16 days longer than government schools (as compared to 20 days longer in 1997).

\section{Material resources}

Material resources within a school shape the context where children are able to learn. Crowded classrooms, a shortage of textbooks or the absence of electricity can all impinge on the quality of classroom instruction and the opportunity to learn.

Among government schools, there were significant improvements in the existence of various amenities on the school premises from 1997 to 2004 (Table 4.2). Although there has been little change in access to drinking water, approximately half of government schools had access to a toilet and electricity in 2004, as compared to 15 and 26 percent respectively in 1997. Although some of these improvements accrued to boys' schools, the greatest improvements were found among girls' schools. Of the 21 girls' schools in 2004, 70 percent had access to drinking water, 70 percent had access to a toilet, and 50 percent had electricity (as compared to 69, 8, and 15 percent in 1997, respectively).

Access to these amenities was summarized in an index in which a score of 1 was assigned for the presence of each of these three amenities. A score of 0 would indicate that a school did not have access to any of these amenities, whereas a score of 3 would indicate that a school had access to all three. In 2004, the mean score among both boys' and girls' schools was 1.9, a substantive increase from the mean score of 1.3 for boys' schools and of 1.0 for girls' schools in 1997 (Table 4.2). In contrast, the mean score among mixed schools only increased from 2.8 to 2.9. Likewise, there was no change in the mean score among private schools, but the mean score among government schools did increase from 1.1 to 1.8 .

Figure 4.1 shows the variation in the availability of physical amenities across the six districts. In both years and in all districts, private schools provide the best access to physical amenities. However, not only are government schools disadvantaged relative to private schools, but girls' government schools are often disadvantaged relative to boys' government schools. This was particularly evident in 1997 in D. G. Khan, Abbottabad, and Swat. Gender disparities were less evident in other districts, such as R.Y. Khan, where there was no difference in the mean number of physical amenities found in boys' and girls' government schools; and Sialkot, where girls' government schools actually had more amenities than boys' government schools. 
However, in the six years between late 1997 and early 2004, conditions in government schools improved, with the greatest gains found in girls' schools. Improvements in D. G. Khan, Abbottabad, and Swat significantly closed the gender gap in amenities observed in 1997 and in Karak, girls government schools surpassed boys' schools. Furthermore, changes in Sialkot and Swat narrowed the gap between government and private schools. However, there is little or no evidence for change in the amenities found in boys' government schools in D. G. Khan and Karak.

Figure 4.1 Mean physical amenities by district, survey year and school type

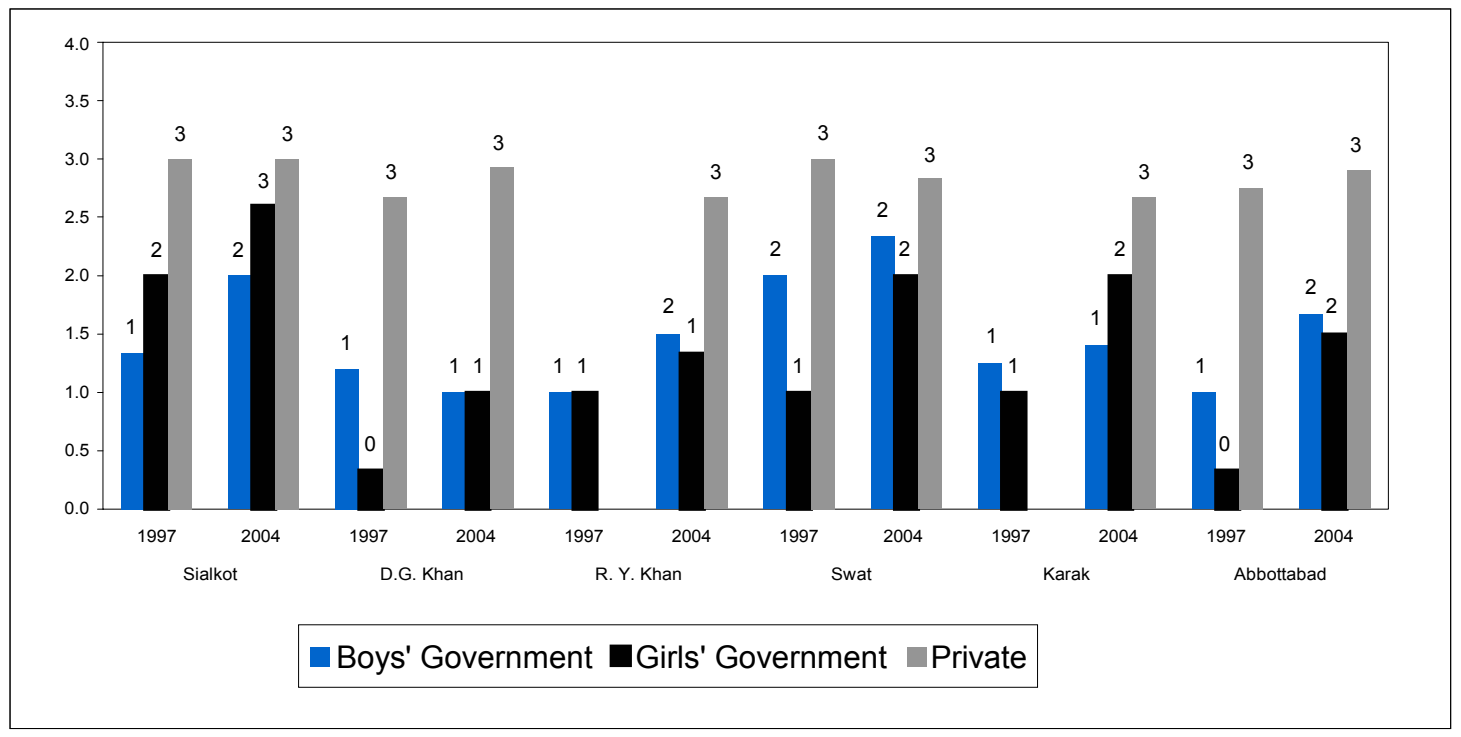

There has been little change in the average number of enrolled students in each classroom. The average number of students per classroom is largest in girls' schools, at 47 students per classroom in 2004. In contrast, the mean for boys' schools is 33 students per classroom, and for mixed schools, it is 20 students per classroom. However, Figure 4.2 makes clear that, with the exception of Sialkot, there is often very little difference between boys' and girls' schools in students per classroom. These variations are observed across government schools, but private schools consistently have fewer students per classroom than government schools. In 2004, only in Karak and Abbottabad was there no difference in the mean classroom size of boys', girls', and private schools.

Although girls' schools are more crowded than boys' schools, the furnishing is at par. In 2004,57 percent of classrooms in girls' schools and 56 percent of classrooms in boys' schools were furnished (i.e., had a seat for each student or a bench for three students), as compared to 94 percent of classrooms in mixed schools (Table 4.2). This compares well with the situation in 1997, when 17 percent of classrooms in girls' schools and 31 percent in boys' schools were furnished. 
Figure 4.2 Mean number of students per classroom, by district, school type, and survey year

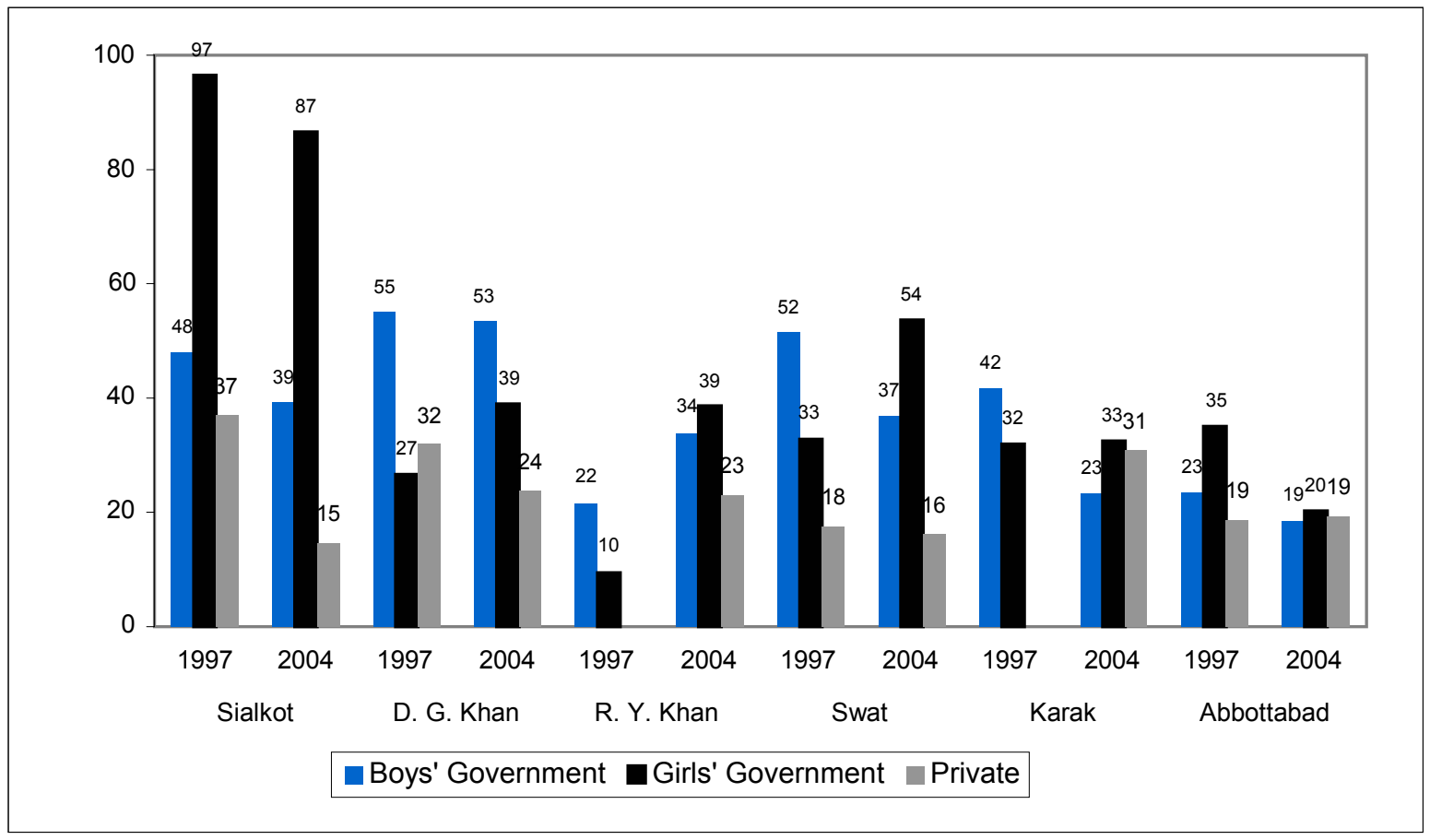

\section{Teachers}

Teachers play an equally important part in school quality; the number of teachers available influences the quality of the education itself. While all primary schools analyzed in Table 4.2 offered grades one through five, not all of them have the facilities or teaching resources for each grade to be taught separately. The mean number of primary teachers per school (grades 1 through 5) is an important indicator of the attention that students enrolled in each grade can expect. While boys' and mixed schools have, on average, more than five teachers (5.2 and 6.1, respectively), girls' schools had a mean of only 4.1 primary teachers for grades 1-5. Not only did the average girl's school have one less teacher than the average boy's school for the first five grades, it also represents the absence of change in the number of available teachers since 1997, when there were 4.2 teachers per girl's school (grades 1-5). On average, private schools had one additional teacher on staff than did government schools, most often an individual hired to teach English to the students. 
Figure 4.3 Mean number of primary teachers per school facility (for grades 1-5), by district, survey year, and school type

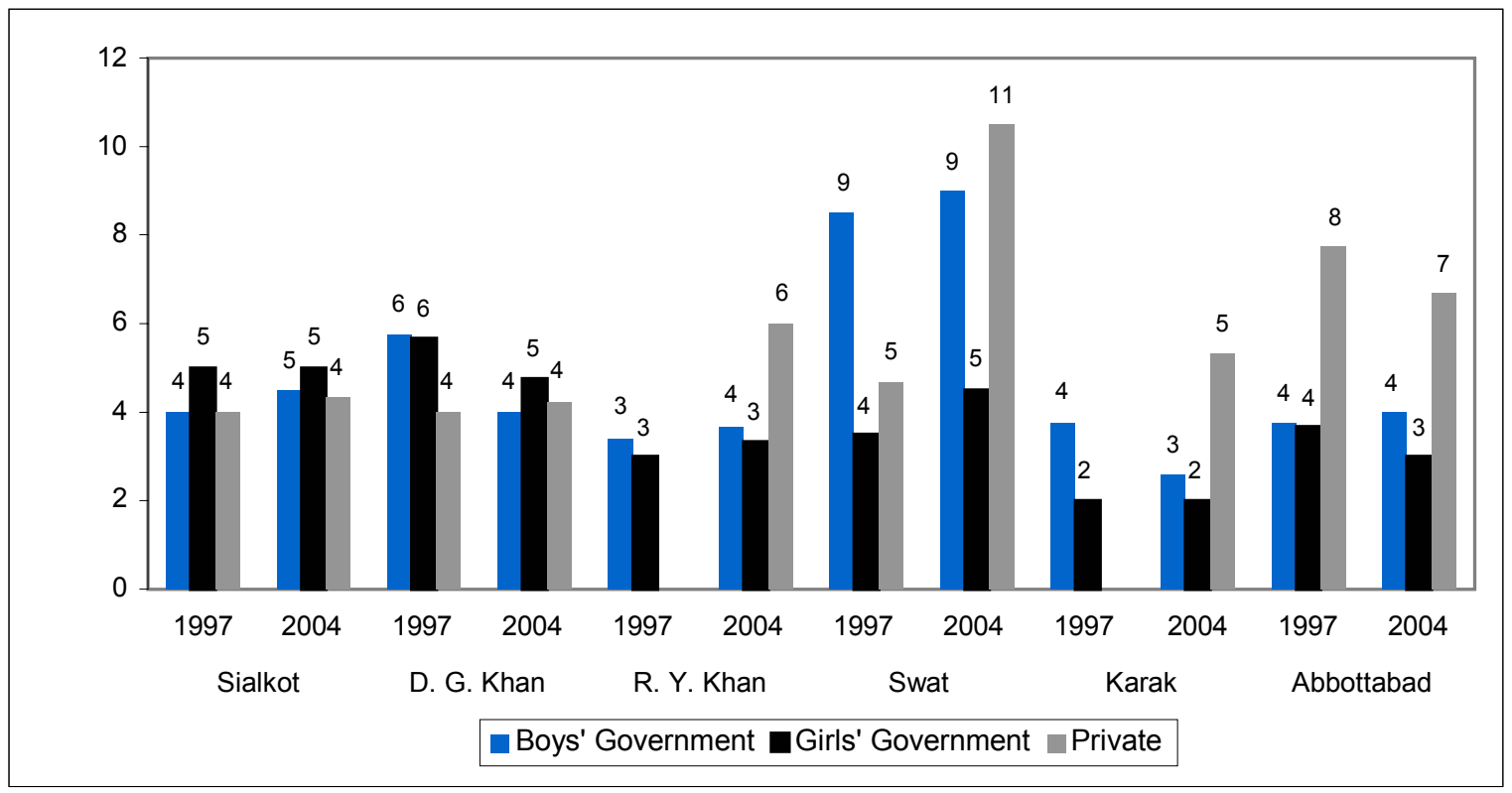

However, teaching resources vary considerably at the district level (Figure 4.3). Compared to other districts, there is virtually no difference between government and private schools in Sialkot and D. G. Khan in the mean number of primary teachers for each school supporting grades 1-5. In contrast, private schools in Abbottabad have almost twice the number of teachers, on average, than government schools for the first five grades. R. Y. Khan and Karak have the least teachers per government school-less than four at the time of each survey-whereas private schools in these districts have more than five primary teachers per school (grades 1-5). Finally, the mean number of primary teachers is particularly high for boys' government and private schools in Swat; this is largely attributable to the fact that several large schools offer two sections at each grade level.

Though government schools may have fewer teachers on staff than private schools, most primary teachers in government schools have a teaching certificate (90 percent). In contrast, in 2004, only 33 percent of private primary school teachers in the sample had a teaching certificate, almost three times the percentage with certification in 1997 (Table 4.2). Furthermore, primary teachers in private schools have significantly less teaching experience than primary teachers in government schools. In 2004, the average private school primary teacher had been teaching for 4.0 years as compared to the 13.1 years' experience of government primary teachers, both values representing a slight increase since 1997. As noted in chapter 3, most of the private schools new to the sample in 2004 had opened within the previous four years, which may partially explain the lack of 
experience exhibited by primary teachers in those schools. There was very little difference in the number of years of education attained by primary teachers in government versus private schools.

Primary teacher absenteeism interferes with the time available for learning. On the day of the school visit in 2004, 14 percent of government school teachers at the primary level were absent as compared to 9 percent of private primary school teachers. While there has been no change in absenteeism since 1997 among private primary school teachers, a decline was visible in absenteeism for government primary teachers (Table 4.2). It is also notable that teacher absenteeism has declined significantly in girls' schools: while 31 percent of primary teachers were absent in 1997, only 14 percent were absent in 2004.

Figure 4.4 Mean primary teacher absenteeism by district, school type, and survey year

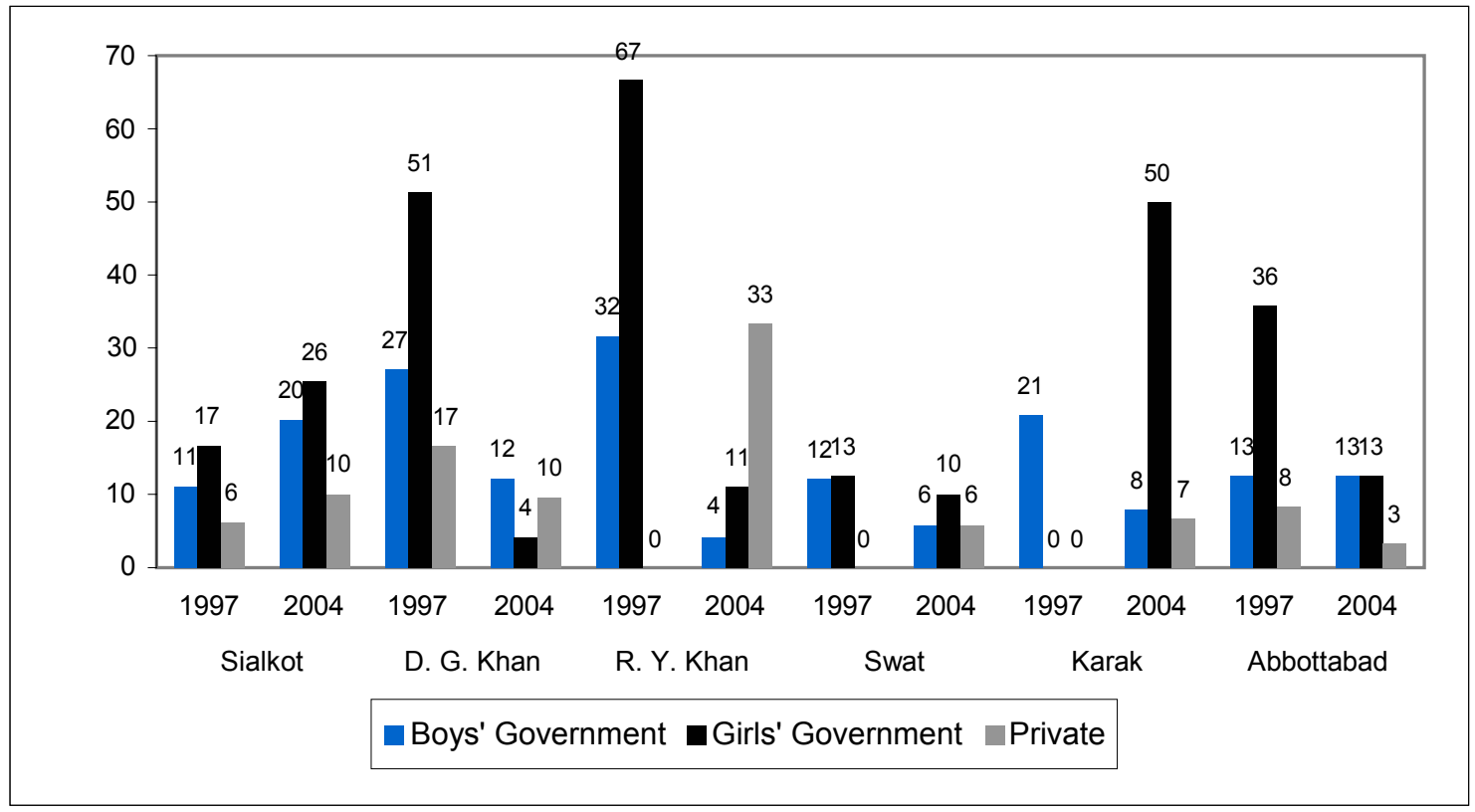

When primary teacher absenteeism is examined by district, the aggregate change observed for primary teachers in girls' government schools becomes more dramatic (Figure 4.4). In 1997, the three highest rates of primary teacher absenteeism were found in girls' government schools in D. G. Khan (51 percent absent), R. Y. Khan (67 percent absent), and Abbottabad (37 percent absent). However, in 2004 these districts showed the greatest declines in teacher absenteeism in government primary schools. In contrast, absenteeism increased in girls' government schools in Karak, from zero to 50 percent; this is all the more striking when compared to Figure 4.3, which shows that the girls' government schools in Karak have, on average, only two teachers per school. 
Primary teacher absenteeism has also declined in boys' government schools in all districts except Abbottabad, where there has been no change, and Sialkot, where teacher absenteeism has increased in both boys' and girls' schools. Primary teacher absenteeism has remained consistently low in private schools across all six districts, with the exception of R. Y. Khan, where over 30 percent of private school teachers were absent in 2004.

One factor that may influence teacher absenteeism is whether or not the teacher resides within the community. In 1997, 31 percent of government primary teachers and 77 percent of private primary school teachers lived in the community. However, by 2004 this difference had narrowed considerably: 37 percent of government primary teachers and 58 percent of private primary school teachers lived in the community. There was little difference between boys' and girls' school primary teachers (41 and 43 percent, respectively).

The mean number of students per primary teacher ranged from 19 in mixed schools to 28 in boys' schools, with girls' schools averaging 27 students per primary teacher. While these values are slightly higher than in 1997, it is striking to compare them to the mean number of students per classroom (Table 4.2). Among government schools, the mean number of students per teacher is considerably less than the mean number of students per classroom, especially for girls' schools. This indicates that in many schools several teachers and classes may share the same classroom space, another factor that diminishes school quality.

In addition to crowded classroom space, some teachers have multiple responsibilities within the school that may reduce the time available to them to adequately prepare lesson plans and work with each class separately. Teaching burdens did not change much from 1997 to 2004 (Table 4.2). There was a slightly greater increase in the teaching burden of private primary school teachers as compared to government primary teachers, although in neither category was the change remarkable. Teachers in girls' primary schools had the greatest teaching burden in 2004 (49 percent).

Another measure of school quality relates to the medium of instruction, both in terms of the language used by the teacher and the language of the textbooks. Whereas 83 percent of government primary schools were taught in the local language in 1997, this was true in only 51 percent of government primary schools in 2004 (Table 4.2). Only 17 percent of private primary schools were taught in the local language in 2004, compared to 14 percent in 1997. Boys' schools were more likely to be taught in the local language than girls' schools (64 and 25 percent, respectively). In most cases, where the local language was not the medium of instruction, classes were taught in Urdu. Although considerably more schools were taught in Urdu by 2004, there was very little change in the proportion of schools using textbooks written in Urdu. 


\subsection{Summary}

Although more private primary schools than government primary schools have opened in these communities since 1997, the gap in school quality between government and private schools is closing. Since 1997, government primary schools have increased access to material resources, in particular physical amenities, such as electricity and toilet facilities, and classroom furnishings. Furthermore, there has been a substantial decline in teacher absenteeism in government schools, particularly girls' schools. Private primary schools still maintain fewer students per classroom and employ more teachers per school than government primary schools, but a higher proportion of teachers in government primary schools have teaching certificates and greater teaching experience. There has been a shift towards instruction in Urdu in government schools, most likely in response to policy change.

One notable finding is that while the quality of teachers in girls' primary schools has improved and is now comparable to the quality of teachers in boys' schools, the quantity of teachers in girls' schools is not keeping pace with demand. On average, girls' primary schools have 4 teachers, one teacher less than in boys' schools and two fewer teachers than in mixed schools. While the student-to-teacher ratio in girls' schools is comparable to that in boys' schools, the classrooms are more crowded. 


single sex vs. mixed) that children attend. Relevant trends will be presented in the aggregate for the sample as a whole and also broken down by district. ${ }^{3}$ Tabulations are based on the education histories of living children, reported by currently married women age 20-45 at the time data were collected in each of the surveys.

School attendance rates are restricted to students who have at any point in time attended government or private (for-profit or NGO) primary schools. Attendance rates exclude students who only attended a religious school. 4 The survey collected data on whether or not each child aged five or older had ever attended school. Mothers were asked if their child had ever attended pre-primary classes; they were then asked if their child had attended class one and which type of school (government, private, NGO) they had attended. Data pertaining to all children who had ever enrolled in class one were collected regarding their subsequent enrollment, progress through school, and educational attainment. Questions related to current school attendance were only asked of children who had ever enrolled in class one.

There was little change to the content and structure of the questionnaire from 1997 to 2004. This design allows for comparable content and validity across the two surveys. However, it also creates some limitations for the analysis, such as the lack of information about current enrollment in pre-primary classes among the younger children in the sample. With this in mind, all references within this chapter to school ever attendance will include attendance in either pre-primary or primary classes. Discussion of current attendance is restricted to attendance in class one or higher.

This chapter is structured as follows: The first section examines trends in the percentage of children who ever attended primary school, including attendance in pre-primary and in classes one and higher. The second section focuses on changes in primary school completion rates amongst those children who ever attended school. The third section examines current attendance in class one or higher, and explores differentials in attendance rates by socioeconomic and demographic characteristics of a child's family. The fourth section shifts the focus to the types of schools attended by primary students, including breakdown by government/private and single sex/mixed sex schools.

\subsection{School attendance}

In 2004, almost three-quarters of male 5-9 year olds had ever attended school (preprimary or primary), as compared to more than 90 percent of older male children (Table

\footnotetext{
${ }^{3}$ When the data on children were disaggregated by 5-year age groups, the sample size was too small to permit statistically valid calculations at the community level. In this chapter, select calculations are presented at the district level; there are two sample communities in each district.

${ }^{4}$ Although the sample of schools included three non-formal NGO schools, no woman reported that her child had attended these schools.
} 
5.1). This is not unexpected, since younger children are still in the process of entering school, whereas most boys have started school by age 10 . While slightly more 15-19 year old males than 10-14 year old males have ever attended school, this is a small and statistically insignificant difference. Over the six-year interval between the surveys, there has been no more than a 3-4 percentage points increase in ever attendance rates for boys in the older age groups. Despite the increased number of schools attended in the sampled communities, as noted in Chapter 3, the increase in boys' primary attendance has been minimal.

Table 5.1 Trends in percentage of children who ever attended school (pre-primary or primary)

\begin{tabular}{crrrrrr}
\hline & \multicolumn{2}{c}{5 -9 year olds } & \multicolumn{2}{c}{$\mathbf{1 0 - 1 4}$ year olds } & \multicolumn{2}{c}{$\mathbf{1 5 - 1 9}$ year olds } \\
\cline { 2 - 7 } & \multicolumn{2}{c}{ Male } & Female & Male & Female & \multicolumn{2}{c}{ Male } & Female \\
\hline $\mathbf{1 9 9 7}$ & & & & & & \\
$\%$ & 67.3 & 52.7 & 89.9 & 66.4 & 91.5 & 57.9 \\
$(\mathrm{~N})$ & $(489)$ & $(427)$ & $(355)$ & $(357)$ & $(201)$ & $(197)$ \\
& & & & & & \\
$\mathbf{2 0 0 4}$ & & & & & & \\
$\%$ & 74.1 & 59.2 & 93.3 & 71.0 & 94.4 & 62.8 \\
$(\mathrm{~N})$ & $(409)$ & $(412)$ & $(359)$ & $(335)$ & $(234)$ & $(250)$ \\
\hline
\end{tabular}

As is the case for boys, not all girls enter school by age 5. Consequently, in both 1997 and 2004, ever attendance rates for girls aged 10-14 and 15-19 exceed rates for those ages 5-9. While there have been increases in ever attendance rates of about 5 percentage points in the past six years for older girls, their overall attendance rates remain substantially below boys' attendance rates and gender gaps in our sample communities do not appear to be narrowing. The gaps in attendance rates between boys and girls ages 10-14 remains a very sizable 22 percentage points.

Average attendance rates for the sample as a whole disguise a substantial amount of inter-district variation. Figure 5.1 shows the percentage of 10-14 year old boys and girls by district who ever attended school at the time of each survey. While most districts show improvements in school attendance from 1997 to 2004, particularly for girls, R. Y. Khan and Swat show only minimal improvements among girls and in Karak there is evidence that school attendance is actually declining among girls. Figure 5.1 also highlights the variation in the percentage of children who ever enroll in school across the six districts surveyed. In four districts, over 90 percent of boys aged 10-14 years and in three districts over 80 percent of 10-14 year old girls have attended school by 2004 . Indeed, there is almost no difference in the percentage of boys and girls who attend school in Sialkot, D. G. Khan, and Abbottabad. However, these instances of gender 
equality bring to light the disparities that continue in other districts, particularly Rahim Yar Khan and Karak.

Figure 5.1 Trends in the percentage of 10-14 year olds who have ever attended school by district and survey year

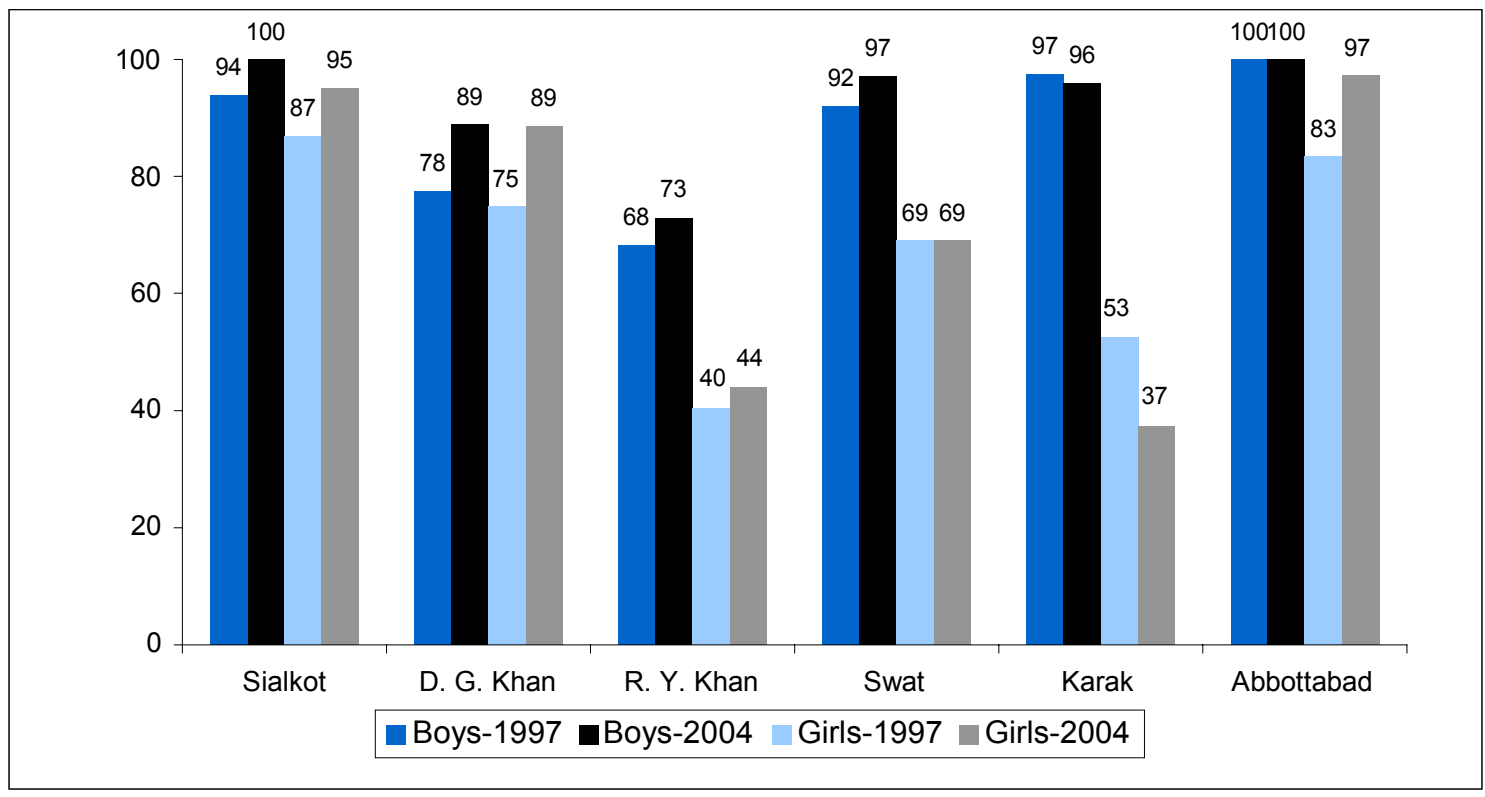

However, the observed increase over time in school attendance amongst 5-9 year old males and females disguises a recent change in the pattern of school entry. Figure 5.2 compares the percentage of children who have ever attended pre-primary with the percentage who have ever attended class one. From this table, it is clear that the pattern of school entry has changed from 1997 to 2004. Enrollment in pre-primary classes has increased significantly, from 50 percent of 5-9 year old boys and 37 percent of 5-9 year old girls in 1997 to 74 percent for boys and 59 percent for girls in 2004. In contrast, a smaller percentage of 5-9 year old children had ever attended class one in 2004 than in 1997. While the separate calculations of pre-primary and class one ever attendance may be influenced by the age structure within the 5-9 year old age group, the calculation of the percentage who ever attended school (pre-primary or class one) is more resistant to this influence and shows evidence that school attendance has increased from 1997 to 2004 among young children.

Examining Figure 5.2 closely, it is clear that in 1997 more 5-9 year old boys and girls attended class one than attended pre-primary classes, meaning that many children entered primary school without first attending a pre-primary class. Of children who had attended pre-primary classes, almost all had entered class one prior to the time of the survey. In contrast, more children had attended pre-primary than class one in 2004 . Of 
those who had ever attended class one, almost all had attended pre-primary classes first. Thus, it has become more common for young children to attend pre-primary classes prior to entering class one. ${ }^{5}$

\section{Figure 5.2 Trends in the percentage of 5-9 year olds who ever attended school by school level attended}

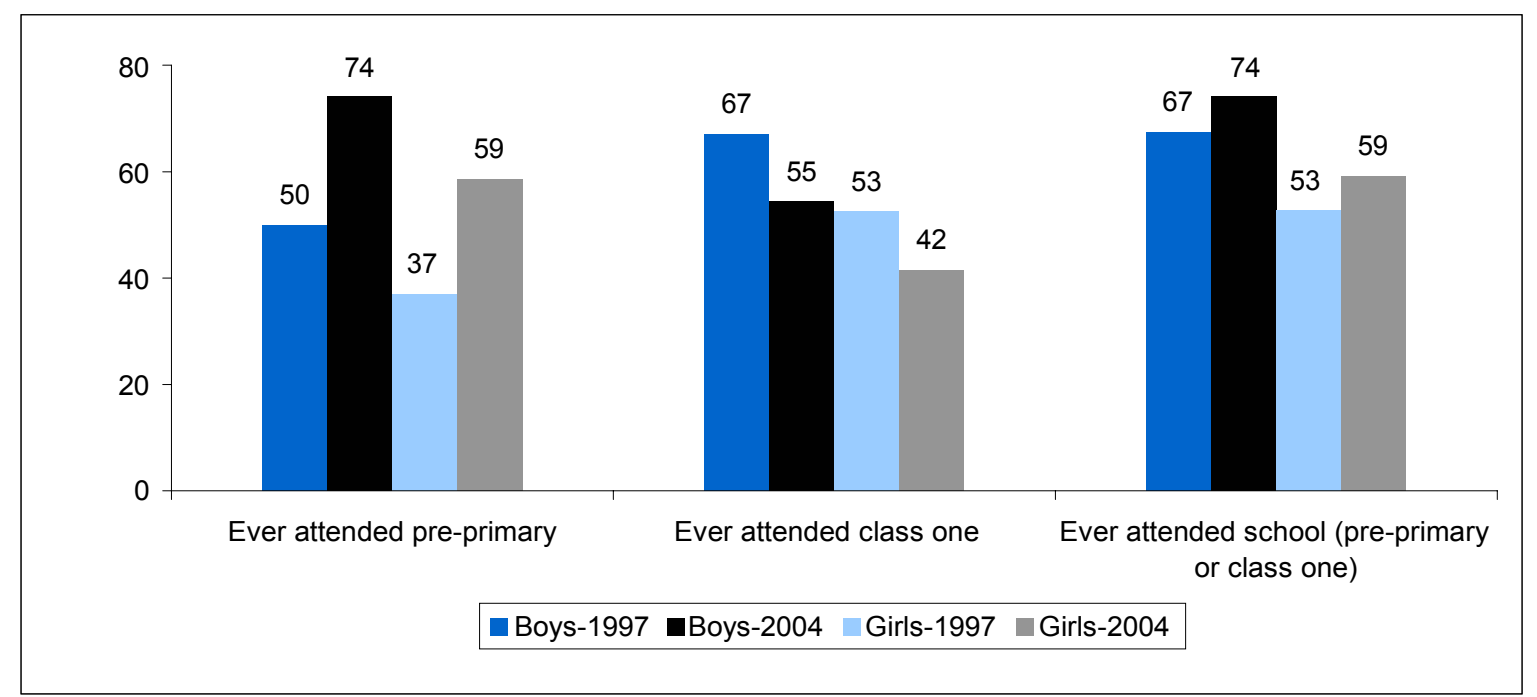

\subsection{Primary completion rates}

While Table 5.1 indicates only marginal increases in school attendance for boys and girls over the past six years, Table 5.2 shows that girls who ever entered school were more likely to remain in school and complete the five grades of primary in 2004 than in 1997. By contrast, retention rates for boys, which were over 20 percentage points higher than girls, have not shown any noticeable improvement. As a result the gender gap in retention rates has narrowed considerably. In 2004, 74 percent of 15-19 year old females who had ever attended school had completed five or more classes, as compared to 62 percent in 1997.

\footnotetext{
${ }^{5}$ No information was collected on current attendance at the pre-primary level, so we are unable to determine whether or not a child who has not yet begun class one is enrolled in school. Furthermore, no information was collected on the age at which children began attending pre-primary, so we are unable to determine to what extent young children are now enrolled in pre-primary at the age at which they would have entered class one in the past, thus delaying their entry into primary school, or whether it is now becoming more common for children to attend pre-primary at a younger age, in effect preparing them for formal primary school.
} 
Table 5.2 Trends in the percentage of 15-19 year olds who completed primary, of those who ever attended school

\begin{tabular}{|c|c|c|c|c|}
\hline & \multicolumn{2}{|c|}{1997} & \multicolumn{2}{|c|}{2004} \\
\hline & Male & Female & Male & Female \\
\hline $\begin{array}{l}\% \\
(\mathrm{~N})\end{array}$ & $\begin{array}{r}85.2 \\
(182)\end{array}$ & $\begin{array}{r}62.2 \\
(111)\end{array}$ & $\begin{array}{c}86.9 \\
(221)\end{array}$ & $\begin{array}{c}73.9 \\
(157)\end{array}$ \\
\hline
\end{tabular}

These trends in retention point to the importance of growing access to schooling opportunities beyond primary for girls. Parents who wanted to educate their daughters in 1997 had fewer options. Young women living in communities with few schools accessible to girls may not have had the opportunity to continue their education through the end of primary school, or may have been discouraged if their community lacked middle or high schools open to girls. As more schools with middle sections have become available to young women, girls have had a greater incentive to complete primary school.

\subsection{School Attendance at the Time of the Survey}

As discussed earlier, many 5-9 year old children are still in the process of entering school. Therefore, the discussion of levels and trends in current school attendance will focus on children aged 10-14 years old.

Current attendance rates for boys aged 10-14 in 2004 ranged from over 90 percent in Sialkot to barely 50 percent in R.Y. Khan (see Figure 5.3). Current enrollment rates for boys were not as high in the Punjab as in the N.W.F.P., and the variation in rates within the Punjab was greater in our sample than in the N.W.F.P. The variation across districts in current enrollment rates for girls is even greater than for boys, ranging from over 80 percent in Sialkot to barely 20 percent in R.Y. Khan, with similar ranges in the N.W.F.P.

Compared to current attendance rates in 1997, a higher proportion of 10-14 year olds were enrolled in school in 2004 (these data are not shown). From Tables 5.1 and 5.2, we know that this is primarily attributable to improved retention for girls and, to a lesser extent, due to some modest increases in ever attendance rates. 
Figure 5.3 Trends in the percent of 10-14 year olds currently attending school by district

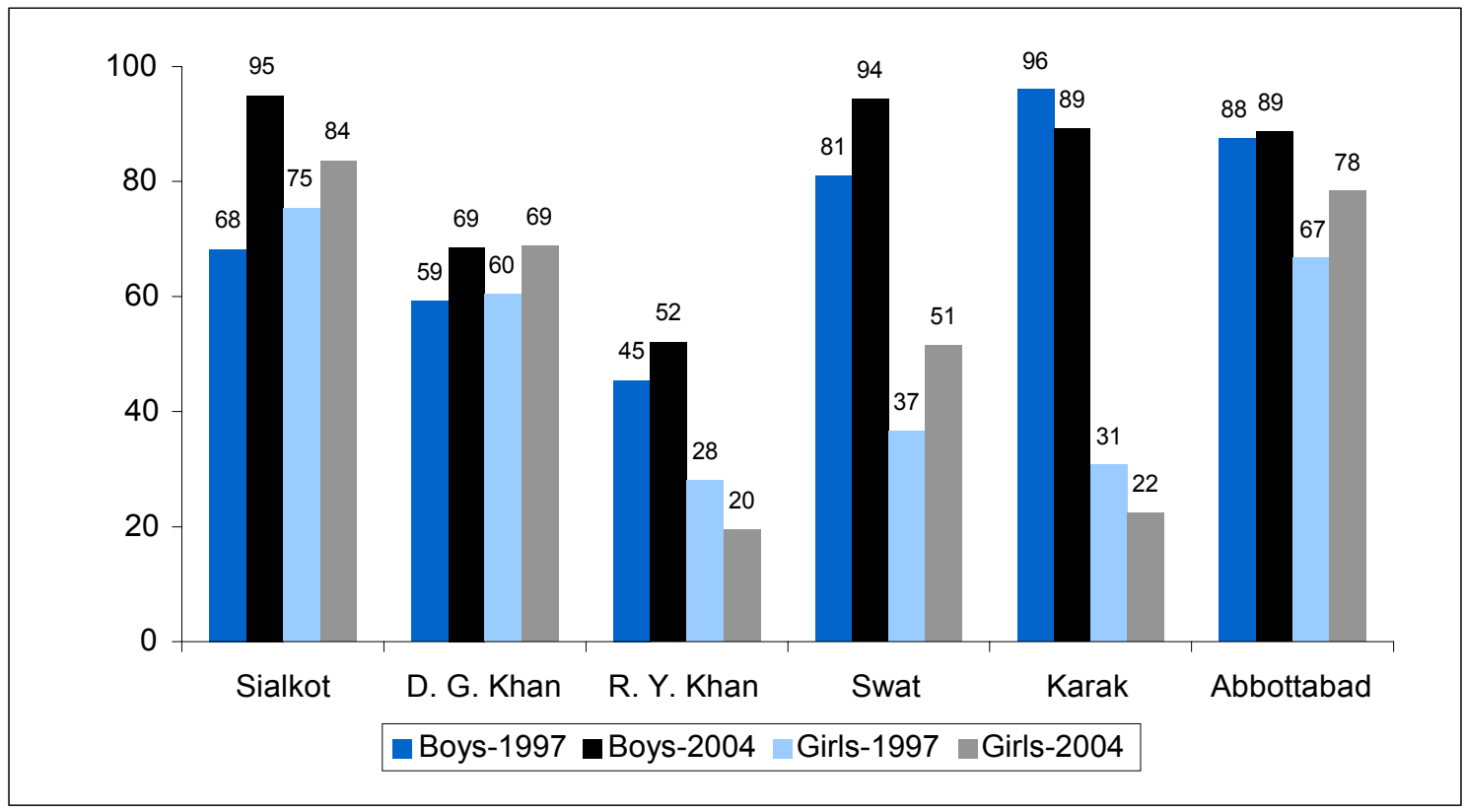

Figure 5.3 shows how current school attendance has changed at the district level. Almost all districts correspond with the overall pattern of increased current attendance.

However, there has been a small decline in girls' school attendance in the districts of R.Y. Khan and Karak. While these changes are not statistically significant when examined using a t-test, they may reflect the scarcity of educational opportunities for girls in these districts. In both years of the survey, communities in R.Y. Khan had the lowest levels of community development. Furthermore, no new government schools for girls opened in Karak during the six years between the two surveys.

Table 5.3 shows the association between parental and demographic characteristics and current school attendance of 10-14 year old children in the sample in 2004 . While there is a positive association between the educational attainment of fathers and the current attendance rates of boys and girls, the educational attainment of mothers has a stronger association with the current attendance of girls than of boys. Almost twice the percentage of girls whose mothers ever attended school are currently enrolled as compared to girls whose mothers had not had any formal education at all. 
Table 5.3 School status of 10-14 year olds in 2004

\begin{tabular}{|c|c|c|c|c|c|c|c|c|}
\hline \multirow[b]{2}{*}{ Characteristic } & \multicolumn{4}{|c|}{ Boys } & \multicolumn{4}{|c|}{ Girls } \\
\hline & $\begin{array}{l}\text { Currently } \\
\text { in school }\end{array}$ & $\begin{array}{r}\text { Left } \\
\text { school }\end{array}$ & $\begin{array}{r}\text { Never } \\
\text { attended }\end{array}$ & (N) & $\begin{array}{l}\text { Currently } \\
\text { in school }\end{array}$ & $\begin{array}{r}\text { Left } \\
\text { school }\end{array}$ & $\begin{array}{r}\text { Never } \\
\text { attended }\end{array}$ & (N) \\
\hline \multicolumn{9}{|c|}{ Fathers' schooling } \\
\hline 0 & 77.5 & 8.3 & 14.2 & 120 & 45.9 & 14.3 & 39.8 & 98 \\
\hline $1-5$ & 78.4 & 9.8 & 11.8 & 51 & 56.9 & 22.4 & 20.7 & 58 \\
\hline $6+$ & 94.6 & 3.0 & 2.4 & 167 & 63.2 & 14.2 & 22.6 & 155 \\
\hline \multicolumn{9}{|c|}{ Mothers' schooling } \\
\hline 0 & 84.2 & 6.4 & 9.4 & 265 & 48.8 & 16.5 & 34.7 & 248 \\
\hline $1-5$ & 94.7 & 1.8 & 3.5 & 57 & 84.9 & 13.2 & 1.9 & 53 \\
\hline $6+$ & 91.7 & 8.3 & 0 & 24 & 93.3 & 6.7 & 0 & 15 \\
\hline \multicolumn{9}{|l|}{ Age of mother } \\
\hline$<30$ & 77.3 & 4.6 & 18.2 & 22 & 46.2 & 23.1 & 30.8 & 26 \\
\hline $30-39$ & 87.3 & 6.3 & 6.3 & 221 & 57.9 & 14.2 & 27.9 & 190 \\
\hline $40+$ & 86.4 & 4.9 & 8.7 & 103 & 58 & 16 & 26 & 100 \\
\hline \multicolumn{9}{|l|}{ Order of birth } \\
\hline $1-2$ & 85.6 & 4.2 & 10.2 & 118 & 56.6 & 17.7 & 25.7 & 113 \\
\hline $3-4$ & 85.9 & 8.8 & 5.3 & 114 & 54.2 & 19.8 & 26.0 & 96 \\
\hline $5+$ & 87.7 & 4.4 & 7.9 & 114 & 59.8 & 9.4 & 30.8 & 107 \\
\hline \multicolumn{9}{|c|}{ Parity of mother } \\
\hline $1-3$ & 90.5 & 0 & 9.5 & 21 & 66.7 & 8.3 & 25 & 12 \\
\hline $4-5$ & 92.9 & 4.7 & 2.4 & 85 & 67.1 & 14.3 & 18.6 & 70 \\
\hline $6+$ & 83.8 & 6.7 & 9.6 & 240 & 53.4 & 16.2 & 30.3 & 234 \\
\hline Total & 86.4 & 5.8 & 7.8 & 346 & 57.0 & 15.5 & 27.5 & 316 \\
\hline
\end{tabular}

Note: Observations with missing information were not included in this table.

Demographic characteristics are also associated with current school enrollment, although not as strongly as parental educational attainment. The children of women older than 30 are more likely to be currently enrolled in school than the children of younger mothers; likewise, they are also less likely to have never attended school (Table 5.3). There was very little association between birth order and current school enrollment, although the cross-tabulations shown in Table 5.3 indicate that a slightly larger percentage of girls of higher birth order ( 5 or higher) are currently enrolled in school than girls of lower birth order. However, a larger percentage of girls of higher birth order have never attended school, leading to inconclusive findings. Finally, a mother's parity has a stronger association with current enrollment for girls than for boys. The children of women with six or more children are less likely to be currently enrolled in 
school, more likely to have dropped out of school, and more likely to have never attended.

\subsection{Attendance rates in government and private schools}

Over the six years between the two surveys, there has been a considerable decline in the proportion of children who attended a government primary school (Table 5.4). Many of the private primary schools were established within the past five years; therefore, this section of the report will include 5-9 year olds, in order to examine very recent trends in the distribution of attendance.

Although there was evidence in 1997 that younger children were less likely to attend a government-run primary school than older children, this trend was much more pronounced in 2004. In 2004, 84 percent of 15-19 year old females attended a government primary school, as compared to 73 percent of 10-14 year olds and 61 percent of 5-9 year olds. Likewise, 76 percent of 15-19 year old males attended a government primary school, compared to 65 percent of 10-14 year olds and 57 percent of 5-9 year olds. The corresponding increase in the proportion of young people attending private primary school parallels the increased availability of private schools in the sample communities as described in Chapter 3.

Table 5.4 Type of primary school last attended of those who ever attended class one or higher

\begin{tabular}{|c|c|c|c|c|c|c|}
\hline \multirow{2}{*}{$\begin{array}{l}\text { School type and } \\
\text { survey year }\end{array}$} & \multicolumn{2}{|c|}{ 5-9 year olds } & \multicolumn{2}{|c|}{$10-14$ year olds } & \multicolumn{2}{|c|}{$15-19$ year olds } \\
\hline & Male & Female & Male & Female & Male & Female \\
\hline \multicolumn{7}{|l|}{1997} \\
\hline Government & 72.4 & 81.3 & 83.0 & 86.5 & 89.6 & 92.8 \\
\hline Private & 27.3 & 18.8 & 16.4 & 13.5 & 10.4 & 7.2 \\
\hline Other & 0.3 & 0 & 0.6 & 0 & 0 & 0 \\
\hline $\mathrm{N}$ & 326 & 224 & 317 & 229 & 182 & 111 \\
\hline \multicolumn{7}{|l|}{2004} \\
\hline Government & 57.4 & 60.8 & 65.2 & 72.7 & 75.6 & 83.6 \\
\hline Private & 41.3 & 38.0 & 34.5 & 25.1 & 24.4 & 16.4 \\
\hline Other & 1.3 & 1.2 & 0.3 & 2.2 & 0 & 0 \\
\hline $\mathrm{N}$ & 223 & 171 & 322 & 231 & 217 & 152 \\
\hline
\end{tabular}




\subsection{Attendance rates in single sex and mixed schools}

In conjunction with the increase in attendance in private primary schools, there has been an increase in the percentage of children attending mixed schools over time. As discussed earlier, in Chapter 3, all government schools are de jure single sex and most private schools are mixed; therefore, the observed changes in attendance in single sex and mixed schools are not unexpected. Although this pattern was present in 1997, it continued in 2004, when 34 percent of 10-14 year old males and 24 percent of 10-14 year old females had attended a mixed primary school, and of those 5-9 year olds who had begun primary school, 38 percent of males and 36 percent of females attended a mixed school.

In addition to those children who attended a school that was officially mixed, it is evident from Table 5.5 that a substantial number of children attended a single sex school that was intended for the opposite sex. Although there is no clear pattern across the two times of the survey, for all age groups, girls were significantly more likely than boys to attend a single sex primary school intended for the opposite sex. This appears to be more common in 2004 than in 1997, indicating that, despite an increased number of mixed private schools, the demand for the education of girls exceeded the supply of available schools officially open to girls.

However, it is important to note that information on the type of school attended was drawn from the school data; therefore the data presented in Table 5.5 are restricted to those children who last attended a primary school that was included in the study. In 1997, approximately 80 percent of currently enrolled children attended a school visited by the sample, as compared to 89 percent of currently enrolled children in 2004.

Table 5.5 De jure type of primary school last attended, of those who have ever attended class one or higher

\begin{tabular}{|c|c|c|c|c|c|c|}
\hline \multirow[b]{2}{*}{ De jure school type } & \multicolumn{2}{|c|}{ 5-9 year olds } & \multicolumn{2}{|c|}{$10-14$ year olds } & \multicolumn{2}{|c|}{$15-19$ year olds } \\
\hline & Male & Female & Male & Female & Male & Female \\
\hline \multicolumn{7}{|l|}{1997} \\
\hline Single sex - boys & 78.0 & 9.7 & 87.0 & 12.9 & 93.8 & 9.5 \\
\hline Single sex - girls & 1.9 & 69.4 & 0.8 & 72.7 & 0.8 & 86.5 \\
\hline Mixed & 20.1 & 20.9 & 12.2 & 14.4 & 5.4 & 4.1 \\
\hline $\mathrm{N}$ & 259 & 134 & 247 & 132 & 129 & 74 \\
\hline
\end{tabular}


Fewer and Better Children: Expanded Choices in Schooling and Fertility in Rural Pakistan

\begin{tabular}{|c|c|c|c|c|c|c|}
\hline \multirow[b]{2}{*}{ De jure school type } & \multicolumn{2}{|c|}{ 5-9 year olds } & \multicolumn{2}{|c|}{$10-14$ year olds } & \multicolumn{2}{|c|}{$15-19$ year olds } \\
\hline & Male & Female & Male & Female & Male & Female \\
\hline \multicolumn{7}{|l|}{2004} \\
\hline Single sex - boys & 56.4 & 17.4 & 60.6 & 13.1 & 71.0 & 20.3 \\
\hline Single sex - girls & 5.6 & 46.5 & 5.0 & 63.1 & 5.1 & 63.3 \\
\hline Mixed & 38.0 & 36.1 & 34.4 & 23.8 & 23.9 & 16.4 \\
\hline $\mathrm{N}$ & 195 & 155 & 282 & 206 & 176 & 128 \\
\hline
\end{tabular}

Note: Calculations in this table are restricted to young people who attended a school visited during data collection.

\subsection{Summary}

The schooling environment in rural Pakistan changed significantly over the six years from 1997 to 2004. Not only were many new schools-mostly private schools open to both boys and girls-established during this period, but there is also evidence of convergence between government and private primary schools in several aspects of school quality. Against this backdrop of a changing school environment, there is evidence that more girls are enrolling in school, that more boys and girls are remaining in school to older ages and through the completion of primary, and that more parents are choosing to send their children to private primary schools than in the past.

However, these overall trends disguise the importance of household and local contexts in shaping children's schooling outcomes. Communities with fewer new schools and less community development show evidence of some improvements in enrollment, but largely preserve the gender disparities in enrollment and schooling attainment present in 1997. In contrast, districts with higher levels of development and numerous recently created schools show little difference in the schooling of girls and boys. Likewise, there is evidence that children whose parents did not attend school are less likely to attend and remain in school than the children of parents who attended primary or higher.

The data also suggest that there have been recent changes in the experience of schooling. As Table 5.2 illustrated, pre-primary classes have now become universal amongst children who eventually enter grade one. Although the cognitive outcomes of pre- primary classes are beyond the scope of this survey, the content of the curriculum and potentially earlier introduction to the classroom may have significant impacts on subsequent school performance and grade retention. Furthermore, the observed shift from government to private schools may have similar implications for educational attainment. Taken together, these recent changes suggest that when educational choice and opportunity are available, households respond in ways that suggest that they are seeking to find the best educational options for their children within the local area. 



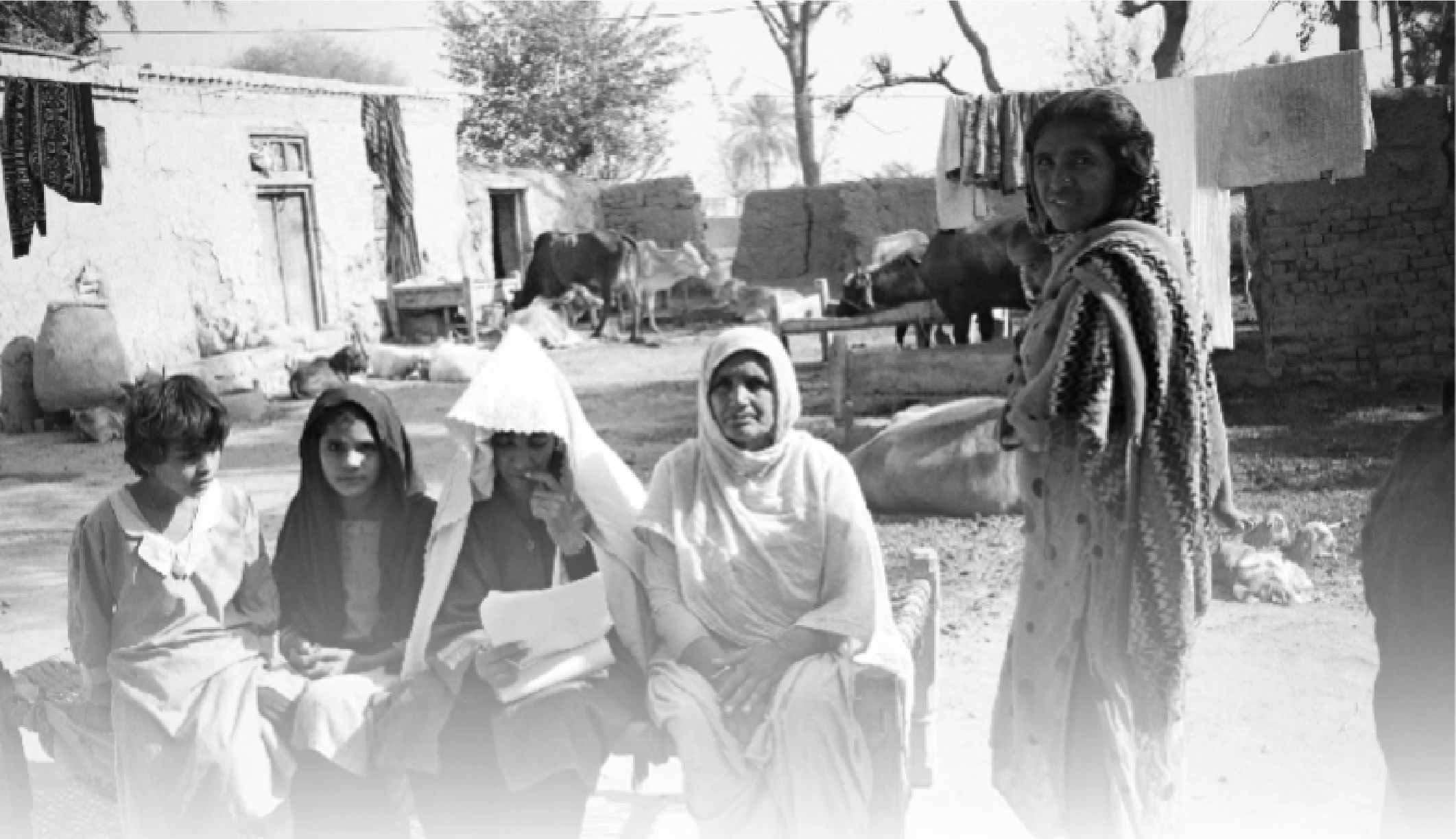

Chapter 6

\section{Trends in Family Building: Fertility Preferences, Contraceptive Use, and Fertility Behavior}

\subsection{Introduction}

This chapter focuses on trends in family building, including fertility preferences, contraceptive use, and fertility behavior. Significant changes in family building behavior have occurred in Pakistan over the years under consideration. While Pakistan has experienced a considerable decline in fertility levels from a Total Fertility Rate of about 5.6 to about 4.0 (FBS 2005), and a rise in contraceptive use levels in the recent past from 24 to 33 percent (NIPS 2001), the change has been less dramatic in rural areas. These data allow us to examine in greater detail and with considerable power the changes in family building behavior at a micro level in twelve villages of rural Pakistan during this period of rapid demographic and educational change. 
Chapter 6 Trends in Family Building: Fertility Preferences, Contraceptive Use, and Fertility Behavior

In the first few sections of the chapter, we compare overall demographic trends using the cross-sectional data collected in each survey year based on interviews with currently married women ages 20-45. This comprises a sample of 722 women in 1997 and 690 women in 2004. Next, a restricted sample of panel women will be examined to determine changes across the cohort of women who were followed up over time. This reduces the sample size to 593.

\subsection{Fertility intentions and behavior}

Fertility levels among currently married women ages 20-45 have declined across each of the six districts, each comprising two villages. Overall, this group of women reported having had almost half a child less in 2004 than women with the same characteristics had reported in 1997. Reported fertility declines are most dramatic in Swat and Karak in the N.W.F.P. (Table 6.1)

\section{Table 6.1 Mean children ever born (standardized by age) by districts, 1997-2004}

\begin{tabular}{lcr}
\hline & \multicolumn{2}{c}{ Currently married women ages 20-45 } \\
\cline { 2 - 3 } District & $\mathbf{1 9 9 7}$ & $\mathbf{2 0 0 4}$ \\
\hline Sialkot & 4.91 & 4.70 \\
D. G. Khan & 5.33 & 5.09 \\
R. Y. Khan & 5.59 & 5.78 \\
Abbottabad & 4.29 & 4.07 \\
Swat & 5.89 & 5.16 \\
Karak & 6.24 & 5.06 \\
\hline
\end{tabular}

Comparing fertility intentions across the two surveys, we find that the proportion of women who want to stop childbearing has increased slightly. In 1997, 53 percent of women did not want more children; this figure rose to 56 percent in 2004 (Table 6.2). But more interestingly the proportion using contraception among those who wanted no more children had risen dramatically from 31 to 44 percent (Table 6.2). Even among those who wanted more children there was a slight rise in contraceptive use from 21 to 22 percent. The change is a direct manifestation of women acting upon their fertility intentions to actually use contraception to control fertility behavior. The rise in this proportion is most dramatic in the less developed districts of Punjab of D. G. Khan and R. Y. Khan and in Karak in the N.W.F.P. Some anomalous results were observed in Swat which show up through out. In terms of age, the changes are most dramatic for women aged 25-40 (data not shown). 


\subsection{Availability of family planning services}

An interesting change in the past six years is the greater availability of services for health and family planning in the twelve villages. There was very little availability of services in 1997-only five out of twelve villages had any such services. However, in 2004 all but one of the villages have some health and family planning services (Table 6.3). This change, also depicted in Chapter 3 , shows a marked increase in health service availability in these twelve villages. The most notable change is in the placement of the community-based LHWs in rural communities to provide primary health care, including family planning. This improved service availability is definitely associated with the rise in the use of family planning services seen in all the areas. The only village which still has no health or family planning services is Feroza in R. Y. Khan in the Punjab.

Table 6.2 Proportion of currently married women 20-45 wanting no more children, and contraceptive use status by fertility intentions

\begin{tabular}{|c|c|c|c|c|c|c|c|c|}
\hline \multirow[b]{3}{*}{ District } & \multicolumn{4}{|c|}{1997} & \multicolumn{4}{|c|}{2004} \\
\hline & \multirow{2}{*}{$\begin{array}{r}\text { Want no } \\
\text { more } \\
\text { children } \\
(\%)\end{array}$} & \multicolumn{2}{|c|}{$\begin{array}{l}\text { Currently using } \\
\text { contraception (\%) }\end{array}$} & \multirow[b]{2}{*}{$\mathbf{N}$} & \multirow{2}{*}{$\begin{array}{r}\text { Want no } \\
\text { more } \\
\text { children } \\
(\%)\end{array}$} & \multicolumn{2}{|c|}{$\begin{array}{c}\text { Currently using } \\
\text { contraception (\%) }\end{array}$} & \multirow[b]{2}{*}{$\mathrm{N}$} \\
\hline & & $\begin{array}{r}\text { Want } \\
\text { more } \\
\text { children }\end{array}$ & $\begin{array}{r}\text { Want no } \\
\text { more } \\
\text { children }\end{array}$ & & & $\begin{array}{r}\text { Want more } \\
\text { children }\end{array}$ & $\begin{array}{r}\text { Want no } \\
\text { more } \\
\text { children }\end{array}$ & \\
\hline Sialkot & 52.1 & 37.9 & 39.7 & 121 & 60.9 & 63.9 & 47.3 & 92 \\
\hline D. G. Khan & 39.3 & 16.2 & 14.6 & 122 & 49.6 & 31.4 & 38.2 & 139 \\
\hline R. Y. Khan & 42.0 & 6.2 & 12.8 & 112 & 59.2 & 10.0 & 44.6 & 98 \\
\hline Abbottabad & 60.6 & 30.2 & 42.4 & 109 & 76.4 & 23.8 & 58.8 & 89 \\
\hline Swat & 64.3 & 31.7 & 51.4 & 115 & 53.5 & 11.9 & 42.6 & 127 \\
\hline Karak & 60.8 & 10.7 & 18.4 & 143 & 47.6 & 5.3 & 32.4 & 145 \\
\hline Total & 53.3 & 20.8 & 31.2 & 722 & 56.2 & 21.5 & 43.9 & 690 \\
\hline
\end{tabular}


Chapter 6 Trends in Family Building: Fertility Preferences, Contraceptive Use, and Fertility Behavior

Figure 6.1 Proportion of women (20-45) who do not want more children by district, 1997-2004

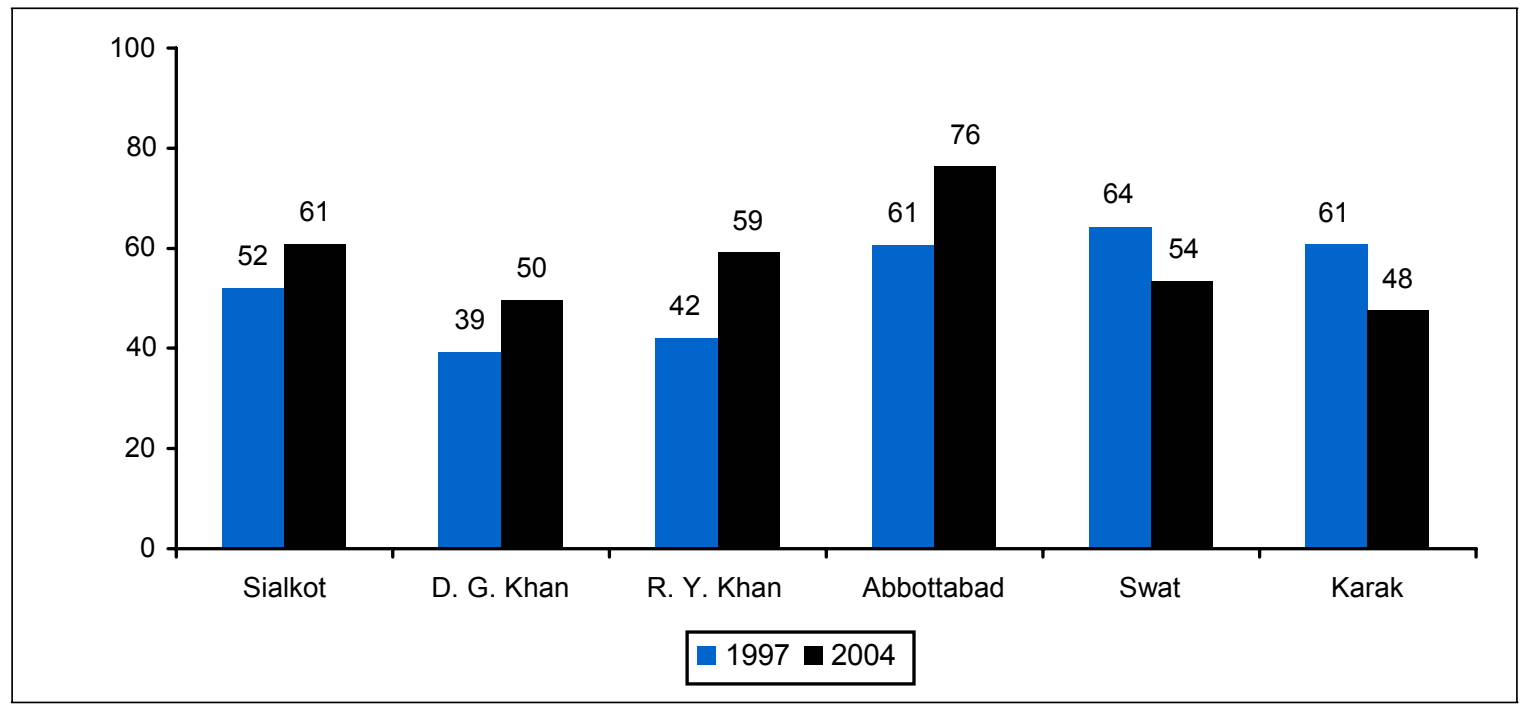

Figure 6.2 Proportion of women (20-45) using contraception among those who do not want more children by district, 1997-2004

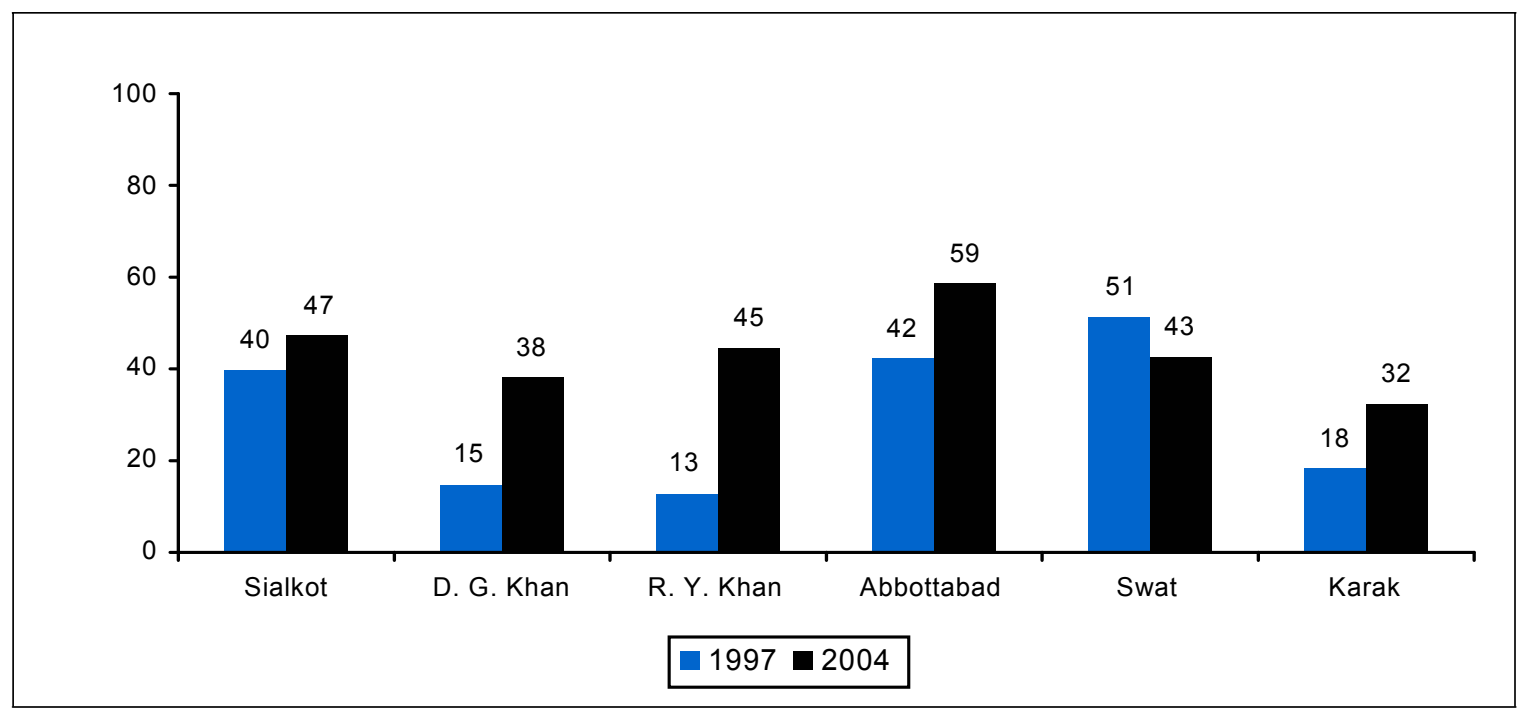


Table 6.3 Presence of family planning services* by location, 1997-2004

\begin{tabular}{|c|c|c|c|c|c|c|c|c|}
\hline & Prior to 1997 & 1997 & 1998 & 1999 & 2000 & 2001 & 2002 & 2003 \\
\hline Dhado Basra & & $\checkmark$ & $\checkmark$ & $\checkmark$ & $\checkmark$ & $\checkmark$ & $\checkmark$ & $\checkmark$ \\
\hline Ram Garha & & & & & & $\checkmark$ & $\checkmark$ & $\checkmark$ \\
\hline Gadai & $\checkmark$ & $\checkmark$ & $\checkmark$ & $\checkmark$ & $\checkmark$ & $\checkmark$ & $\checkmark$ & $\checkmark$ \\
\hline Noorpur & & & & $\checkmark$ & $\checkmark$ & $\checkmark$ & $\checkmark$ & $\checkmark$ \\
\hline Feroza & $\checkmark$ & & & & & & & \\
\hline \multicolumn{9}{|l|}{ Kotla Drigh } \\
\hline Islampur & & & & & $\checkmark$ & $\checkmark$ & $\checkmark$ & $\checkmark$ \\
\hline Alaabad & $\checkmark$ & $\checkmark$ & $\checkmark$ & $\checkmark$ & $\checkmark$ & $\checkmark$ & $\checkmark$ & $\checkmark$ \\
\hline Duresh Khel & $\checkmark$ & $\checkmark$ & $\checkmark$ & $\checkmark$ & $\checkmark$ & $\checkmark$ & $\checkmark$ & $\checkmark$ \\
\hline \multicolumn{9}{|l|}{ Mandawa } \\
\hline Tarmuchian & & & $\checkmark$ & $\checkmark$ & $\checkmark$ & $\checkmark$ & $\checkmark$ & $\checkmark$ \\
\hline Kakul & $\checkmark$ & & & & & $\checkmark$ & $\checkmark$ & $\checkmark$ \\
\hline
\end{tabular}

* (Includes presence of a Family Welfare Center, Lady Health Worker, or Lady Health Visitor) 
Table 6.4 Distribution of decision-makers among female contraceptive users by district, 1997-2004

\begin{tabular}{|c|c|c|c|c|c|c|c|c|c|c|c|c|}
\hline \multirow[b]{2}{*}{ District } & \multicolumn{5}{|c|}{1997} & \multicolumn{7}{|c|}{2004} \\
\hline & Self & Spouse & $\begin{array}{r}\text { Joint } \\
\text { decision by } \\
\text { couple }\end{array}$ & $\begin{array}{r}\text { Joint } \\
\text { decision } \\
\text { with others }\end{array}$ & $\begin{array}{r}\text { Service } \\
\text { provider's } \\
\text { advice }\end{array}$ & (N) & Self & Spouse & $\begin{array}{r}\text { Joint } \\
\text { decision by } \\
\text { couple }\end{array}$ & $\begin{array}{r}\text { Joint } \\
\text { decision } \\
\text { with others }\end{array}$ & $\begin{array}{r}\text { Service } \\
\text { provider's } \\
\text { advice }\end{array}$ & (N) \\
\hline Sialkot & 22.9 & 15.7 & 60.0 & 0.0 & 0.0 & 70 & 14.3 & 22.9 & 48.6 & 0.0 & 0.0 & 70 \\
\hline D. G. Khan & 37.8 & 13.5 & 43.2 & 0.0 & 5.4 & 37 & 16.0 & 24.0 & 53.3 & 0.0 & 4.0 & 75 \\
\hline R. Y. Khan & 5.3 & 26.3 & 57.9 & 5.3 & 5.3 & 19 & 15.0 & 22.5 & 55.0 & 0.0 & 2.5 & 40 \\
\hline Karak & 7.5 & 7.5 & 85.0 & 0.0 & 0.0 & 40 & 7.7 & 28.9 & 50.0 & 0.0 & 1.9 & 52 \\
\hline Total & 21.6 & 12.5 & 62.4 & 1.4 & 1.1 & 287 & 18.3 & 24.1 & 46.7 & 0.0 & 1.3 & 377 \\
\hline
\end{tabular}




\subsection{Family building, initiation of contraception, and participation in decisions}

A striking feature of the change in family building behavior appears to be the growing involvement of husbands in the decision to use family planning. In 1997, among women using contraception, 62 percent reported that the use was a joint decision with their husbands, 22 percent reported that it was their own decision, and 13 reported that it was their husbands' decision (Table 6.4). In 2004, female contraceptive users reported that 47 percent decided jointly with their husbands, 18 percent reported that it was their own decision, and 24 percent reported that it was their husbands' decision. Clearly, this depicts a trend of men decidedly entering the reproductive health arena in a proactive way to use contraception to curtail childbearing. Once again these changes appear to be most dramatic in Swat and Karak where we also saw a closing of the gap between demand and utilization of need for family planning services.

Family building patterns have undergone a change in most of the areas where the survey was conducted. Comparing the parity at first use across the six districts, one finds that, while on average women are starting contraceptive use with 0.2 child less, that this difference is almost as large as one child in D. G. Khan, and more than one child in R. Y. Khan and Swat (Table 6.5). These three districts are distinctly poor and rural in the context of Pakistan, making these changes all the more dramatic. A comparison across age groups shows that younger women are the ones beginning to use contraception at lower parities, demonstrating that a profound behavioral change to plan families is actually underway in rural Pakistan.

Table 6.5 Parity at first use by district and by age, currently married women aged 20-45

\begin{tabular}{|c|c|c|c|c|c|c|c|c|c|}
\hline \multirow[b]{2}{*}{ District } & \multicolumn{2}{|l|}{1997} & \multicolumn{2}{|c|}{2004} & \multirow[b]{2}{*}{ Age } & \multicolumn{2}{|c|}{1997} & \multicolumn{2}{|c|}{2004} \\
\hline & $\begin{array}{r}\text { Parity } \\
\text { (mean) }\end{array}$ & $\mathbf{N}$ & $\begin{array}{r}\text { Parity } \\
\text { (mean) }\end{array}$ & $\mathbf{N}$ & & $\begin{array}{r}\text { Parity } \\
\text { (mean) }\end{array}$ & $\mathbf{N}$ & $\begin{array}{r}\text { Parity } \\
\text { (mean) }\end{array}$ & $\mathbf{N}$ \\
\hline Sialkot & 3.8 & 66 & 3.8 & 59 & $20-24$ & 2.1 & 25 & 1.6 & 38 \\
\hline D. G. Khan & 4.8 & 37 & 3.9 & 73 & $25-29$ & 3.2 & 58 & 2.8 & 63 \\
\hline R. Y. Khan & 3.7 & 19 & 4.9 & 37 & $30-34$ & 4.1 & 79 & 3.8 & 75 \\
\hline Abbottabad & 3.4 & 55 & 3.3 & 52 & $35-39$ & 4.8 & 66 & 5.0 & 90 \\
\hline Swat & 4.5 & 62 & 3.7 & 66 & $40-45$ & 5.9 & 51 & 5.7 & 66 \\
\hline Karak & 5.5 & 40 & 5.0 & 46 & & & & & \\
\hline Total & 4.2 & 279 & 4.0 & 333 & Total & 4.2 & 279 & 4.0 & 332 \\
\hline
\end{tabular}


Chapter 6 Trends in Family Building: Fertility Preferences, Contraceptive Use, and Fertility Behavior

Yet another encouraging indicator of changes in fertility behavior is the shift away from traditional towards modern contraception. The current use of contraception went up from 26 to 34 percent and most of the rise was in modern contraception which rose from 18 to 24 percent-a 50 percent increase (Table 6.6). This increase in modern contraception was most pronounced in the lesser developed areas of R. Y. Khan, D. G. Khan, and Karak. Swat once more presents an anomalous picture. While the more developed districts of Sialkot and Abbottabad show a substantial rise, their base for modern contraceptive use was quite high to begin with in 1997. There appears to be more of a 'catch-up' effect on the part of the relatively less developed districts of R. Y. Khan and D. G. Khan, and Karak.

Table 6.6 Contraceptive use rates 1997-2004, currently married women aged 20-44

\begin{tabular}{|c|c|c|c|c|c|c|c|}
\hline District & $\begin{array}{l}\text { Current } \\
\text { modern }\end{array}$ & $\begin{array}{r}\text { Current } \\
\text { traditional }\end{array}$ & $\begin{array}{l}\text { Current } \\
\text { any type }\end{array}$ & $\begin{array}{r}\text { Ever } \\
\text { modern }\end{array}$ & $\begin{array}{r}\text { Ever } \\
\text { traditional }\end{array}$ & $\begin{array}{r}\text { Ever } \\
\text { any type }\end{array}$ & $\mathbf{N}$ \\
\hline \multicolumn{8}{|l|}{1997} \\
\hline Sialkot & 23.3 & 16.5 & 38.8 & 43.8 & 35.5 & 57.9 & 121 \\
\hline D. G. Khan & 14.8 & 1.6 & 15.6 & 29.5 & 7.4 & 30.3 & 122 \\
\hline R. Y. Khan & 6.3 & 1.8 & 8.9 & 10.7 & 7.1 & 17.0 & 112 \\
\hline Abbottabad & 26.6 & 12.8 & 37.6 & 42.2 & 26.6 & 51.4 & 109 \\
\hline Swat & 35.7 & 10.5 & 44.3 & 49.6 & 20.2 & 56.5 & 115 \\
\hline Karak & 4.9 & 10.4 & 15.3 & 20.1 & 15.3 & 27.8 & 144 \\
\hline Total & 18.0 & 9.0 & 26.3 & 32.2 & 18.6 & 39.7 & 723 \\
\hline \multicolumn{8}{|l|}{2004} \\
\hline Sialkot & 36.3 & 17.6 & 53.8 & 65.9 & 45.1 & 76.9 & 91 \\
\hline D. G. Khan & 23.2 & 10.9 & 34.8 & 47.1 & 23.2 & 54.3 & 138 \\
\hline R. Y. Khan & 18.8 & 11.6 & 30.2 & 33.3 & 20.0 & 41.7 & 96 \\
\hline Abbottabad & 36.7 & 16.7 & 50.0 & 61.1 & 38.9 & 63.3 & 90 \\
\hline Swat & 26.8 & 1.6 & 28.3 & 62.2 & 9.5 & 65.4 & 127 \\
\hline Karak & 15.1 & 3.4 & 17.8 & 29.5 & 8.2 & 35.6 & 146 \\
\hline Total & 25.0 & 9.3 & 33.9 & 48.5 & 22.0 & 54.8 & 688 \\
\hline
\end{tabular}

Perhaps even more striking is the reporting of ever use of contraception and its rise from about 40 to 55 percent. The figure implies that an even larger proportion of womenindeed a majority-have used some form of contraception in the past. Roughly twenty percent have stopped using contraception. The proportion of contraceptive users who have discontinued is indeed considerable and worth further investigation. 
Figure 6.3 Proportion of currently married women aged 20-44 currently using contraception by district, 1997-2004

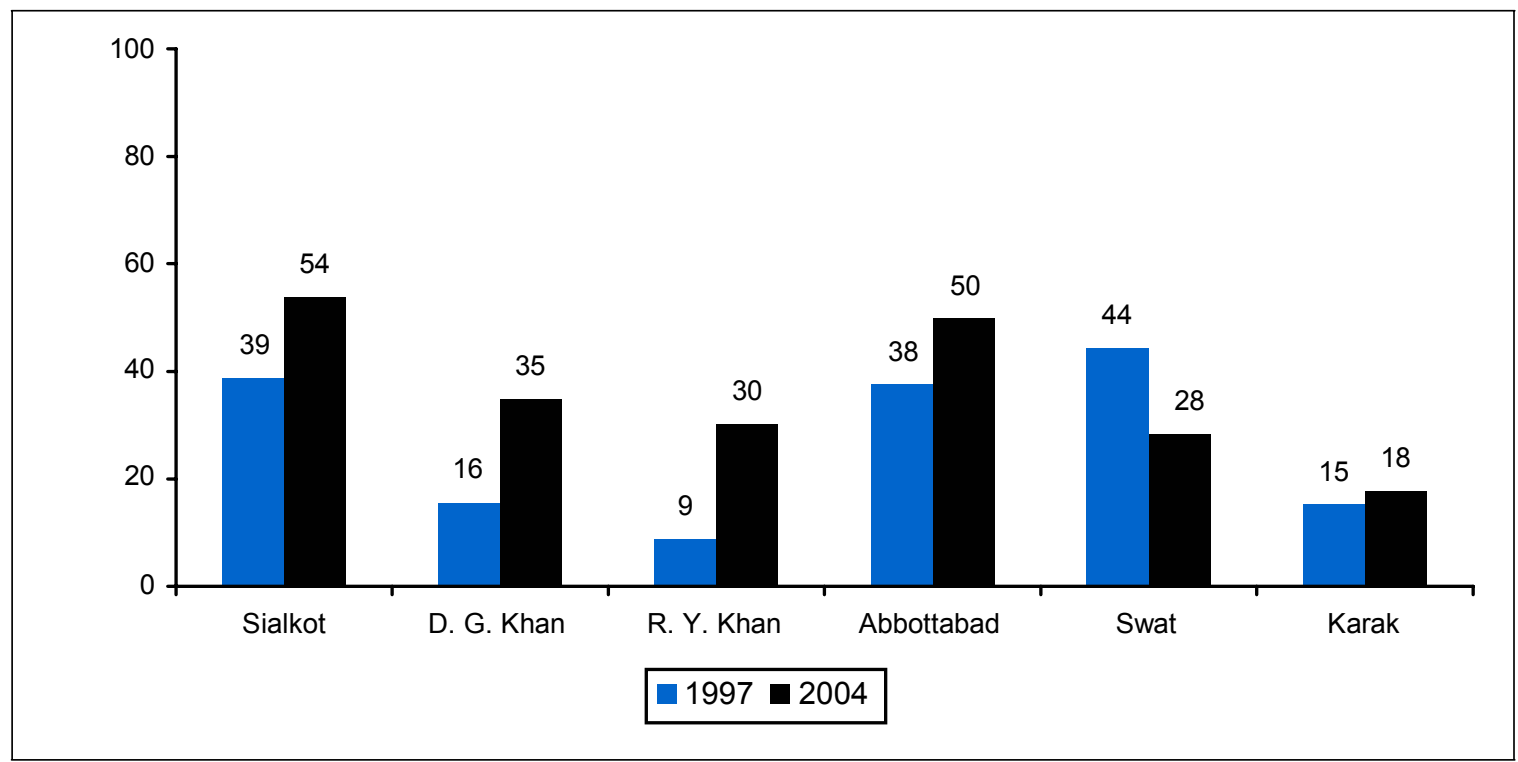

Figure 6.4 Currently married women aged 20-44 who have ever used a contraceptive method by district, 1997-2004

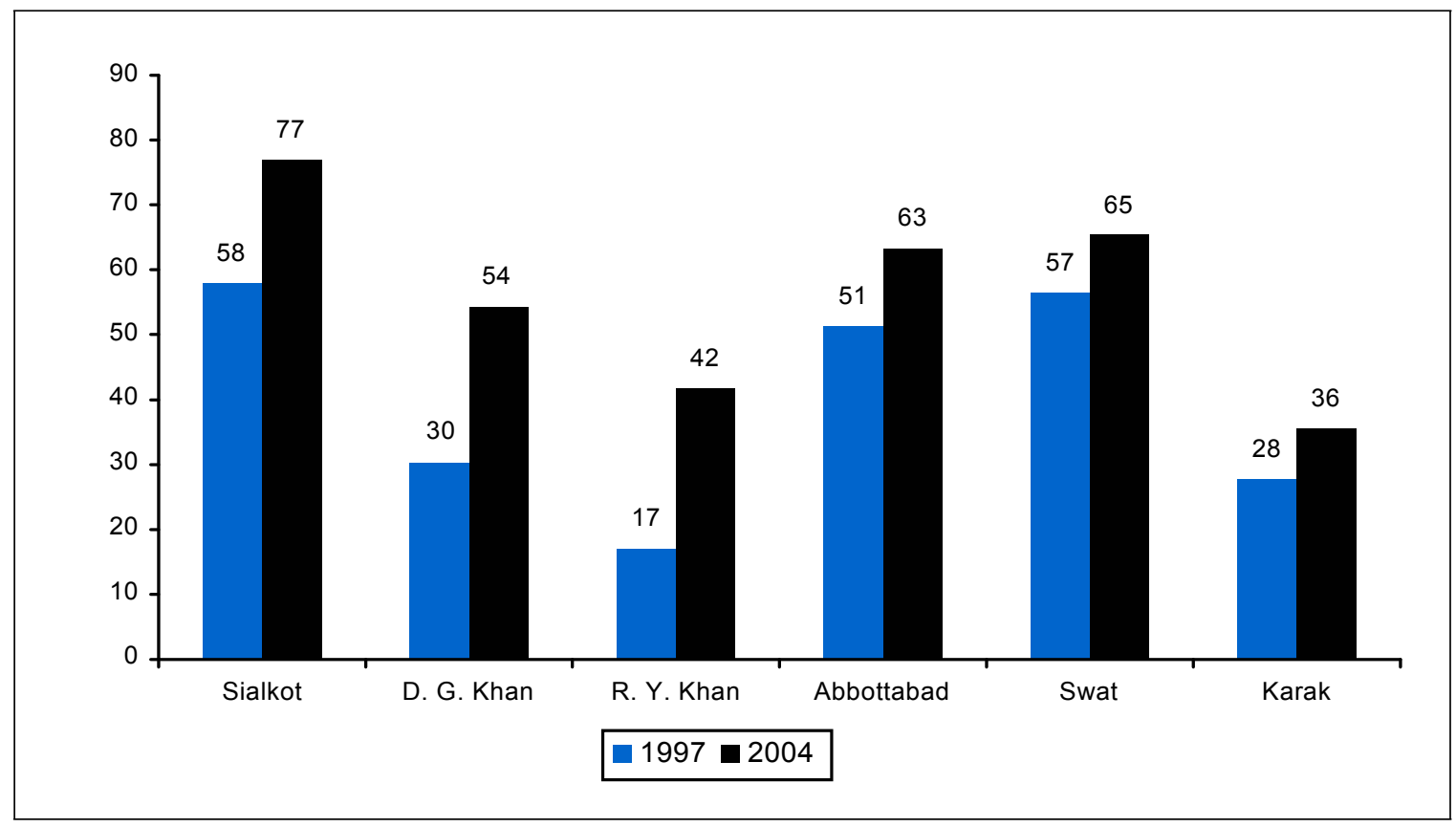

One final finding of interest, based on an analysis of trends using two cross-sectional surveys of currently married women ages $20-45$, is the change in the mix of 
contraceptive methods reported. The use of the condoms has risen from 8 percent in 1997 to 15 percent in 2004 (Table 6.7). The other method which has risen in popularity appears to be the injectable (also a modern reversible method as is the condom), while the use of the IUD and withdrawal has stayed about the same and the use of the pill and female sterilization (both female methods) has declined. Once more, the rise in condom use is most dramatic in Karak (from 0 to 21 percent), Abbottabad from 11 to 28 percent, and Sialkot from 13 to 21 percent. 
Table 6.7 Most recent contraceptive method used, currently married women, ages 20-44, using contraception by district

\begin{tabular}{|c|c|c|c|c|c|c|c|c|c|c|}
\hline District & Pill & IUD & Injectable & Condom & $\begin{array}{r}\text { Female } \\
\text { sterilization }\end{array}$ & $\begin{array}{r}\text { Male } \\
\text { sterilization }\end{array}$ & Rhythm & Withdrawal & Other & $\mathbf{N}$ \\
\hline \multicolumn{11}{|l|}{1997} \\
\hline Sialkot & 2.9 & 10.0 & 1.4 & 12.9 & 27.1 & 0.0 & 4.3 & 37.1 & 4.3 & 70 \\
\hline D. G. Khan & 18.9 & 16.2 & 18.9 & 13.5 & 27.0 & 0.0 & 2.7 & 2.7 & 0.0 & 37 \\
\hline R. Y. Khan & 5.3 & 10.5 & 21.1 & 5.3 & 10.5 & 0.0 & 10.5 & 21.1 & 15.8 & 19 \\
\hline Abbottabad & 10.7 & 16.1 & 19.6 & 10.7 & 10.7 & 0.0 & 3.6 & 26.8 & 1.8 & 56 \\
\hline Swat & 23.1 & 6.2 & 32.3 & 4.6 & 15.4 & 0.0 & 10.8 & 6.2 & 0.0 & 65 \\
\hline Karak & 32.5 & 7.5 & 12.5 & 0.0 & 5.0 & 0.0 & 15.0 & 25.0 & 2.5 & 40 \\
\hline Total & 15.3 & 10.8 & 17.1 & 8.4 & 17.1 & 0.0 & 7.3 & 20.9 & 2.8 & 287 \\
\hline \multicolumn{11}{|l|}{2004} \\
\hline Sialkot & 2.9 & 8.6 & 8.6 & 21.4 & 20.0 & 0.0 & 1.4 & 34.3 & 1.4 & 70 \\
\hline D. G. Khan & 4.0 & 25.3 & 12.0 & 9.3 & 16.0 & 0.0 & 5.3 & 21.3 & 5.3 & 75 \\
\hline R. Y. Khan & 10.0 & 12.5 & 22.5 & 5.0 & 12.5 & 2.5 & 15.0 & 20.0 & 0.0 & 40 \\
\hline Abbottabad & 3.5 & 5.3 & 21.1 & 28.1 & 15.8 & 0.0 & 1.8 & 22.8 & 0.0 & 57 \\
\hline Swat & 24.1 & 4.8 & 49.4 & 4.8 & 7.2 & 0.0 & 3.6 & 4.8 & 0.0 & 83 \\
\hline Karak & 17.3 & 3.9 & 32.7 & 21.2 & 5.8 & 0.0 & 3.9 & 15.4 & 0.0 & 52 \\
\hline Total & 10.6 & 10.3 & 24.9 & 14.6 & 13.0 & 0.3 & 4.5 & 19.4 & 1.3 & 377 \\
\hline
\end{tabular}




\subsection{Panel study: cohort changes in family building intentions}

We now turn to the panel data for the 593 women who were interviewed during both surveys of data collection. The analytical power of studying the panel lies in discovering how the same women interviewed in 1997 kept to or changed their fertility intentions and behavior. It is of particular interest to explore to what extent their reproductive intentions have changed over this period and how their contraceptive behavior and fertility experiences relate to those preferences.

A direct comparison of the cohort aged 20-45 (who would be six years older in 2004) reveals, not surprisingly, a rise in the proportion not wanting any more children (Table 6.8) This change was more pronounced for women aged under 35, while there was little change above that age. In terms of fertility intentions, we find that the majority falls into the same category as the one they were placed in earlier. Forty-five percent did not want more children earlier, nor do they do now; 26 percent wanted more children earlier and do so now too. However, the other thirty percent of women have changed their fertility intentions. Nearly twenty-one percent wanted more children then and do not want them now, while about 8 percent have changed their minds and do want more. It is interesting to note that the major areas which have become more inclined towards curtailing childbearing are D. G. Khan, R. Y. Khan, and Abbottabad, while Swat and Karak may have moved in the opposite direction. The last two may reflect recent conservative trends in the province of the N.W.F.P.

\section{Table 6.8 Changes in fertility intentions of panel women}

\begin{tabular}{lrrrr}
\hline & \multicolumn{3}{c}{ 1997-2004 Fertility intentions for wanting more children } \\
\cline { 2 - 5 } District & $\begin{array}{r}\text { No more (1997) } \\
\text { - No more (2004) }\end{array}$ & $\begin{array}{r}\text { More (1997) } \\
\text { - More 2004) }\end{array}$ & $\begin{array}{r}\text { No more (1997) } \\
\text { - More (2004) }\end{array}$ & $\begin{array}{r}\text { More (1997) } \\
\text { - No more (2004) }\end{array}$ \\
\hline Sialkot & 46.7 & 28.9 & 8.9 & 15.6 \\
D. G. Khan & 30.5 & 34.3 & 5.7 & 29.5 \\
R. Y. Khan & 42.1 & 29.5 & 1.1 & 27.4 \\
Abbottabad & 61.2 & 11.8 & 2.4 & 24.7 \\
Swat & 49.5 & 19.2 & 15.2 & 16.2 \\
Karak & 43.7 & 26.9 & 16.0 & 13.4 \\
Total & 45.0 & 25.5 & 8.6 & 20.9 \\
\hline
\end{tabular}


Figure 6.5 Distribution of women in the panel by status of fertility intentions by district, 1997-2004
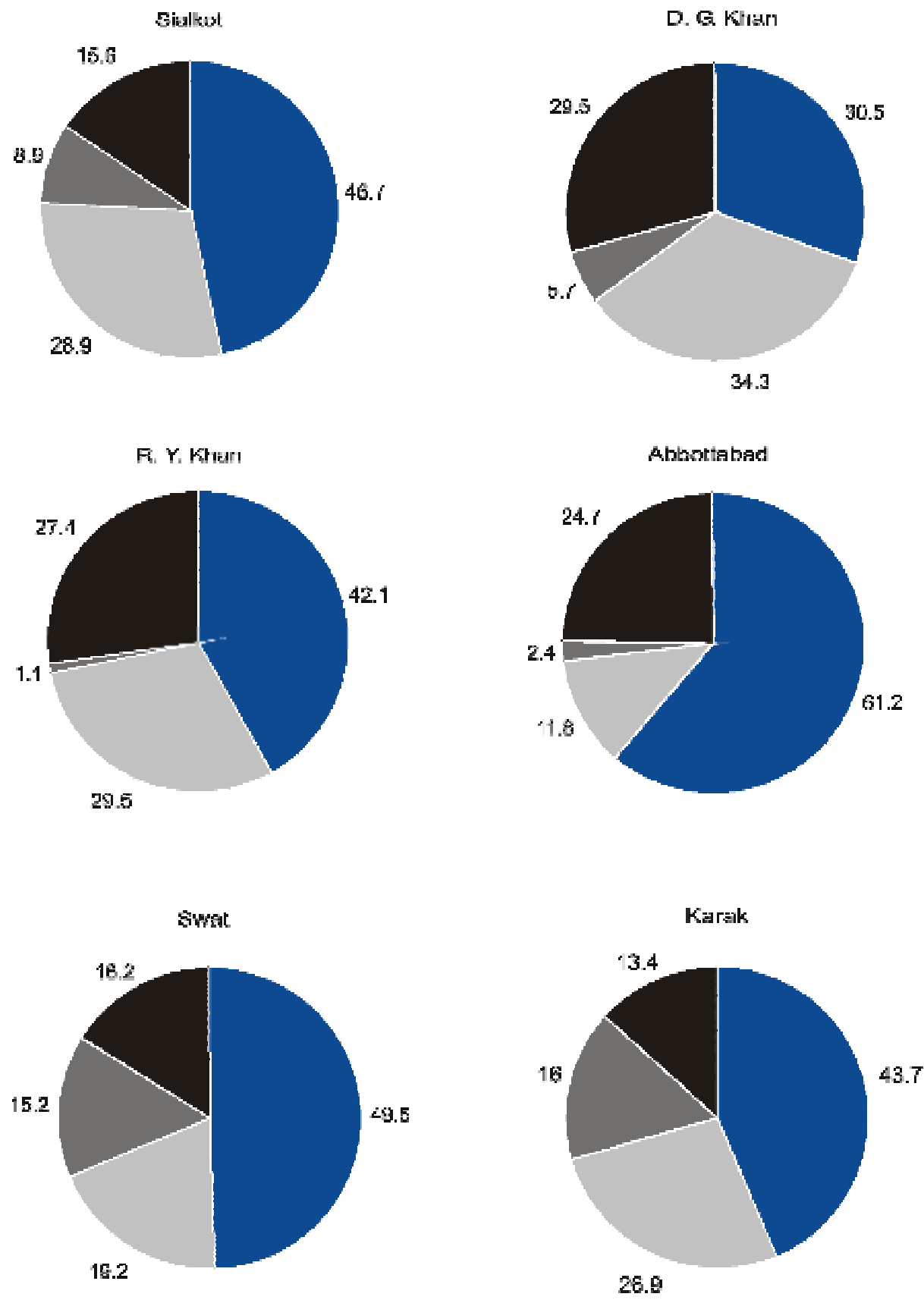

No more 1997 - No imore 2004

No imore 1997 - More 2004

Bhrs 1stof - More 2004

More 7907 - No mors $2(64$ 
Chapter 6 Trends in Family Building: Fertility Preferences, Contraceptive Use, and Fertility Behavior

A more interesting comparison is presented in Table 6.9, which shows that the proportion who wanted no more children but were using contraception in 2004 has risen dramatically for younger women who were under age 35 in 1997. It has stayed more or less static for the above 35 group. The most dramatic rises in net need (the proportion wanting no more children and using contraception) are found in D. G. Khan, R. Y. Khan, Abbottabad and Karak. Sialkot shows little change and Swat a slight decline in this measure, which is a bit troubling once again.

Table 6.9 Changes in fertility preferences and in contraceptive use by preference, age, and district

\begin{tabular}{lrrrr}
\hline & \multicolumn{2}{c}{$\begin{array}{c}\text { Wanted no } \\
\text { more children }\end{array}$} & \multicolumn{2}{c}{$\begin{array}{c}\text { Wanted no more children } \\
\text { and used contraception }\end{array}$} \\
\cline { 2 - 5 } & $\mathbf{1 9 9 7}$ (\%) & $\mathbf{2 0 0 4}(\%)$ & $\mathbf{1 9 9 7}$ (\%) & $\mathbf{2 0 0 4}$ (\%) \\
\hline \hline Ages in 1997 & & & & \\
20-24 & 20.4 & 47.8 & 4.4 & 17.7 \\
25-29 & 46.3 & 64.7 & 14.0 & 32.4 \\
30-34 & 65.6 & 74.8 & 22.3 & 36.0 \\
35-39 & 73.3 & 74.3 & 22.9 & 28.6 \\
40-45 & 72.3 & 68.1 & 21.3 & 23.4 \\
& & & & \\
District & & & & \\
Sialkot & & & & \\
D. G. Khan & 55.6 & 62.2 & 23.3 & 27.8 \\
R. Y. Khan & 36.2 & 60 & 5.7 & 25.7 \\
Abbottabad & 43.2 & 69.5 & 5.3 & 28.4 \\
Swat & 65.5 & 85.9 & 28.2 & 44.7 \\
Karak & 64.6 & 65.7 & 30.3 & 26.3 \\
\hline
\end{tabular}

\subsection{Panel study: fertility during the six-year panel period}

Lastly, we turn to look at changes in actual fertility behavior over the six-year period. Importantly, the very group, the under 35 year olds in 1997, whose contraceptive use has risen are also the ones who have had the highest fertility of between one child and over 2 children (20-34 year olds) (Table 6.10). The majority of those above 35 in 1997 did not have a birth in the past six years. The highest number of births in the last six years took place in R. Y. Khan, followed by D. G. Khan, Swat, and Karak. Some of the larger increases in contraceptive use also occurred in these districts, particularly R. Y. Khan and D. G. Khan reflecting a positive correlation between fertility in the recent past and contraceptive uptake. 
Table 6.10 Number of births in the period by age and district, 1997-2004

\begin{tabular}{rrrrrr}
\hline Ages & $\begin{array}{r}\text { Number of } \\
\text { births in past } \\
\text { 6 years }\end{array}$ & $\begin{array}{r}\text { No new birth } \\
\text { in past 6 years } \\
(\mathbf{\%})\end{array}$ & District & $\begin{array}{r}\text { Number of } \\
\text { births in past } \mathbf{r} \\
\text { years }\end{array}$ & $\begin{array}{r}\text { No new birth in } \\
\text { past 6 years } \\
(\%)\end{array}$ \\
\hline $20-24$ & 2.29 & 5.3 & Sialkot & 1.02 & 47.8 \\
$25-29$ & 1.74 & 13.2 & D. G. Khan & 1.44 & 29.5 \\
$30-34$ & 1.35 & 28.8 & R. Y. Khan & 1.60 & 25.3 \\
$35-39$ & 0.73 & 53.3 & Abbottabad & 1.07 & 47.1 \\
$40-45$ & 0.34 & 76.6 & Swat & 1.42 & 26.3 \\
& & & Karak & 1.39 & 28.6 \\
\hline
\end{tabular}

What were the fertility intentions of the women who had had a birth in the last seven years? We now turn to look at the characteristics of the births that took place to our panel of women in the last six years and find that the majority were wanted, though as high as 47 percent were unwanted (Table 6.11). The majority of births were to those women who did not want a birth in either 1997 and nor in 2004. This is a clear case of births that could have been averted with successful contraception. Only 7 percent had changed their minds since 1997 and since then had a birth. Twenty-seven percent wanted a birth in 1997 and wanted to continue childbearing, while 28 percent wanted a birth but now did not want to continue childbearing. We would have expected a larger proportion of births to fall in the last two categories and clearly the case of contraceptive discontinuation and ineffectiveness cannot be ruled out.

This is also demonstrated in the last panel of the table, which demonstrates that current fertility intentions are the most important determinant of current contraceptive use. 41 percent of those whose birth was unwanted and the mother wanted no further children were using contraception; followed by 35 percent of those whose birth was wanted but now the mother wanted no more children. Fertility intentions in 1997 had less bearing on current contraceptive use; in fact, contraceptive use is much lower among those who want more children in 2004, regardless of whether mothers wanted more or no children in 1997. However, contraceptive use is not insubstantial among those women and ranges from 18 to 21 percent. 
Chapter 6 Trends in Family Building: Fertility Preferences, Contraceptive Use, and Fertility Behavior

\section{Table 6.11 Births in the last six years by fertility intentions of mothers and current contraceptive use levels}

\begin{tabular}{lrr}
\hline & $\begin{array}{c}\text { Distribution of births in } \\
\text { the past six years by } \\
\text { wantedness status }\end{array}$ & $\begin{array}{r}\text { Current contraceptive use } \\
\text { of mothers who had a } \\
\text { birth in the last six years } \\
\text { by fertility intentions }\end{array}$ \\
\hline Mothers' Characteristics & 27.0 & 21.0 \\
Mother wanted more births in 1997 and in 2004 & 28.4 & 35.1 \\
$\begin{array}{l}\text { Mother wanted more births in 1997 not in 2004 } \\
\text { more in 2004 }\end{array}$ & 7.1 & 17.9 \\
$\begin{array}{l}\text { Mother wanted no more in 1997, but wants } \\
\text { in 2004 }\end{array}$ & 37.5 & 41.4 \\
\hline
\end{tabular}

\subsection{Linking schooling and reproductive behavior}

Finally, one of the main aims of this study was also to study the link between investments in children and reproductive behavior. Analysis of the earlier survey data found a strong and significant association between the presence of girls' school in the community and contraceptive behavior of couples (Sathar, Lloyd and Mete 2003). The second survey presents an opportunity to assess whether the link persists and also whether changes in reproductive behavior are linked to greater or lesser investments in schooling of children. In this report we present some preliminary findings based on scatter plots of contraceptive prevalence rates standardized for age of women in each of the twelve communities and enrollment rates of children.

Figure 6.6 Scatter plot of standardized CPR and standardized school enrollment for boys 5-9 years

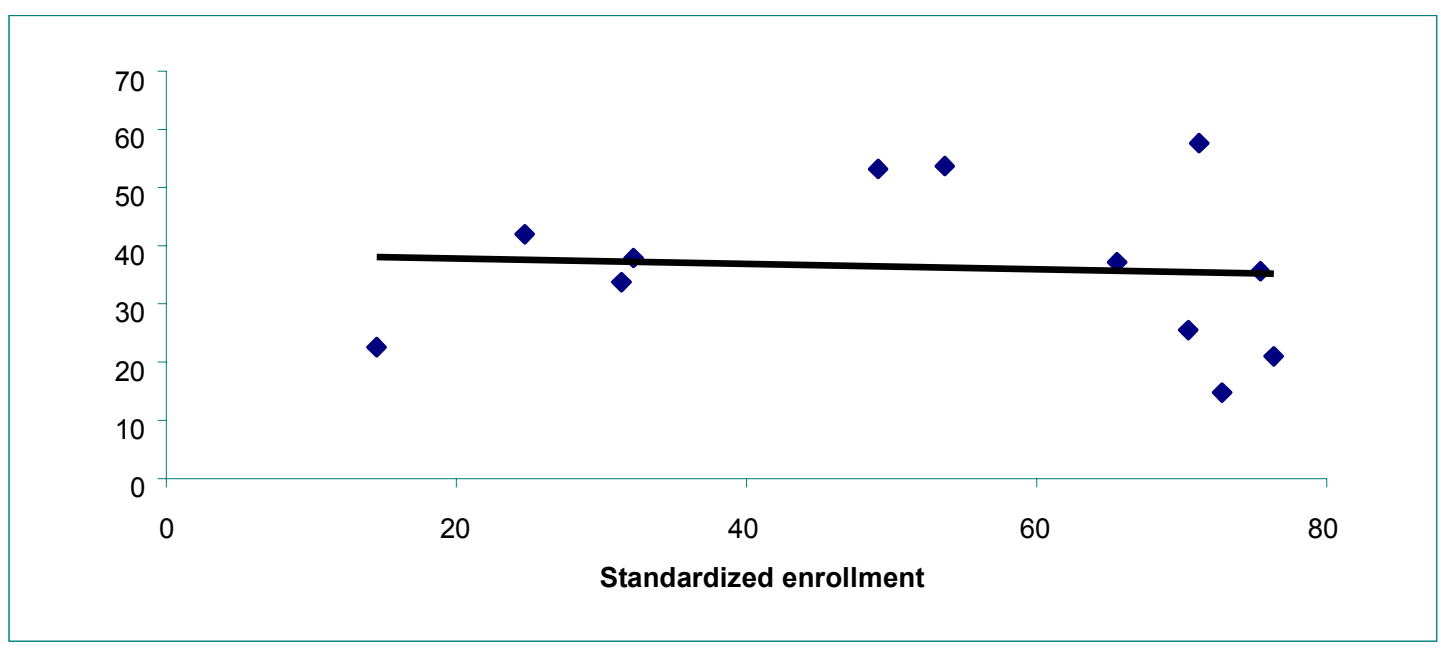


Figure 6.7 Scatter plot of standardized CPR and standardized school enrollment for boys 10-14 years

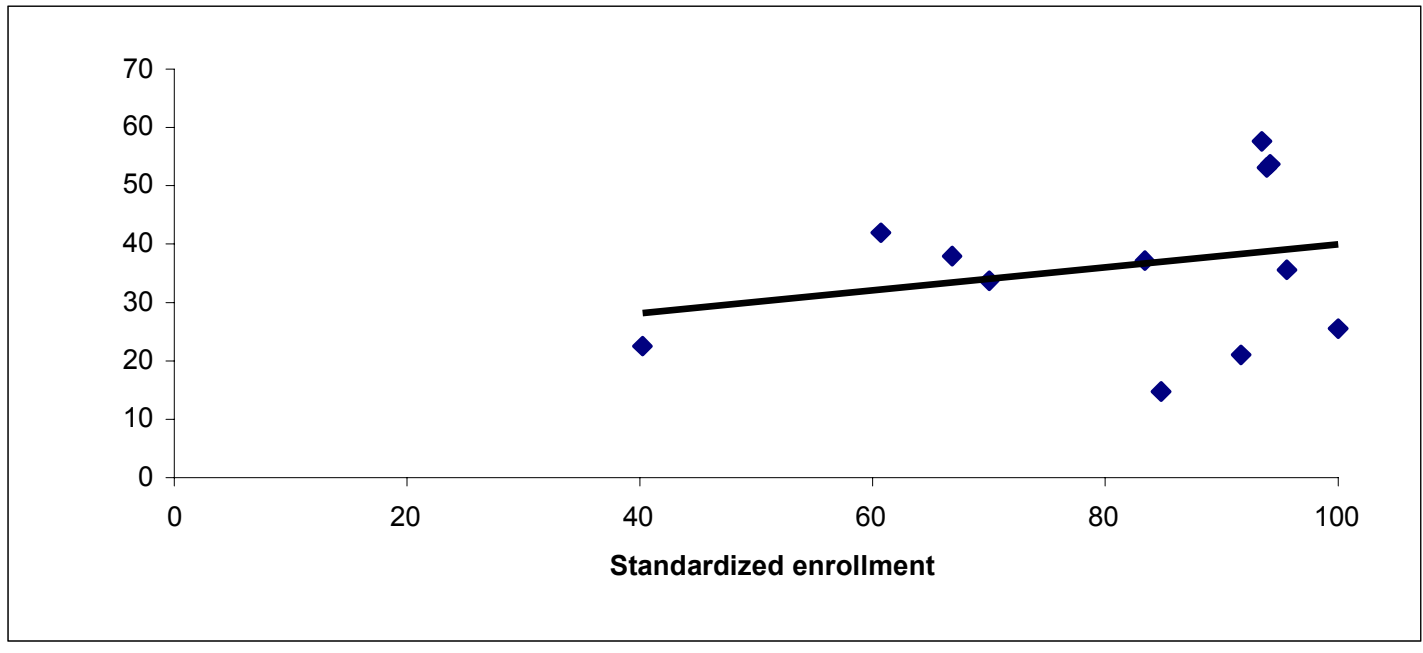

Figure 6.8 Scatter plot of standardized CPR and standardized school enrollment for boys 15-19 years

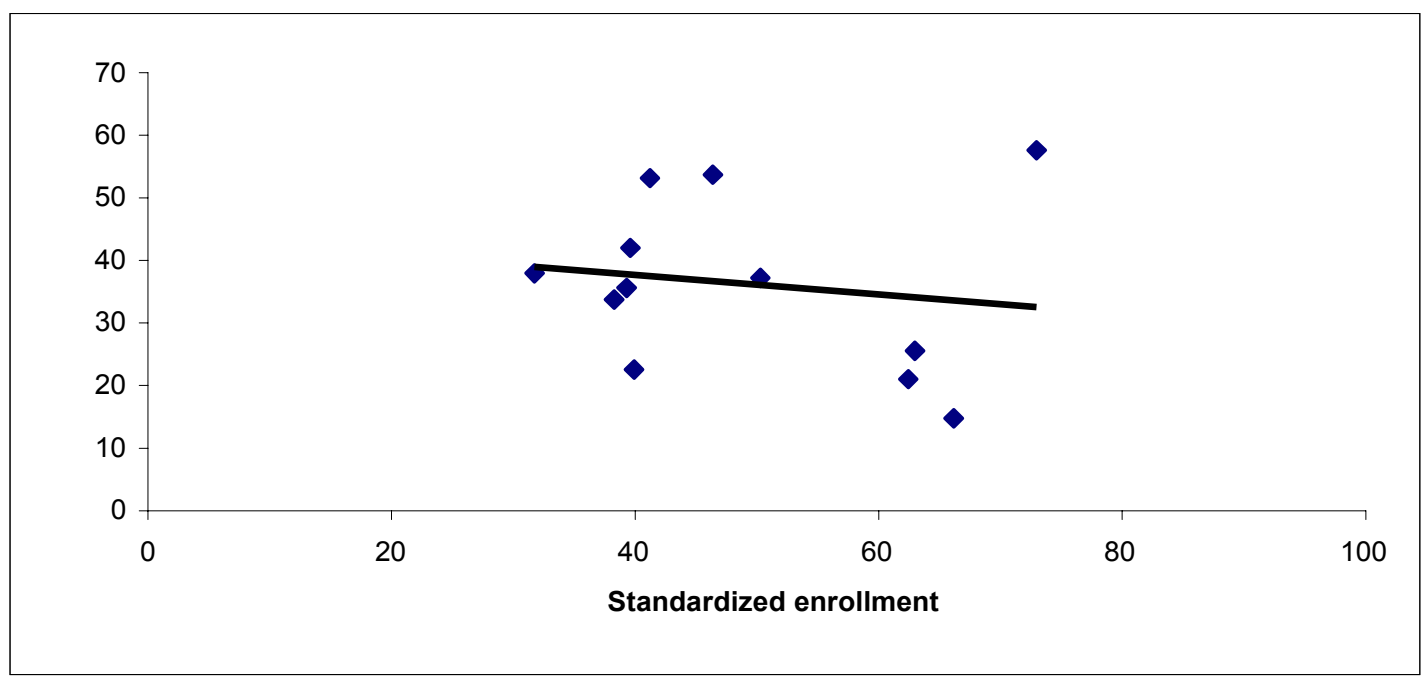


Chapter 6 Trends in Family Building: Fertility Preferences, Contraceptive Use, and Fertility Behavior

Figure 6.9 Scatter plot of standardized CPR and standardized school enrollment for girls 5-9 years

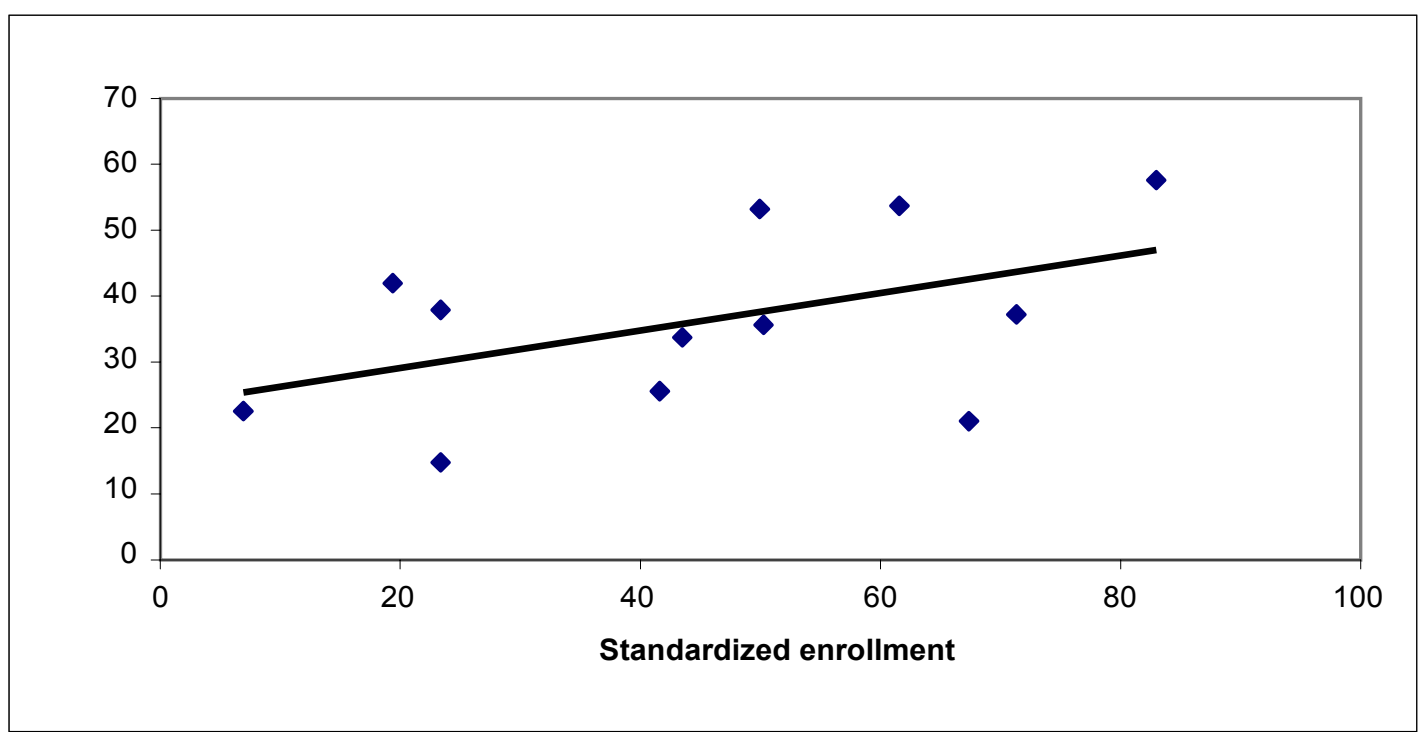

Figure 6.10 Scatter plot of standardized CPR and standardized school enrollment for girls 10-14 years

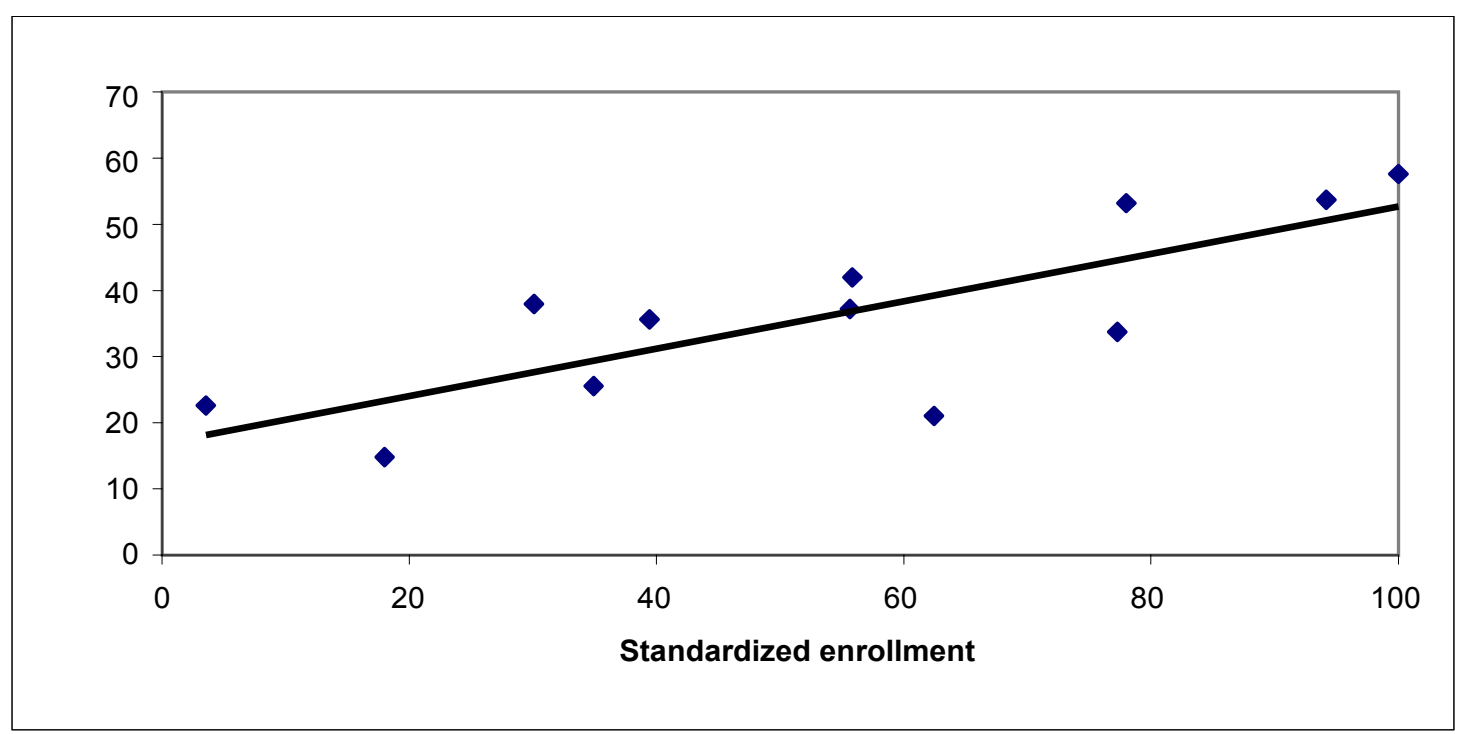


Figure 6.11 Scatter plot of standardized CPR and standardized school enrollment for girls 15-19 years

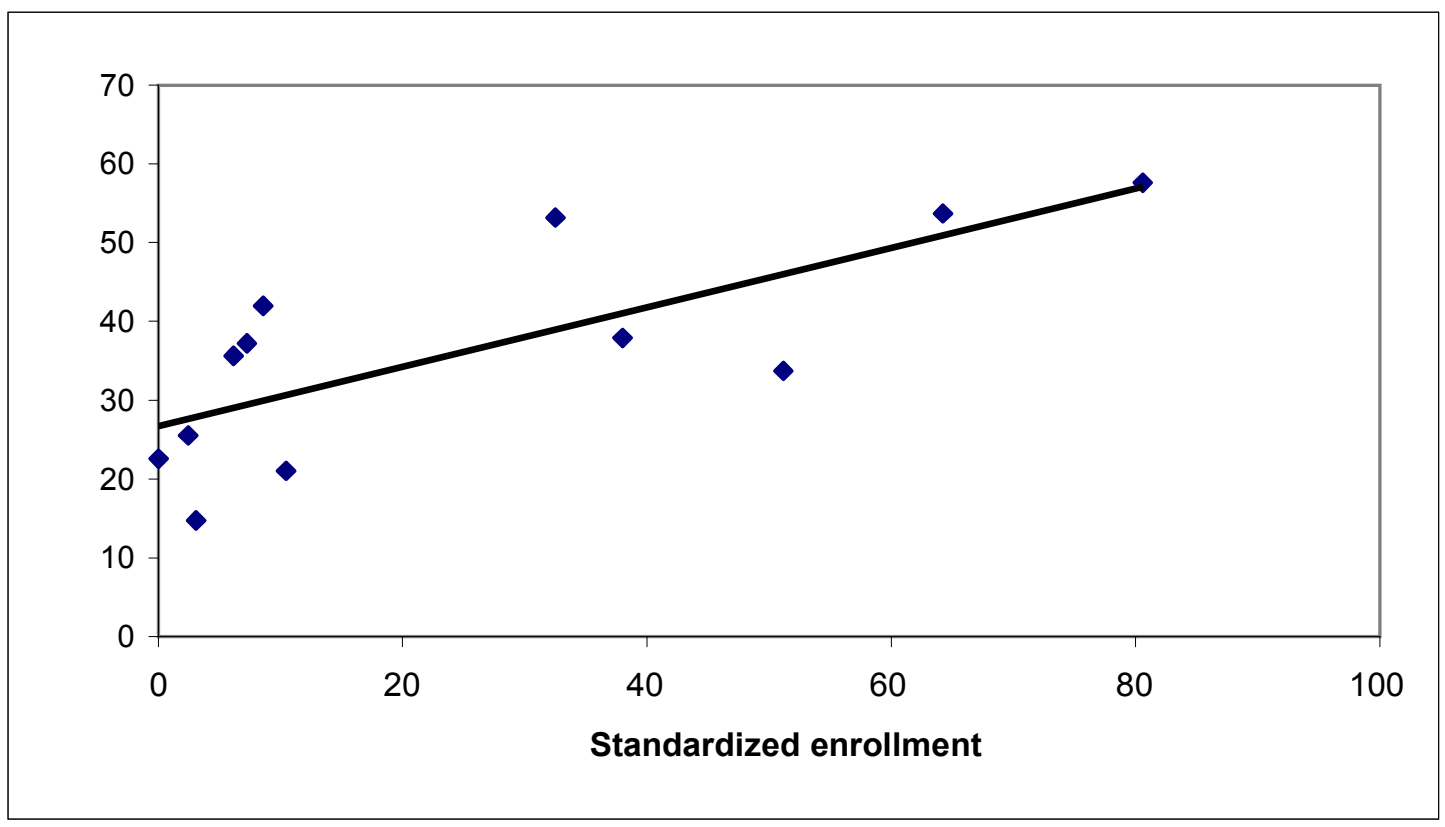

While these associations would certainly need to be investigated in greater detail, these initial scatter plots depict a stronger positive association between enrollments for girls and contraceptive prevalence rates. Similar associations between boys' enrollments and contraceptive prevalence rates are much weaker and in the case of boys aged 15-19 even inversely associated. Further, it does appear that contraceptive prevalence is more strongly associated with older girls, implying that there is a lagged association between investments in schooling for girls and contraceptive uptake. 
Chapter 6 Trends in Family Building: Fertility Preferences, Contraceptive Use, and Fertility Behavior

Figure 6.12 Scatter plot of mean number of births in last 5 years and school enrollment for boys 5-9 years

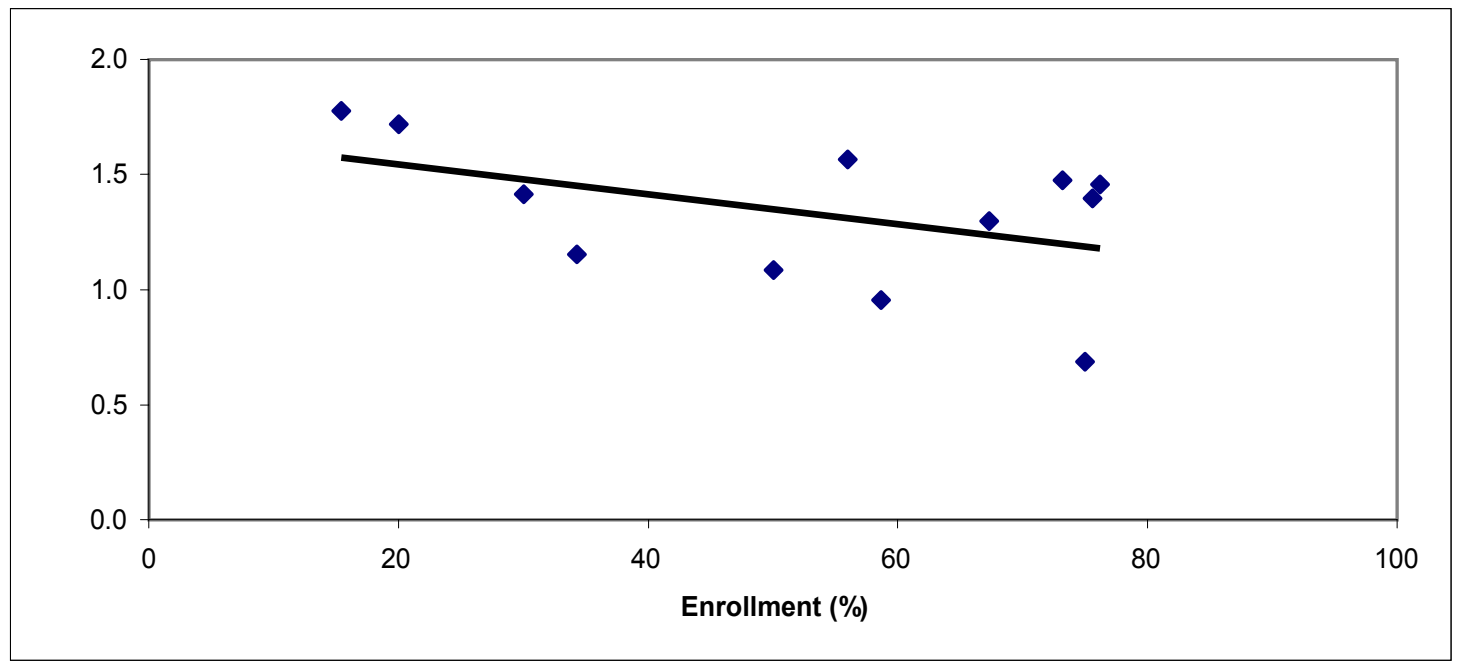

Figure 6.13 Scatter plot of mean number of births in last 5 years and school enrollment for boys 10-14 years

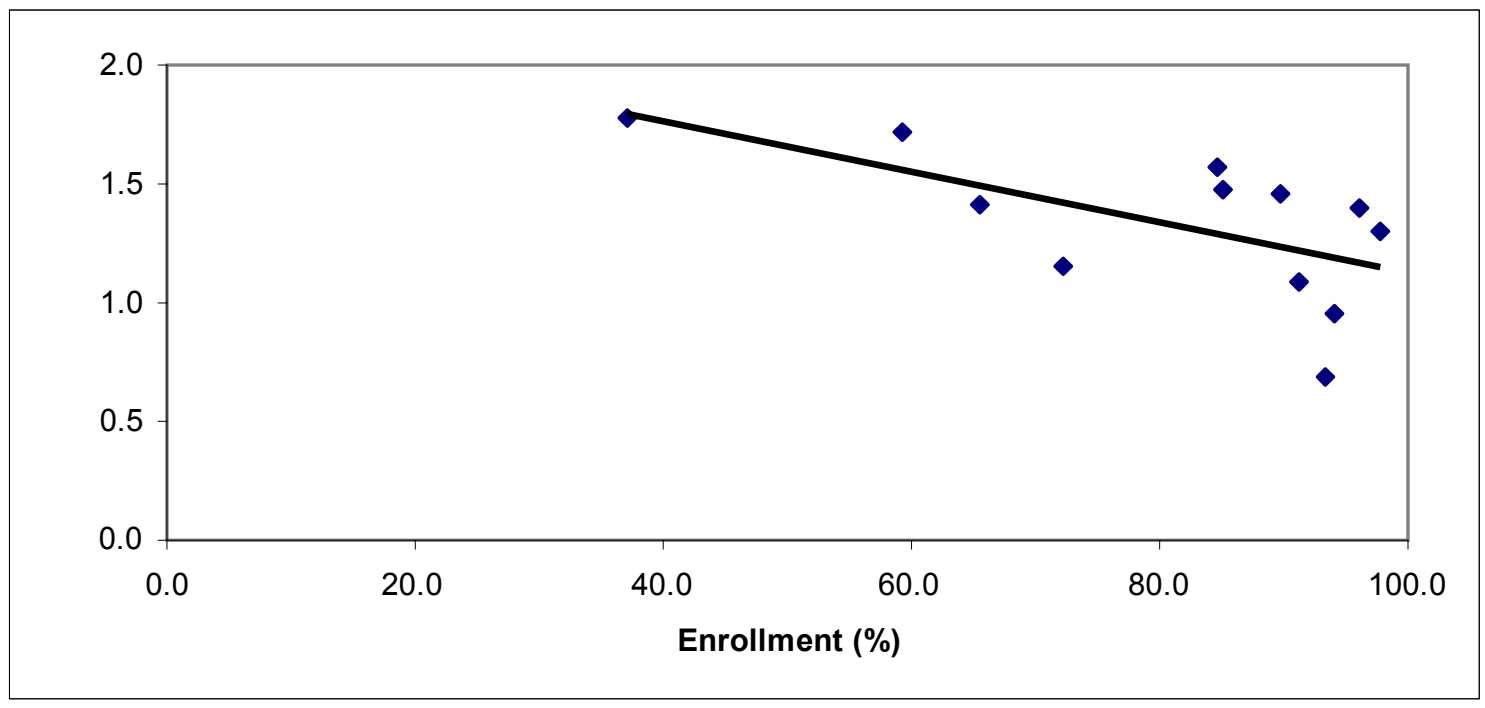


Figure 6.14 Scatter plot of mean number of births in last 5 years and school enrollment for boys 15-19 years

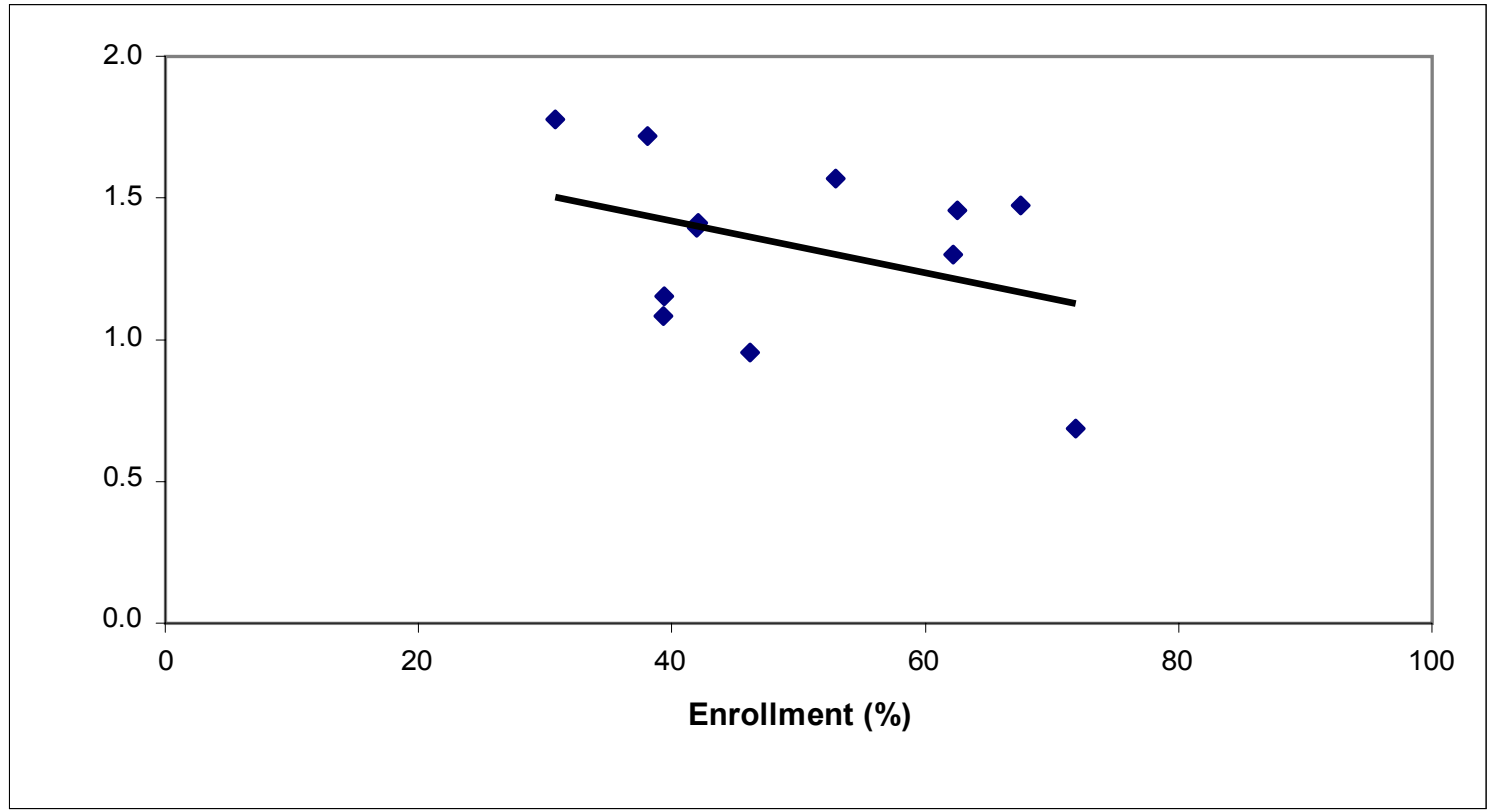

Figure 6.15 Scatter plot of mean number of births in last 5 years and school enrollment for girls 5-9 years

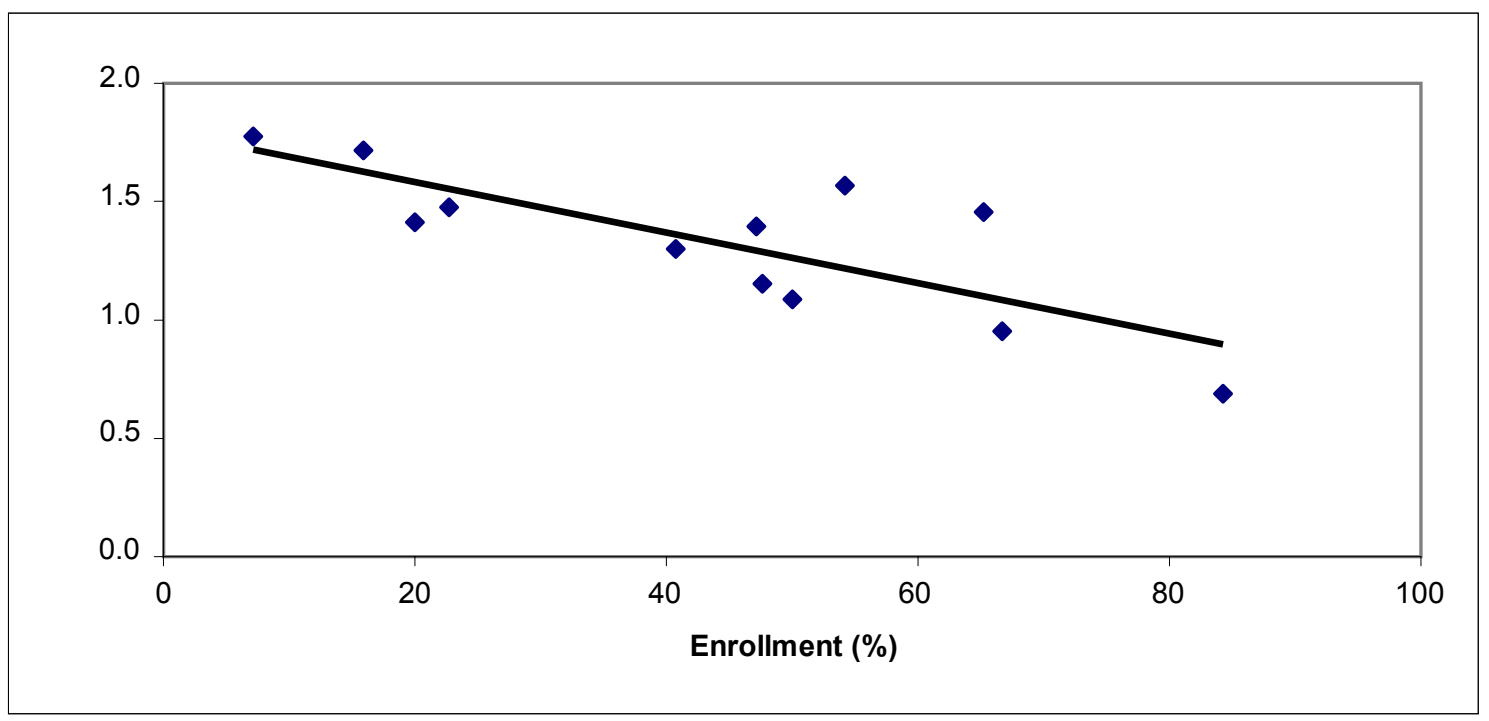


Chapter 6 Trends in Family Building: Fertility Preferences, Contraceptive Use, and Fertility Behavior

Figure 6.16 Scatter plot of mean number of births in last 5 years and school enrollment for girls 10-14 years

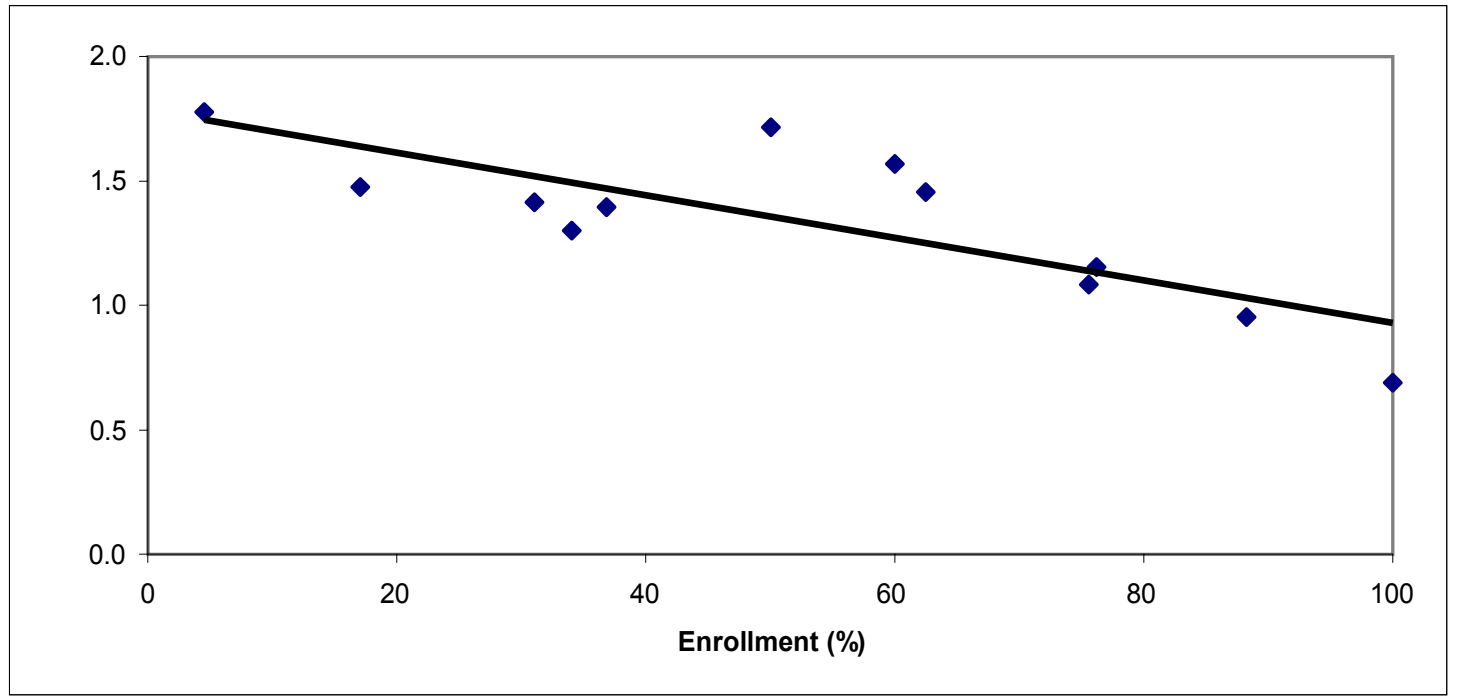

Figure 6.17 Scatter plot of mean number of births in last 5 years and school enrollment for girls $15-19$ years

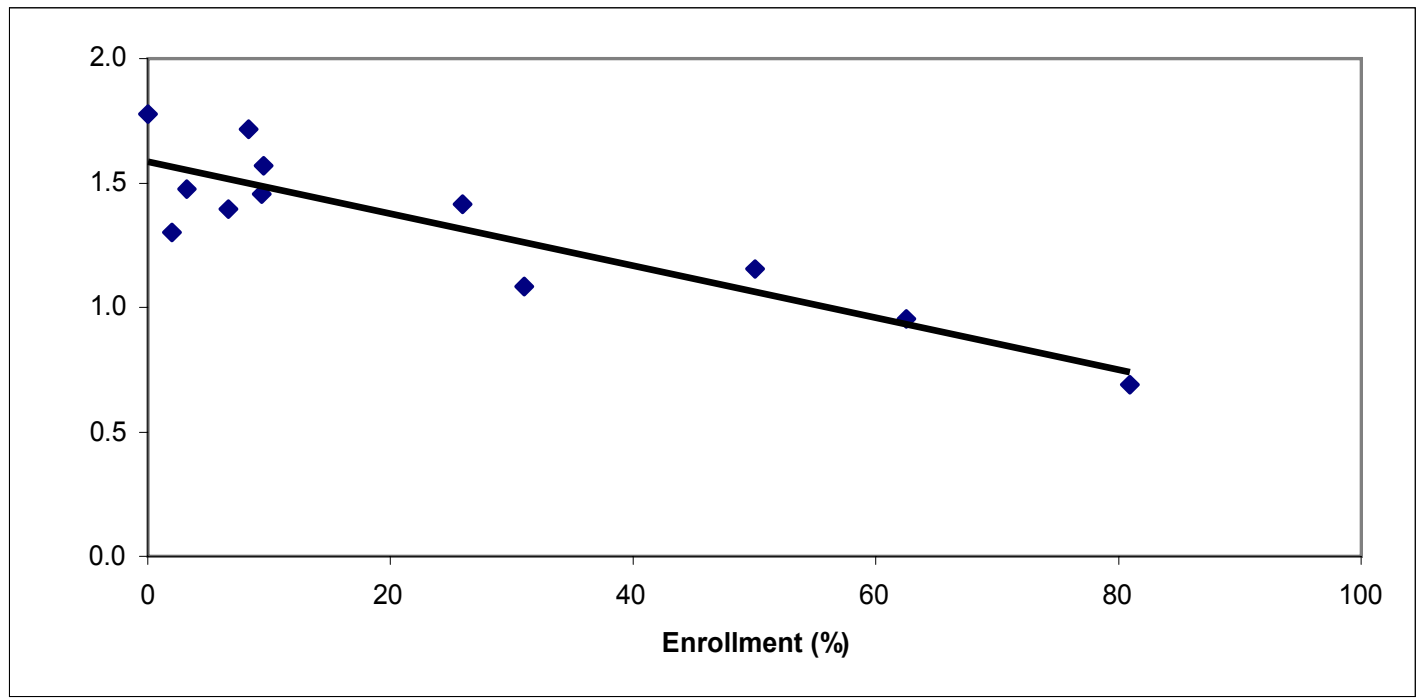

In the graphs (Figures 6.7-6.12) presented above, we see a negative association between the mean number of births in the last five years and enrollment rates of boys and girls. In this particular relationship investment in children's education for both genders is associated with lower recent fertility. 


\subsection{Summary}

Several interesting findings emerge from exploring trends in family building. There is a clear change in family building patterns in these twelve villages in the six districts of Pakistan. Younger women are in the lead with their adoption of modern reversible methods at lower parities. The cross-sectional data over the two time periods shows categorically that condoms and injectables have emerged as more popular contraceptive methods and that women are starting to use contraceptives with fewer average children. Further, men appear to be more dominant in the decision to start using a family planning method than they were seven years ago. The availability of family planning services has increased substantially over the communities in our sample, with all but one having access to services within the community. The increased placement of LHWs has had a visible impact in increasing health facilities. All these changes augur well for fertility decline in rural communities across Pakistan.

In looking at the panel data it is clear that the cohort of women followed across the six year period have largely maintained their earlier fertility intentions: for the majority, fertility preferences have remained the same. However, among those that have changed their intentions, the majority from wanting more to wanting no more children, a substantially larger proportion of women were acting upon their intentions by using contraception in 2004 than were in 1997. The need for family planning services has been met, and the 'catch-up' effect appears to be more notable in the districts that lagged behind in contraceptive use levels in 1997.

When investigating the association between investments in children through schooling and reproductive behavior in the twelve villages, we found a positive association between contraceptive prevalence rates and girls' enrollment rates, particularly for 15-19 year olds. No such association was seen with boys' enrollments. However, a negative association was found between boys and girls enrollment rates and mean number of births in the last five years, reflecting the negative association between investments in children and recent fertility. While there appears to be a strong relationship between schooling and reproductive behavior in these communities, these associations have to be investigated in greater detail for their statistical significance while controlling for other confounding variables. 


ESR- described earlier. In the twelve villages where this study took place, one villageKotla Drigh-still remained without a government girls' primary school in 2004.

In conjunction with these changes in the supply and quality of schools, the data reveal that more girls are enrolling in school, more boys and girls are remaining in school to older ages and through the completion of primary, and more parents are choosing to send their children to private primary schools than in the past. However, these trends are not as pronounced as might have been expected, given the increase in school choice and the improvement in the quality of government primary schools. In particular, further exploration of the data reveal that it is the establishment of a new government primary school for girls, not the establishment of a private school, that appears to make the most difference to girls' enrollment (Lloyd, Mete and Grant 2006); (Lloyd, Mete and Sathar 2005). Thus, greater school choice has had more impact on the distribution of students between the government and private sectors than on the overall enrollment rate.

The results also bring out the importance of household and local contexts in shaping children's schooling outcomes. Communities with fewer new schools and less community development show evidence of some improvements in enrollment, but largely preserve the gender disparities in enrollment and schooling attainment present

in 1997. In contrast, districts with higher levels of development and numerous recently created schools show little difference in the schooling of girls and boys. Likewise, there is evidence that children whose parents did not attend school are less likely to attend and remain in school than the children of parents who attended primary or higher.

Taken together, these changes imply that, when educational choice and opportunity are available, households who are committed to educating their children respond in ways that suggest that they are seeking to find the best educational options for their children within the local area. Unfortunately, nearly one-third of girls in these villages remain outside the school system, having never attended school. The recent changes described here have been insufficient to bring these girls into the school system.

The study also found clear changes in family building patterns in these twelve villages in six districts of Pakistan. Younger women were in the lead with their adoption of modern reversible methods at lower parities. Condoms and injectables, modern reversible methods, have emerged as more popular contraceptive methods and women are starting to use contraceptives earlier in the family building process, when they have fewer children. Importantly, men appear to be more dominant in the decision to start using a family planning method than they were.

Also there appeared to be more convergence in the proportions of women using contraception to act upon their fertility intentions. Districts that had lagged behind in 
1997 had experienced a 'catch-up' effect. This is a positive reflection of the increasing demand for family planning services for both spacing and limiting and of the improvement in the availability and knowledge of sources of services. Indeed, the availability of family planning services has increased substantially across most of the communities in our sample with all but one having access to services within the community. The increased placement of LHWs has had a visible impact in increasing health services. Most significantly, it demonstrates that fertility patterns have most definitely begun to change in rural Pakistan.

Since we were able to track the fertility intentions of the very same women over six years, we found that most of them retained their earlier intentions. However, among the ones that have shifted their intentions, the majority moved from wanting more to wanting no more children, as they aged. The more important finding was the substantially larger proportion of women who were acting upon their intentions by using contraception in 2004 than were in 1997. Nonetheless, despite this encouraging progress, over 50 percent of the births which occurred to women in our study in the past 6 years were unwanted, confirming that much more work will have to be done building on past progress to help women fully achieve their desires.

When investigating the association between children's schooling and reproductive behavior in the twelve villages, we found a positive association between contraceptive prevalence rates and girls' enrollment rates, particularly for 15-19 year olds. No such association was seen with boys' enrollments. Similarly, we found a negative association between both boys' and girls' enrollment rates and mean number of births in the last six years, reflecting higher investments in children and lower recent fertility. These findings support Caldwell's hypothesis of an association between family building and educational attainment, particularly of girls (Sathar, Lloyd and Mete 2003).

The results of these surveys provide a clear policy message. The trends and associations presented in this report illuminate the synergy that exists between the social sectors with positive strides in family planning contributing to enrollment gains, particularly for girls, and enrollment gains contributing to growing preferences for smaller families. In an extended analysis of these data, we also found that the arrival of an unwanted birth in the household in the previous 6 years had a large and statistically significant negative effect on the likelihood that a girl attending primary school will complete her schooling; on the other hand, boys' school retention was unaffected by the arrival of an unwanted birth in the household (Lloyd, Mete, and Grant 2006). As long as the prevalence of unwanted fertility stays high, families' ability to support their girls' primary school completion will be compromised. Furthermore, without progress toward gender equality and without a rise in the enrollment rates of girls, rural communities (and therefore the majority of Pakistan) will continue to lag in the pace of fertility decline. 



\section{References}

Andrabi, Tahir, Jishnu Das, et. al. 2002. "The rise of private schooling in Pakistan:

Catering to the urban elite or educating the rural poor?" Manuscript.

Andrabi, Tahir, Jishnu Das, et. al. 2005. "Religious school enrollment in Pakistan: A look at the data." Manuscript.

Caldwell, John C. 1980. "Mass Education as a Determinant of the Timing of Fertility Decline". Population and Development Review 6: 225-55.

Federal Bureau of Statistics (FBS). 2005. Pakistan Demographic Survey 2003. Islamabad: Federal Bureau of Statistics.

Lavy, Victor. 1996. "School supply constraints and children's educational outcomes in rural Ghana." Journal of Development Economics 51: 291-314.

Lloyd, Cynthia B., Cem Mete and Zeba A. Sathar. 2005. “The Effect of Gender Differences in Primary School Access, Type, and Quality on the Decision to Enroll in Rural Pakistan." Economic Development and Cultural Change 53(3): 685710.

Lloyd, Cynthia B., Cem Mete and Monica Grant. 2006. "The current challenges to achieving universal primary enrollment for girls in Pakistan." Paper commissioned by the Center for Global Development for a project on Doubly Excluded Girls.

Lloyd, Cynthia B., Cem Mete and Monica Grant. 2006. “The implications of changing educational and family circumstances for children's grade progression in rural Pakistan: 1997-2004." Policy Research Division Working Paper No. 209. New York: Population Council.

National Institute of Population Studies (NIPS). 2001. The Pakistan Reproductive Health and Family Planning Survey 2000-2001. Islamabad: National Institute of Population Studies.

Sathar, Zeba A., Cynthia B. Lloyd, and Minhaj ul Haque. 2000. Investments in Children's Education and Family-Building Behavior in Pakistan: Findings from Rural N.W.F.P. and Punjab. Islamabad: Population Council. 
References

Sathar, Zeba A., Cynthia B. Lloyd and Cem Mete. 2003. "Schooling Opportunities for Girls as a Stimulus for Fertility Change in Rural Pakistan" Economic Development and Cultural Change, 51(3): 677-698.

Sathar, Zeba A., Cynthia B. Lloyd, Minhaj ul Haque et. al. 2003. Adolescents and Youth in Pakistan 2001-2002: A Nationally Representative Survey. Islamabad: Population Council.

Social Policy and Development Centre (SPDC). 2003. "Social Development in Pakistan: Annual Review 2002-2003 ". Karachi: Social Policy and Development Centre. 


\section{Annex \\ List of Staff Involved in the Survey}

Trainers

Minhaj ul Haque

Mumraiz Khan

Tahira Perveen

Aneela Sardar

Data Matching

Tahira Perveen

Shaheen Islam

Naseem Raza

Data Entry and Processing

Muhammad Rehan Niazi (Incharge)

Shahid Mehmood Abbasi

Fahad Naqvi

Editing and Quality Checks

Tahira Perveen

Shaheen Islam

Naseem Raza

Aneela Sardar

Ehtesham ul Haq

Nasir Aziz

Field Staff

Team 1 (Abbottabad, Sialkot)

Aneela Sardar

Supervisor

Imrana Jabeen

Interviewer

Azra Jabeen

Interviewer

Shazia Rafaq

Interviewer

Madiha Khan

Interviewer 
Raja Nasir Aziz

Shahid Mehmood

Arshad Iqbal

Khizar Hayat
Logistic Supervisor

Interviewer

Interviewer

Interviewer

Team 2 (R. Y. Khan, D. G. Khan)

Anjum Seemaab

Supervisor

Saira Iqbal

Samina Abbas

Sajida Naheed

Interviewer

Interviewer

Interviewer

Naseem Raza

Ehtesham ul Haq

Hussain Zulfiqar

M. Arslan Akhtar

M. Saboor Saqib

Team 3 (Karak, Swat)

Salma Mumtaz

Asma Akbar

Supervisor

Falak Shahid Yousaf Zai

Interviewer

Nabeela Sahrai

Interviewer

Interviewer

Nadeema Begum

Interviewer

Amir Muhammad Khan

Logistic Supervisor

Said Muhammad Shah

Interviewer

Interviewer

Fazli-e-Wadood

Shahid Hussain

Interviewer 

